\title{
Repression der cytosolischen GS1 \\ von Zuckerrüben (Beta vulgaris L. var. altissima) \\ durch Antisense-DNA-Konstrukte
}

\author{
Dissertation \\ zur Erlangung des Doktorgrades \\ der Mathematisch-Naturwissenschaftlichen Fakultäten \\ der Georg-August-Universität zu Göttingen
}

vorgelegt von

Guido Wolf Hoffmann

aus Braunschweig

Göttingen 2000 
D 7

Referent: Prof. Dr. Rudolf Tischner

Korreferent: Prof. Dr. Dietrich Gradmann

Tag der mündlichen Prüfung: 21. Juni 2000 


\section{INHALTSVERZEICHNIS}

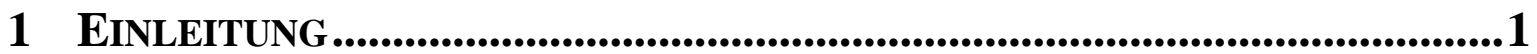

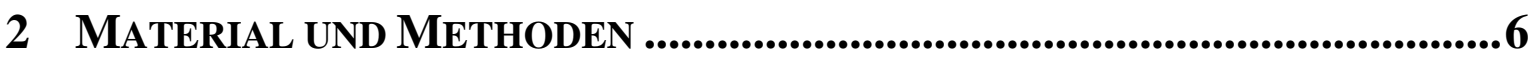

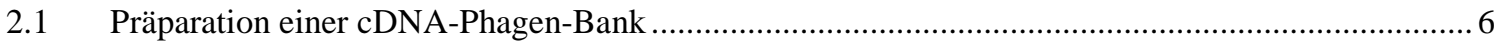

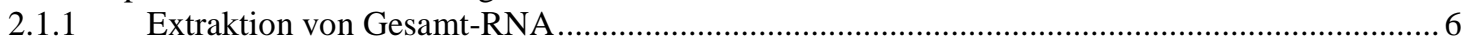

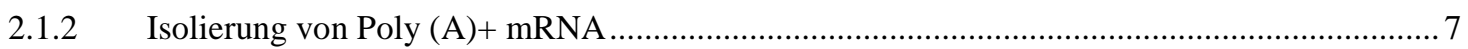

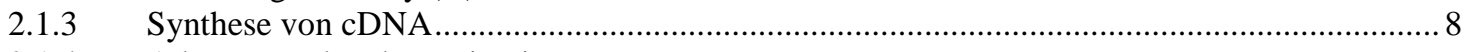

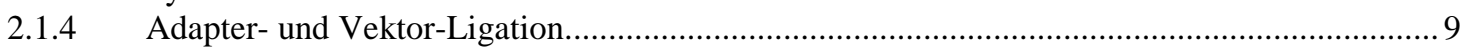

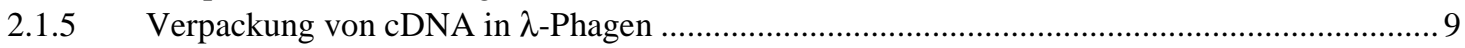

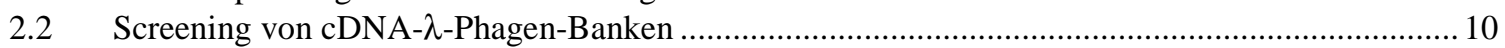

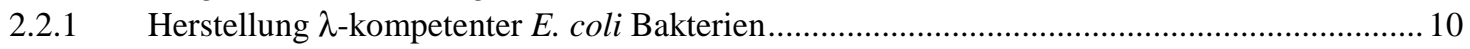

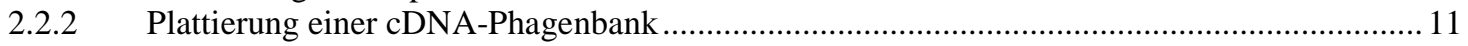

2.2.3 Herstellung von Nitrocellulose Replika-Filtern ...................................................................... 11

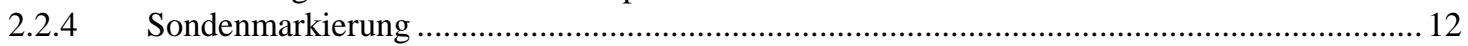

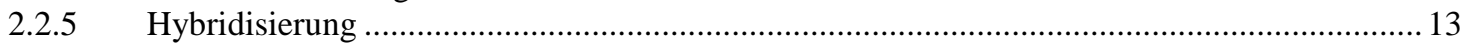

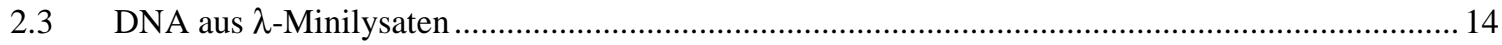

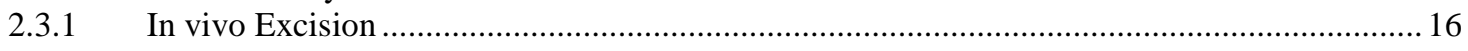

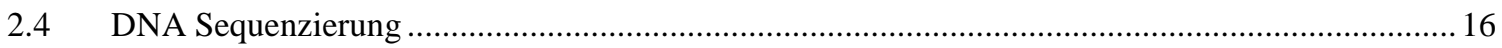

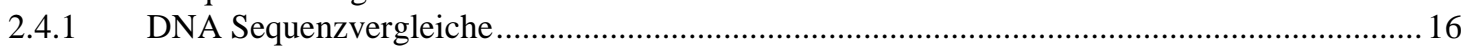

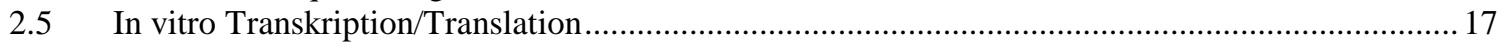

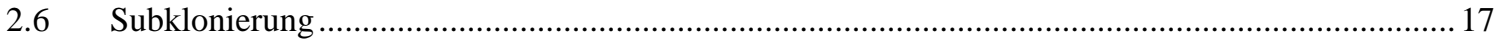

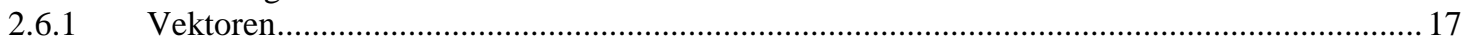

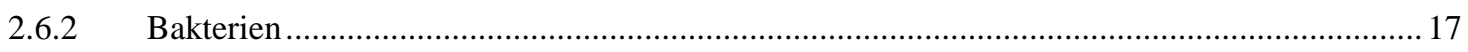

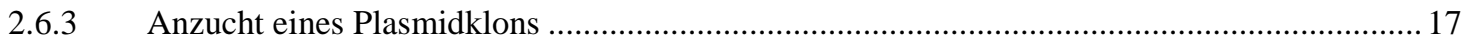

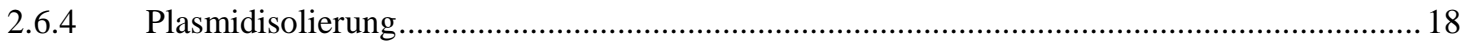

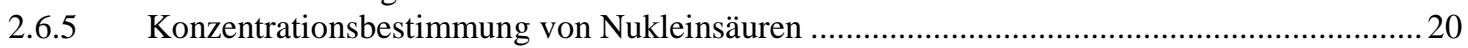

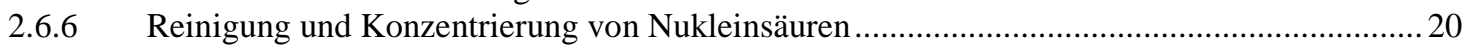

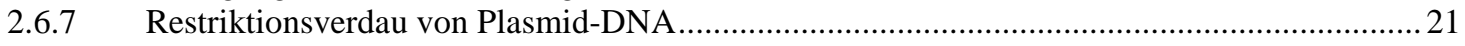

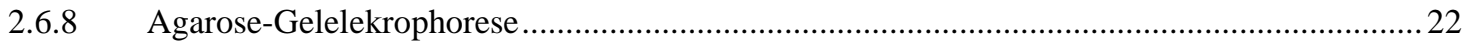

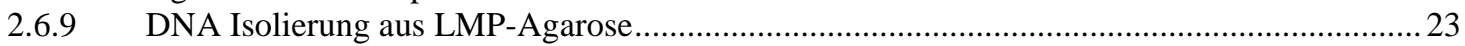

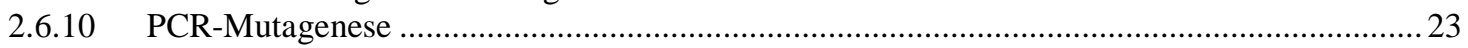

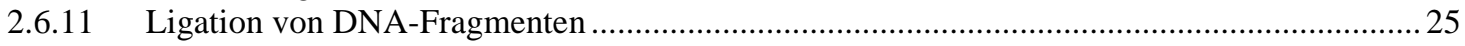

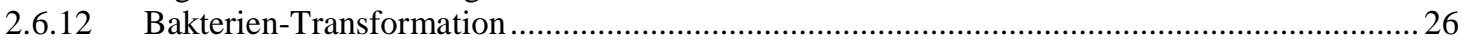

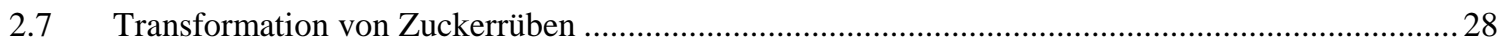

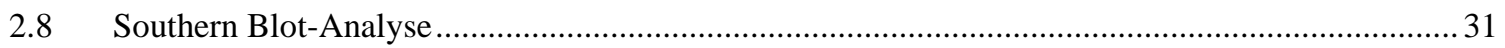

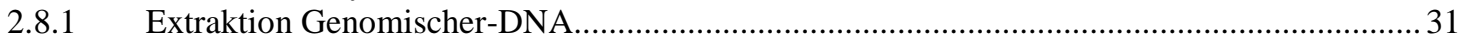

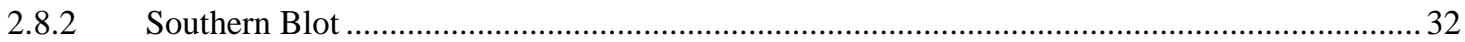

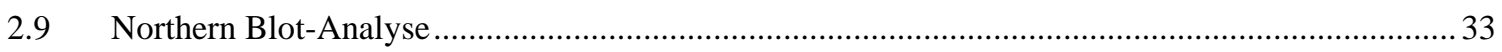

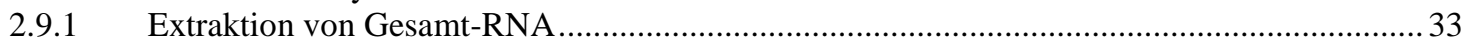

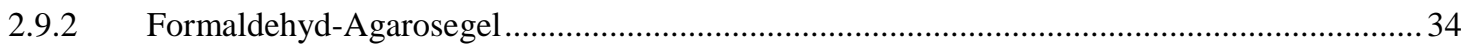

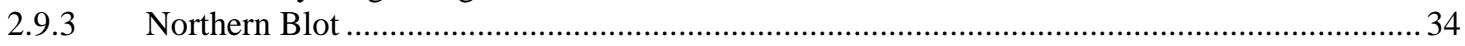

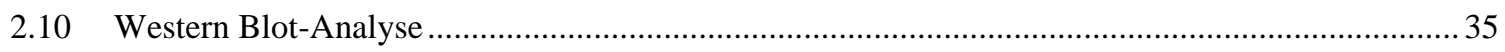

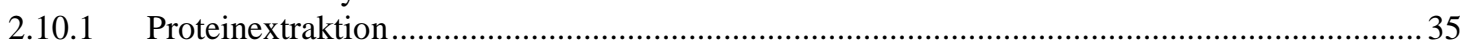

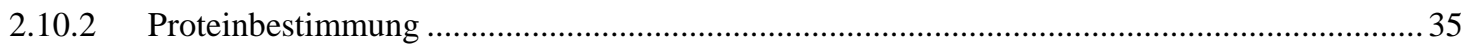

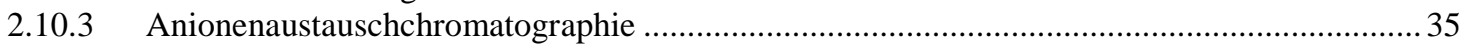

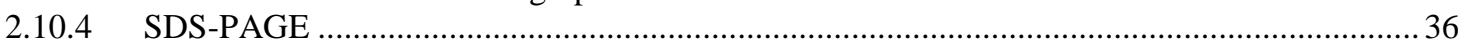

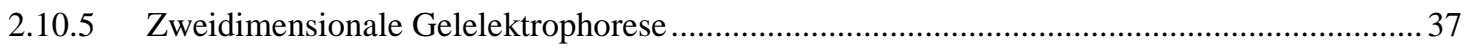

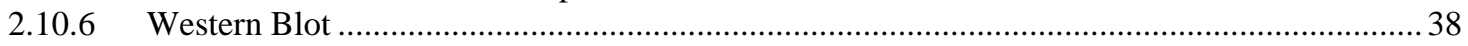

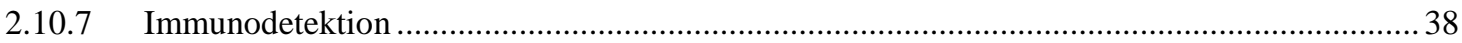

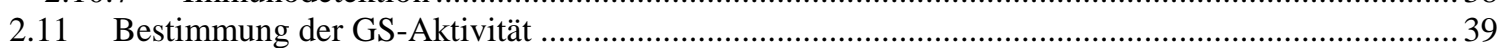

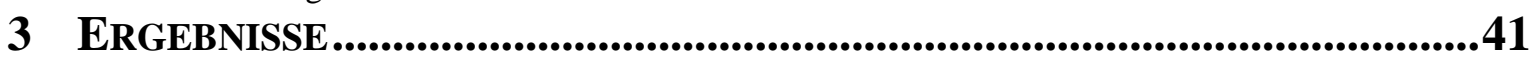

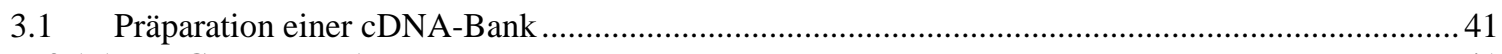

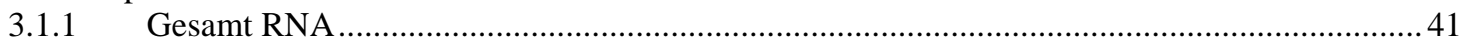

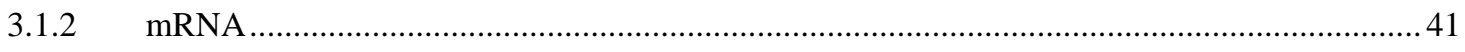

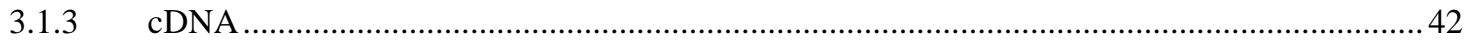

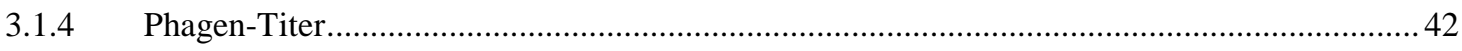




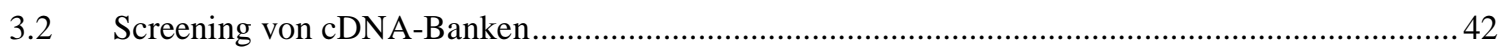

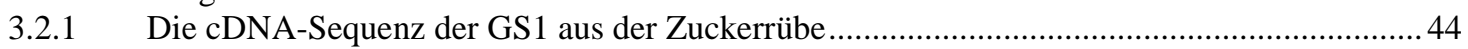

3.2.2 Die Aminosäure-Sequenz der GS1-Untereinheit der Zuckerrübe ........................................ 45

3.2.3 Die cDNA-Sequenz der GS2 aus der Zuckerrübe.......................................................... 46

3.2.4 Die Aminosäure-Sequenz der GS2-Untereinheit der Zuckerrübe ..................................... 47

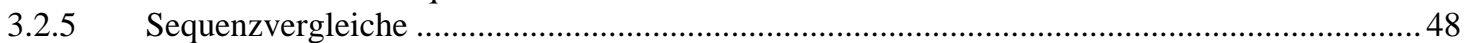

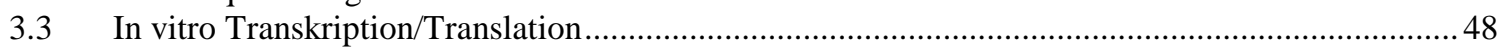

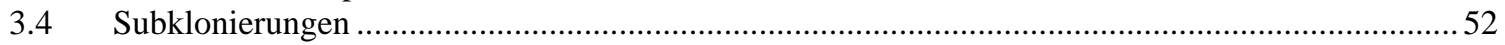

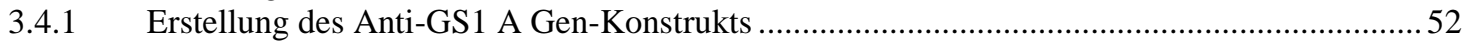

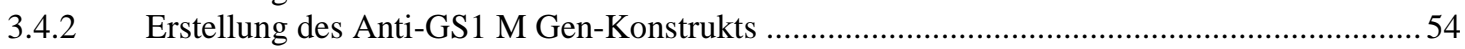

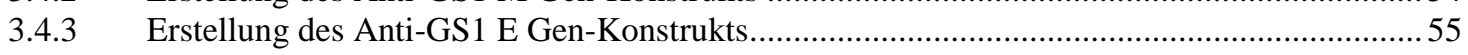

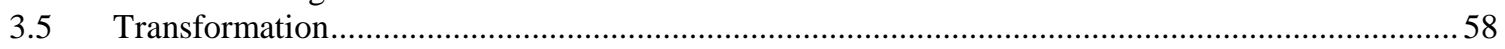

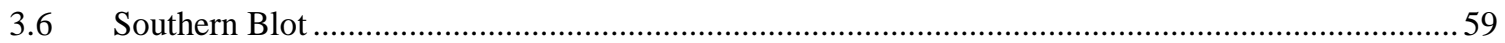

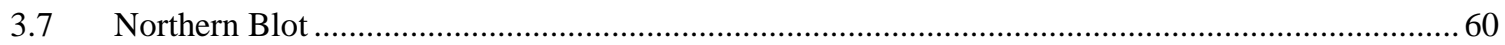

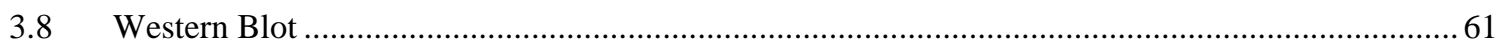

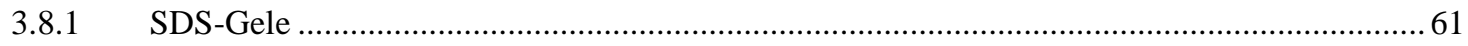

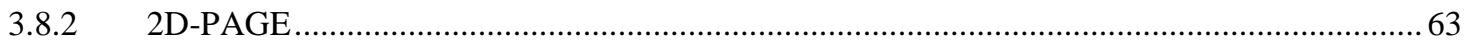

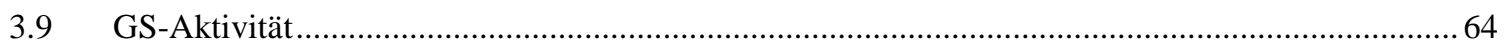

4 DISKUSSION „......................................................................................69

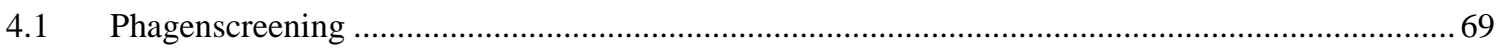

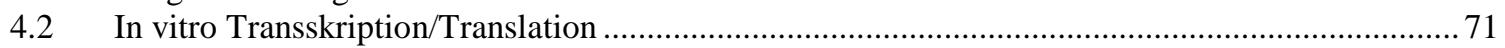

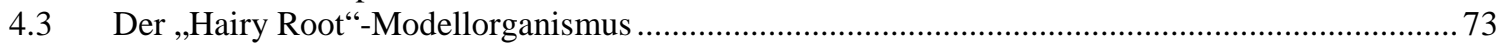

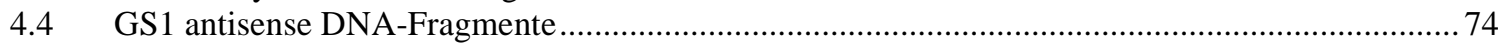

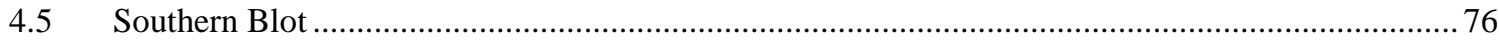

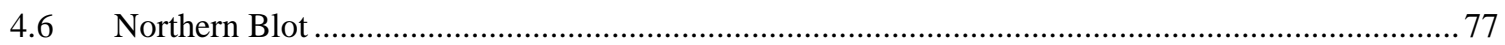

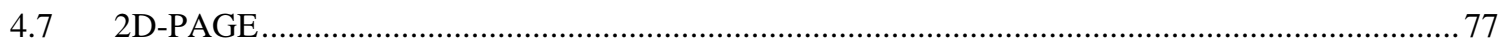

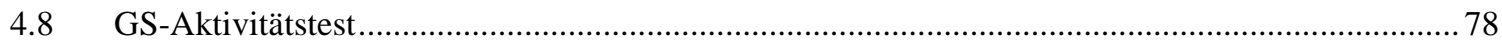

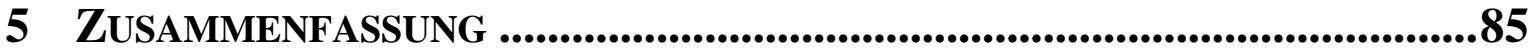

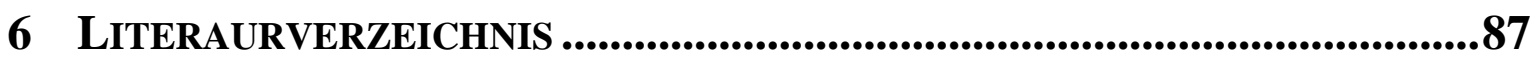




\section{ABKÜRZUNGSVERZEICHNIS}

\section{$3^{\prime} / 5^{\prime}-$-UTR}

A

Abb.

Ac

ADP

amp.

APS

AS

ATP

BCIP

bidest.

bp

BSA

$\mathrm{C}$

$\mathrm{C}$

cDNA

cpm

CTAB

d

DMF

DNA

dNTPs

\section{DTT}

$\mathrm{e}^{-}$

EDTA

$\mathrm{EtBr}$

$\mathrm{EtOH}$

$\mathrm{Fd}_{\text {red }} / \mathrm{Fd}_{\mathrm{ox}}$

FG

FPLC

G

g

$\mathrm{X} g$

gDNA

GHA

GOGAT

GS

GS1

GS2

GSA

GUS

$\mathrm{h}$

HBP

HEPES

IEF
3'/ 5'-untranslatierte Region

Adenin

Abbildung

Acetat

Adenosindiphosphat

Ampicillin

Amoniumperoxodisulfat

Aminosäure

Adenosintriphosphat

5-Bromo-4-chlor-3-indolyl-phosphat

bidestilliert

Basenpaare

Rinderserumalbumin

Konzentration

Cytosin

von RNA kopierte DNA (copy DNA)

counts per minute

Cetyltrimethylammoniumbromid

Tag

N, N-Dimethylformamid

Desoxyribonukleinsäure

äquimolare Mischung der Nukleotide Adinosin-,

Guanosin-, Cytosin- und Thymintriphosphat

Dithiothreitol

Elektron

Ethylendiamintetraessigsäure, Natriumsalz

Ethidiumbromid

Ethanol

reduziertes / oxydiertes Ferredoxin

Frischgewicht

Fast Protein Liquid Chromatography

Guanin

Gramm

Erdbeschleunigung $\left(1 \times \mathrm{g}=9,81 \mathrm{~m} \mathrm{x} \mathrm{s}^{-2}\right)$

genomische Desoxyribonukleinsäure

Glutamyl-Hydroxamat

Glutamin 2-Oxoglutarat Aminotransferase

Glutaminsynthetase

cytosolische Glutaminsynthetase

plastidäre Glutaminsynthetase

Glutaminsynthetase-Aktivität

Glucuronidase

Stunde

Harnstoffbeladungspuffer

N-2-Hydroxyethylpiperazin-N-ethansulfonsäure

Isoelektrische Fokussierung 


\begin{tabular}{|c|c|}
\hline $\operatorname{IgG}$ & Immunoglobulin $\mathrm{G}$ \\
\hline Kap. & Kapitel \\
\hline $\mathrm{kb}$ & Kilobasenpaar \\
\hline $\mathrm{kDa}$ & Kilodalton \\
\hline 1 & Liter \\
\hline LMP & Low meltig point \\
\hline Lsg. & Lösung \\
\hline $\mathrm{M}$ & Molarität [mol x l ${ }^{-1}$ ] \\
\hline MCS & Multi cloning side \\
\hline ME & 2-Mercaptoethanol \\
\hline $\mathrm{mg}$ & Milligramm \\
\hline MG & Molekulargewicht \\
\hline $\min$ & Minute \\
\hline $\mathrm{ml}$ & Milliliter \\
\hline MOPS & 3-[N-morpholino]-2-hydroxypropanesulfonic acid \\
\hline mRNA & messenger Ribonukleinsäure \\
\hline NBT & 4-Nitroblautetrazoliumchlorid \\
\hline OD & Optische Dichte \\
\hline PAGE & Polyacrylamid-Gelelektrophorese \\
\hline PCR & $\begin{array}{l}\text { Polymerase-Kettenreaktion (polymerase chain } \\
\text { reaction) }\end{array}$ \\
\hline $\mathrm{pfu}$ & plaque forming units \\
\hline$P_{i}$ & anorganisches Phosphat \\
\hline Prot. & Protein \\
\hline Prot. K & Proteinase K \\
\hline PVP & Polyvinylpyrrolidon \\
\hline RNA & Ribonukleinsäure \\
\hline RT & Raumtemperatur (ca. $21^{\circ} \mathrm{C}$ ) \\
\hline SDS & Natriumdodecylsulfat \\
\hline SSC & Saline Sodium Citrat \\
\hline SSPE & Saline Sodium Phosphate EDTA \\
\hline $\mathrm{T}$ & Thymin \\
\hline TBS & Tris-buffered saline \\
\hline TEMED & $\mathrm{N}, \mathrm{N}, \mathrm{N}^{`}, \mathrm{~N}^{`}$ Tetramethylethylendiamin \\
\hline $\mathrm{T}_{\mathrm{M}}$ & Schmelztemperatur \\
\hline Tris & Tris-(hydroxymetyl)-aminomethan \\
\hline $\mathrm{U}$ & Units (Enzymeinheit) \\
\hline UE & Untereinheit \\
\hline $\mathrm{v} / \mathrm{v}$ & Volumen pro Volumen \\
\hline Vol. & Volumen \\
\hline $\mathrm{w} / \mathrm{v}$ & Gewicht pro Volumen \\
\hline
\end{tabular}




\section{Einleitung}

Die Zuckerrübe (Beta vulgaris L. var. altissima) gehört zur Familie der Chenopodiaceae. Die zweijährige Pflanze bildet im ersten Jahr unter der Blattrosette eine verdickte Pfahlwurzel aus, in der verschiedene Stoffe, wie Zucker und Stickstoffverbindungen gespeichert werden. Im zweiten Jahr wird die Blattrosette aufgelöst und die Zuckerrübe bildet unter Verbrauch der gespeicherten Stoffe den Blütenstand aus.

Die Zuckerrübe ist eine sehr junge Kulturpflanze und wurde erst am Ende des 18. Jahrhunderts aus der Futterrübe gezüchtet. Durch immer neu gezüchtete Sorten konnte der Zuckergehalt des Rübenkörpers von ursprünglich $2-3 \%$ auf bis zu $18 \%$ gesteigert werden (BURBA et al., 1984; SCHIWECK et al., 1993).

Für die Zuckergewinnung in heutigen Großanlagen ist nicht allein der Zuckergehalt des Rübenkörpers von besonderer Bedeutung. Auch der Anteil des sog. „schädlichen Stickstoffs“ bildet ein wichtiges Kriterium in der Beurteilung der technischen Qualität von Zuckerrüben. Als „schädlicher Stickstoff“ werden die Stickstoffverbindungen bezeichnet, die während des Verarbeitungsprozeßes von Rohsaft nicht abgetrennt werden können und als Melassebildner die Auskristallisation des Zuckers erschweren.

$\mathrm{Zu}$ diesen Stickstoffverbindungen gehören unter anderem auch Aminosäuren von denen das Glutamin mit über $50 \%$ die Haupt-Aminosäure darstellt (BurbA et al., 1984). Die Aminosäuren erschweren den Prozeß der Zuckergewinnung zusätzlich, da sie für die Ansäuerung des Zuckerrüben-Rohsaftes verantwortlich sind, und der saure Rohsaft daher unter Einsatz alkalischer Stoffe neutralisiert werden muß.

Die Aminosäure Glutamin entsteht in Pflanzen als primäre organische Stickstoffverbindung bei der Stickstoffassimilation. Als Ausgangssubstrate dienen die anorganischen Stickstoffverbindungen Nitrat oder Ammonium. Elementarer Stickstoff kann von Pflanzen nicht verwertet werden, wobei verschiedene Pflanzen in der Lage sind den elementaren Stickstoff indirekt über eine Symbiose mit Stickstoff-fixierenden Rhizobien (Knöllchenbakterien) zu nutzen. Nitrat ist für die meisten Pflanzen die wichtigste Stickstoff-Quelle und muß zur weiteren Nutzung reduziert werden. Die Reduktion erfolgt nach Aufnahme durch spezifische Transporter (GLASS et al., 1990; 
GOYAL und HuFFAKER, 1986) im Cytosol durch die NAD(P)H-abhängige Nitratreduktase. Das gebildete Nitrit wird in die Chloroplasten importiert und durch die Ferredoxinabhängige Nitritreduktase zu Ammonium reduziert (CRAWFORD, 1995; HoFF et al., 1994; WARNER und KLEINHOFS, 1992):

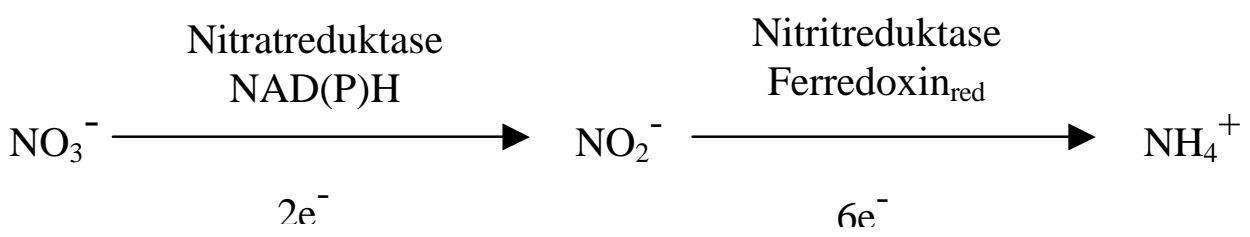

Der Einbau des anorganischen Ammoniums in organische Verbindungen wird durch die Glutaminsynthetase (GS) katalysiert:

GS

L-Glutamat $+\mathrm{NH}_{4}^{+}+\mathrm{ATP} \longrightarrow$ L-Glutamin + ADP $+\mathrm{P}_{\mathrm{i}}$

Die Amidgruppe des Glutamins wird dann durch die Glutamin-2-OxoglutaratAminotransferase (GOGAT) auf das 2-Oxoglutarat übertragen:

L-Glutamin +2 -Oxoglutarat $+\mathrm{Fd}_{\mathrm{red}} \stackrel{\text { GOGAT }}{\longrightarrow} 2$ L-Glutamat $+\mathrm{Fd}_{\mathrm{ox}}$

Durch diese Reaktion werden zwei Moleküle Glutamat gebildet, wovon ein Molekül wieder als Akzeptor für Ammonium und als Substrat für die GS dienen kann. Das andere Molekül steht als Substrat für den N-Metabolismus zur Verfügung. Das Zusammenwirken der Glutaminsynthetase und der Glutamin-2-Oxoglutarat-Aminotransferase ist auch als GS/GOGAT-Zyklus bekannt und bildet eine Schnittstelle zwischen C- und NMetabolismus (JOY, 1988; MifLIN und LEA, 1976).

Die aktive Glutaminsynthetase (GS) liegt in höheren Pflanzen als Oktamer oder als Tetramer vor (MÄCK und TISCHNER, 1990 und 1994). Das Oktamer hat ein Molekulargewicht zwischen 330 und 370 kDa (MCNALly und HiREL, 1983), wobei die 
Untereinheiten zwischen 38 und $45 \mathrm{kDa}$ schwer sind (LEA et al., 1990). In höheren Pflanzen kommen zwei Isoformen der GS vor. Eine Isoform, die GS2, liegt in den Plastiden vor. Die Untereinheiten der GS2 sind mit 44 - $45 \mathrm{kDa}$ größer als die Untereinheiten der im Cytosol vorkommenden GS1, die ein Molekulargewicht zwischen 38 und 45 kDa besitzen (CUllimore Und BENNET, 1988; LARA et al., 1984; Tingey et al., 1987). Der plastidären GS2 wird die Funktion der Primärassimilation des Stickstoffs zugeschrieben (LAM et al., 1995). Die Hauptfunktion der GS2 besteht aber auch in der Refixierung des photorespiratorisch freigesetzten Ammoniums (KEYS et al., 1978; FRANZ et al., 1982; HemON et al., 1990; TJADEN et al., 1995). In den meisten höheren Pflanzen wird die GS2 von nur einem Gen pro diploidem Genom im Kern kodiert (LIGTHFOOT et al., 1988; BeCKer et al., 1992; StANFORd et al., 1993; ElmLinger et al., 1994). Die Expression der GS2 wird durch Licht reguliert (EDWARDS und CORRUZZI, 1989; EDWARDS et al., 1990; MigGE et al., 1998; CocK et al., 1991).

Die Funktionen der cytosolische GS1 sind noch nicht vollständig aufgeklärt. Es wurde vorgeschlagen, daß die GS1 in jungen Blättern eine Funktion bei der Entladung des Phloems hat (DuBOIS et al., 1996). Diese Vermutung wird durch den Befund gestützt, daß die GS1 im Cytoplasma von Phloem-Begleitzellen (PEREIRA et al., 1992) sowie in Phloemund Xylemparenchymzellen nachgewiesen wurde (SAKURAI et al., 1996; DuBOIS et al., 1996). In seneszenten Blättern wird der GS1 eher eine Rolle beim Export von Glutamin zugeschrieben. Da die Aktivität der GS1 in seneszenten Blättern ansteigt (BUCHANANWollaston, 1997; BreChlin et al., 1999) wird vermutet, das die GS1, das Ammonium, das in diesem Entwicklungsstadium bei der Degradation von Proteinen und Nukleinsäuren verstärkt freigesetzt wird (GIVAN, 1979), als Glutamin refixiert und dieses dann über das Phloem in die Sinkorgane der Pflanzen transportiert wird (KAWAKAMI und WATANABE, 1988; KAMACHI et al., 1991 und 1992; VINCENT et al., 1997).

Die GS1 wird im Gegensatz zur GS2 in den bisher untersuchten Pflanzen von einer Multigenfamilie kodiert (PETERMAN UND GOODMAN, 1991; WALKER und CORUZZI, 1989; TingeY und CORUZZI, 1987; SAKAKIBARA et al., 1992; Li et al., 1993; SuKANYA et al., 1994). Die einzelnen Gene dieser Genfamilie können organ- und gewebespezifisch exprimiert werden (STANFORD et al., 1993; DuBOIS et al., 1996; RocHE et al., 1993).

In der Zuckerrübe erscheint die GS1 entwicklungsspezifisch als Homo- oder Heterooktamer, wobei das Heterooktamer in jungen und ausgewachsenen Blättern aus bis 
zu zwei verschiedenen Untereinheiten gleicher Größe (43 kDa) zusammengesetzt sein kann. In seneszenten Blättern wird die GS1 aus acht identischen Untereinheiten zusammengesetzt (BRECHLIN et al., 1999).

Die bisherigen Untersuchungen der GS1 weisen darauf hin, daß die GS1 Glutamin für den phloemgebundenen Transport bereitstellt. Die speziell in seneszenten Blättern der Zuckerrübe gesteigerte GS1-Aktivität trägt entscheidend dazu bei den anfallenden Stickstoff aus der Proteindegradation zur Speicherung in den Rübenkörper zu überführen. Deshalb bieten sich molekularbiologische Methoden zur Beeinflussung der GS1 an um eine Reduzierung des Gehaltes an „schädlichem Stickstoff“ in der Zuckerrübe zu erreichen.

Die GS1 tritt im seneszenten Zuckerrübenblatt als Homooktamer auf. Sie wird also in diesem Stadium von nur einem Gen exprimiert. Eine spezifische Ausschaltung dieses Gens könnte ausreichen, den Glutamingehalt in der Speicherwurzel zu senken.

Eine Möglichkeit die Expression eines speziellen Gens zu unterdrücken ist die AntisenseRNA-Methode (VAN DER KROL et al., 1988b; BouRQUE, 1995), die auch in dieser Arbeit eingesetzt wurde. Dabei wird ein antisense DNA-Konstrukt durch Transformation in das Wirtsgenom integriert. Das antisense DNA-Konstrukt enthält einen Promoter von dem aus die Transkription der Antisense-RNA startet. Dieser muß im Wirtsorganismus wirksam sein. An den Promoter schließt sich in 5'- 3'-Richtung (,upstream“) die Antisense-DNA an. Diese kann aus der kompletten cDNA-Sequenz oder einem Teilstück der cDNASequenz des Gens bestehen, dessen Expression unterdrückt werden soll. Die AntisenseDNA wird aber im Gegensatz zum natürlichen Gen in umgekehrter Orientierung zum Promoter eingesetzt, so daß bei der Transkription ein RNA-Strang synthetisiert wird, der zu der mRNA des natürlichen Gens in der Nukleotidsequenz komplementär ist. Beide RNA-Spezies sind somit in der Lage miteinander zu hybridisieren und einen RNADoppelstrang zu bilden. Der RNA-Doppelstrang kann nicht translatiert werden und wird durch Nukleasen schnell abgebaut (JIANG et al, 1994). An die Antisense-DNA wird abschließend noch eine Terminationssequenz angehängt um den Abbruch der Transkription zu erwirken.

Um die Antisense-DNA in den Wirtsorganismus einzuschleusen wurde in dieser Arbeit eine abgewandelte Form der Blattscheibentransformation nach HoRsCH (1985) 
durchgeführt. Dabei wird die Antisense-DNA zuerst in die T-DNA eines Binärvektors kloniert, der dann in ein Agrobacterium tumefaciens Bakterium eingebracht wird. Das gramnegative Bodenbakterium A. tumefaciens gehört zu der Familie der Rhizobiaceae und hat die natürliche Eigenschaft einen DNA-Abschnitt des Ti-Plasmids (ein Binärvektor ist ein modifiziertes Ti-Plasmid), die T-DNA, in die Zellen der meisten dikotylen Pflanzen einzuschleusen und dort die DNA stabil in das Genom zu integrieren (SCHLEGEL, 1985). Transformierte Pflanzenzellen werden wieder teilungsfähig und können somit durch Hormon-Behandlung zu ganzen Pflanzen regeneriert werden. Die Transformations- und Regenerationsfähigkeit ist bei verschiedenen Pflanzen jedoch unterschiedlich gut. Transformanten der Zuckerrübe lassen sich, wenn sie auf diese Weise transformiert wurden, nur schwer regenerieren. Dagegen läst sich Zuckerrübengewebe nach einer Cotransformation, bei der ein Pflanzenstück sowohl mit einem Agrobacterium tumefaciens als auch mit einem Agrobacterium rhizogenes-Stamm cokultiviert wird, gut regenerieren. Diese Methode hat jedoch den Nachteil, daß sich aus dem transformierten Gewebe nur Faserwurzeln („Hairy Roots“) regenerieren lassen. Diese zeigen aber eine stabile Expression aller Wurzel-spezifischen Stoffwechselwege (FLORES et al., 1993) und können als Modellpflanze für verschiedene Untersuchungen eingesetzt werden.

Das Ziel dieser Arbeit bestand darin, einen cDNA-Klon zu finden, der für die GS1Untereinheit kodiert, die in seneszenten Zuckerrübenblättern als einzige exprimiert wird. Dazu wurde eine cDNA-Genbank erstellt.

Es sollten dann mit der GS1 kodierenden cDNA verschiedene Antisense-Konstrukte erstellt werden, die für eine Cotransformation von Zuckerrüben eingesetzt werden sollten, um transgene Zuckerrübenwurzeln (,Hairy Roots“) zu erzeugen.

Nach der Selektion sollten die Transformanten mit molekularbiologischen und proteinbiochemischen Methoden untersucht werden, um die Effektivität und die Auswirkungen einer Reduzierung der GS1-Aktivität in der Zuckerrübe mit Hilfe der Antisense-RNA-Methode zu dokumentieren. 


\section{MATerial UND Methoden}

\subsection{Präparation einer cDNA-Phagen-Bank}

\subsubsection{Extraktion von Gesamt-RNA}

Für die RNA-Isolierung wurden $20 \mathrm{~g}$ seneszentes Blattmaterial von Zuckerrüben (Beta vulgaris L. var. altissima, Sorte 9E0111) der Kleinwanzlebener Saatzucht AG (KWS, Einbeck) in flüssigem Stickstoff gemörsert.

Das feine Pulver wurde in $100 \mathrm{ml}$ Aufnahmepuffer überführt, der $20 \mathrm{mg}$ frisch zugesetzte Proteinase $\mathrm{K}$ enthielt. Das Gemisch wurde für $15 \mathrm{~min}$ auf einem Magnetrührer homogenisiert, mit $50 \mathrm{ml}$ Phenol (80 \% w/v, pH 7,5-8) versetzt. Nach 5 minütigem Rühren wurden $50 \mathrm{ml}$ Chloroform/Isoamylalkohol hinzugegeben und für weitere $5 \mathrm{~min}$ gerührt.

Das Gemisch wurde anschließend $10 \mathrm{~min}$ bei $15000 \mathrm{x}$ g und $20^{\circ} \mathrm{C}$ zentrifugiert. Die wässrige obere Phase wurde abgenommen, mit $100 \mathrm{ml}$ Phenol/Chloroform versetzt und gemischt. Nach erneuter Zentrifugation wurden der wässrigen Phase 1/10 Vol. 3 M NaAc (pH 6,5) und 1 Vol. Isopropanol hinzugegeben. Die RNA-Fällung erfolgte für $2 \mathrm{~h}$ bei $-20^{\circ} \mathrm{C}$. Bei $20000 \mathrm{x}$ g und $4^{\circ} \mathrm{C}$ wurde für 30 min zentrifugiert, das RNA-Pellet mit EtOH $(70 \% \mathrm{v} / \mathrm{v})$ gewaschen und erneut zentrifugiert. Nach Entfernen des Ethanols wurde das Pellet 10 min bei RT getrocknet.

Das Pellet wurde in $10 \mathrm{ml} \mathrm{H} \mathrm{H}_{2} \mathrm{O}$ (bidest), das $10 \mu \mathrm{g} / \mathrm{ml}$ Proteinase K enthielt, gelöst und mit 2,5 $\mathrm{ml} 10 \mathrm{M} \mathrm{LiCl}$ versetzt. Die selektive Präzipitierung der RNA erfolgte für $16 \mathrm{~h}$ bei $0^{\circ} \mathrm{C}$. Die anschließende Zentrifugation wurde bei $20000 \mathrm{x} \mathrm{g}$ und $4^{\circ} \mathrm{C}$ für $30 \mathrm{~min}$ durchgeführt. Der Überstand wurde verworfen und das Pellet in $2 \mathrm{ml} \mathrm{H}_{2} \mathrm{O}$ (bidest) aufgenommen. Für die Bestimmung der RNA-Konzentration und deren Reinheit wurde die OD eines Aliquots der Lösung im Spektralphotometer bei den Wellenlängen 280, 260 und $230 \mathrm{~nm}$ gemessen (siehe Kap. 2.6.5.). 


$\begin{array}{lll}\text { Aufnahmepuffer: } & 50 \mathrm{mM} & \text { Tris- } \mathrm{HCl}(\mathrm{pH} 9,0) \\ & 100 \mathrm{mM} & \mathrm{NaCl} \\ 10 \mathrm{mM} & \text { EDTA } \\ 2 \%(\mathrm{w} / \mathrm{v}) & \text { SDS } \\ 0,2 \mathrm{mg} / \mathrm{ml} & \text { Proteinase K }\end{array}$

Chloroform/Isoamylalkohol: Chloroform/Isoamylalkohol 24/1 (v/v); pH 7,5

Phenol/Chloroform:

Phenol/Chloroform/Isoamylalkohol

25/24/1 (v/v/v); pH 7,5

\subsubsection{Isolierung von Poly (A)+ mRNA}

In ein steriles $50 \mathrm{ml}$ Röhrchen wurden $200 \mathrm{mg}$ Oligo-dT Cellulose sowie $25 \mathrm{ml}$ Bindungspuffer gegeben. Die Gesamt-RNA Präparation wurde hinzupipettiert und das verschlossene Röhrchen bei RT für 30 min sanft geschwenkt. Anschließend wurde 1 min bei 1000 x g zentrifugiert und der Überstand mit den nicht gebundenen RNA-Spezies dekantiert. Die Oligo-dT Cellulose mit der gebundenen Poly (A)+ mRNA wurde in $25 \mathrm{ml}$ Bindungspuffer resuspendiert und erneut zentrifugiert. Danach wurde die Cellulose mit 25 $\mathrm{ml}$ Waschpuffer versetzt, geschwenkt und abzentrifugiert. Dieser Waschschritt wurde noch einmal wiederholt. Die Cellulose wurde in $15 \mathrm{ml}$ Waschpuffer aufgenommen und in eine Glassäule mit Baumwollfritte überführt. Die Säule wurde solange mit Waschpuffer gewaschen, bis das Eluat bei $\mathrm{OD}_{260}$ den Wert von ca. 0,005 aufwies. Mit $10 \mathrm{ml}$ auf $55^{\circ} \mathrm{C}$ vorgewärmten Elutionspuffer wurde die mRNA eluiert, mit 1/10 Vol. $3 \mathrm{M}$ NaAc und dem zweifachen Vol. EtOH versetzt und für $16 \mathrm{~h}$ bei $-20^{\circ} \mathrm{C}$ gefällt. Die anschließende Zentrifugation erfolgte bei $20000 \mathrm{x} \mathrm{g}, 4^{\circ} \mathrm{C}$ für $45 \mathrm{~min}$. Das Pellet wurde in $10 \mathrm{ml}$ Bindungspuffer gelöst und in diesem Volumen ein zweites Mal über eine Oligo-dT Cellulosesäule gereinigt. Nach der Fällung wurde das mRNA-Pellet in $400 \mu \mathrm{TE}$ aufgenommen und die RNA-Konzentration bestimmt. Um noch vorhandene Proteinase K $\mathrm{zu}$ inaktivieren und $\mathrm{zu}$ entfernen wurde eine Phenolisierung mit anschließender Fällung durchgeführt. Das mRNA-Pellet wurde in TE zu $1 \mu \mathrm{g} / \mu \mathrm{l}$ aufgenommen. 


$\begin{array}{lll}\text { Bindungspuffer: } & 400 \mathrm{mM} & \mathrm{NaCl} \\ & 10 \mathrm{mM} & \text { Tris- } \mathrm{HCl}(\mathrm{pH} 7,5) \\ & 2 \%(\mathrm{w} / \mathrm{v}) & \mathrm{SDS} \\ & & \\ & 100 \mathrm{mM} & \mathrm{NaCl} \\ \text { Waschpuffer: } & 10 \mathrm{mM} & \text { Tris- } \mathrm{HCl}(\mathrm{pH} \mathrm{7,5}) \\ & 0,2 \%(\mathrm{w} / \mathrm{v}) & \mathrm{SDS} \\ & & \\ & 10 \mathrm{mM} & \text { Tris- } \mathrm{HCl}(\mathrm{pH} 7,0) \\ \text { Elutionspuffer: } & & \\ & 10 \mathrm{mM} & \text { Tris- } \mathrm{HCl}(\mathrm{pH} 8,0) \\ \text { TE: } & 1 \mathrm{mM} & \text { EDTA }\end{array}$

\subsubsection{Synthese von cDNA}

Die cDNA-Synthese wurde mit dem cDNA Synthesis Kit der Firma Boehringer Mannheim nach einer modifizierten Methode von GUBLER und HOFFMAN (1983) durchgeführt. Es wurden $5 \mu \mathrm{g}$ der mRNA mit $\mathrm{H}_{2} \mathrm{O}$ (Kit) auf $18 \mu \mathrm{l}$ aufgefüllt, für 3 min bei $65^{\circ} \mathrm{C}$ erhitzt und danach auf Eis abgekühlt. Dazu kamen $1 \mu 1$ der DTT-Solution (Kit) und der gesamte Inhalt des First Strand Reaction Mix (Kit). Zur Überprüfung der Synthese-Reaktion wurde zu einem parallel Ansatz $2 \mu 1$ radioaktives $\alpha-{ }^{32} \mathrm{P}$ dCTP hinzupipettiert. Die Ansätze wurden zuerst eine Stunde bei $37^{\circ} \mathrm{C}$ und dann für weitere $30 \mathrm{~min}$ bei $42^{\circ} \mathrm{C}$ inkubiert. $\mathrm{Zu}$ je einem Ansatz kam das Gesamtvolumen des Second Strand Reaction Mix (Kit). Die Reaktionsgemische wurden für $1 \mathrm{~h}$ bei $12^{\circ} \mathrm{C}$ und anschließend $1 \mathrm{~h}$ bei $22^{\circ} \mathrm{C}$ inkubiert. Um die synthetisierte doppelsträngige cDNA mit "Blunt"-Enden zu versehen, wurden je $1 \mu 1$ Klenow Fragment (Kit) in die Ansätze gegeben und für $30 \mathrm{~min}$ inkubiert. Die Reaktionsgemische wurden dann phenolisiert und die cDNA über Sephacryl S-300 spin columns entsalzt. Die cDNAs wurden anschließend mit 1/10 Vol. 3 M NaAc und 2 Vol. EtOH (96\%) für $1 \mathrm{~h}$ bei $-20^{\circ} \mathrm{C}$ gefällt, zentrifugiert $\left(2000 \mathrm{x} \mathrm{g}, 15 \mathrm{~min}, 4^{\circ} \mathrm{C}\right)$ und die Pellets in je $80 \mu \mathrm{H}_{2} \mathrm{O}$ (bidest) aufgenommen. Aliquots der radioaktiv markierten cDNA wurden auf einem Agarosegel elektrophoretisch aufgetrennt. Mittels Autoradiografie (Hyperfilm $\beta$-max, Amersham) des getrockneten Gels wurde die Qualität der cDNASynthese bezüglich ihrer Größe und Menge abgeschätzt. 


\subsubsection{Adapter- und Vektor-Ligation}

Zu den $80 \mu 1$ cDNA wurden $10 \mu 110$ x Ligasepuffer (Kit), $1 \mu 1$ Spermidin-HCL (Kit), $5 \mu 1$ EcoR I/Not I Adapter Solution (Kit) sowie $3 \mu 1$ T4 DNA Ligase (1 U/ $\mu 1$, Kit) hinzugefügt und für $16 \mathrm{~h}$ bei $12^{\circ} \mathrm{C}$ inkubiert. Nach einer Phenolisierung wurde die DNA gefällt (30 $\left.\min ,-20^{\circ} \mathrm{C}\right)$ und für $15 \mathrm{~min}$ bei $2000 \mathrm{x} \mathrm{g}\left(4^{\circ} \mathrm{C}\right)$ zentrifugiert. Das Pellet wurde in $43 \mu \mathrm{l}$ $\mathrm{H}_{2} \mathrm{O}$ (bidest) aufgenommen, für die Phosphorylierung der 5-Enden mit $5 \mu \mathrm{l} 10 \mathrm{x}$ Kinasepuffer (Kit) 0,5 $\mu 1100$ mM ATP (Kit) und $2 \mu 1$ T4 Polynukleotid Kinase (10 U/ $\mu 1$, Kit) vermischt und für $30 \mathrm{~min}$ bei $37^{\circ} \mathrm{C}$ inkubiert. Das Reaktionsgemisch wurde dann phenolisiert, gefällt, zentrifugiert und die cDNA in einem Volumen von $10 \mathrm{ng}$ DNA/ $\mu \mathrm{l}$ in $\mathrm{H}_{2} \mathrm{O}$ (bidest) aufgenommen.

$\mathrm{Zu} 400$ ng EcoR I geschnittener und dephosphorylierter $\lambda$-Phagen-DNA (NM 1149) wurden $1 \mu 110$ x Ligationspuffer (Kit), $2 \mu \mathrm{l}$ cDNA (10ng/ $\mu \mathrm{g}), 0,5 \mu 1 \mathrm{BSA}(2 \mu \mathrm{g} / \mu \mathrm{l}$, Kit) sowie $0,5 \mu 1 \mathrm{~T} 4$ DNA Ligase $\left(1 \mathrm{U} / \mu 1\right.$, Kit) pipettiert, mit $\mathrm{H}_{2} \mathrm{O}$ (bidest) auf ein Endvolumen von $10 \mu \mathrm{l}$ aufgefüllt und für $16 \mathrm{~h}$ bei $16^{\circ} \mathrm{C}$ inkubiert. Anschließend wurde für $10 \mathrm{~min}$ bei $55^{\circ} \mathrm{C}$ erhitzt um die Ligase zu inaktivieren.

EcoR I/Not I Adapter: $\quad 5$ HO-AATTCGCGGCCGC-OH 3`

3. $\mathrm{HO}-\mathrm{GCGCCGGCG- \textrm {PO } _ { 4 } 5}$

\subsubsection{Verpackung von cDNA in $\lambda$-Phagen}

Die in vitro Verpackung der $\lambda$-Phagen-DNA mit der inserierten cDNA erfolgte mit dem Gigapack II Packaging Extract Kit der Firma Statagene. $5 \mu$ l (ca. 200 ng) der $\lambda$-PhagenDNA wurden zu dem Freeze/Thaw extract (rotes Gefäß) zugegeben. Dazu wurden $15 \mu 1$ des Sonic extract (gelbes Gefäß) pipettiert, gemischt und für $2 \mathrm{~h}$ bei $22^{\circ} \mathrm{C}$ inkubiert. Abschließend wurden $200 \mu \mathrm{l}$ SM Puffer und $10 \mu$ l Chloroform hinzugefügt. Die fertige cDNA-Phagen-Bank wurde bei $4^{\circ} \mathrm{C}$ gelagert. 


$\begin{array}{lll}\text { SM Puffer: } & 100 \mathrm{mM} & \mathrm{NaCl} \\ & 10 \mathrm{mM} & \mathrm{MgSO}_{4} \times 7 \mathrm{H}_{2} \mathrm{O} \\ & 50 \mathrm{mM} & \text { Tris/HCl }(\mathrm{pH} 7,5) \\ 2 \%(\mathrm{w} / \mathrm{v}) & \text { Gelatine } \\ & & \text { in } 11\left(\mathrm{H}_{2} \mathrm{O}\right)\end{array}$

\subsection{Screening von cDNA- $\lambda$-Phagen-Banken}

\subsubsection{Herstellung $\lambda$-kompetenter $E$. coli Bakterien}

Für die Herstellung $\lambda$-kompetenter E.coli Bakterien (XL-1 Blue MRF', Stratagene) wurden $25 \mathrm{ml} \mathrm{NZY-Medium} \mathrm{mit} \mathrm{0,4} \mathrm{\%} \mathrm{(w/v)} \mathrm{Maltose} \mathrm{in} \mathrm{einem} \mathrm{sterilen} 100 \mathrm{ml}$ Erlenmeyerkolben mit einer Einzelkolonie der Bakterien angeimpft und bei $37^{\circ} \mathrm{C}$ in einem Schüttler für acht Stunden inkubiert $\left(\mathrm{OD}_{600}=0,2-0,5\right)$. Die Zellsuspension wurde dann für 15 min bei 1000 $\mathrm{x} \mathrm{g}$ zentrifugiert, der Überstand verworfen und die pelletierten Zellen in $5 \mathrm{ml} 10 \mathrm{mM}$ $\mathrm{MgSO}_{4}$ vorsichtig resuspendiert. Die $\mathrm{OD}_{600}$ wurde bestimmt und anschließend mit $10 \mathrm{mM}$ $\mathrm{MgSO}_{4}$ auf 0,5 eingestellt.

Die Zellen sind bei $4^{\circ} \mathrm{C}$ ca. zwei Wochen haltbar.

\begin{tabular}{|c|c|c|}
\hline \multirow[t]{4}{*}{ NZY: } & $0,5 \%(\mathrm{w} / \mathrm{v})$ & $\mathrm{NaCl}$ \\
\hline & $0,2 \%(\mathrm{w} / \mathrm{v})$ & $\mathrm{MgSO}_{4} \times 7 \mathrm{H}_{2} \mathrm{O}$ \\
\hline & $0,5 \%(\mathrm{w} / \mathrm{v})$ & Hefeextrakt \\
\hline & $0,5 \%(\mathrm{w} / \mathrm{v})$ & NZ Amine (Caseinpepton) \\
\hline
\end{tabular}

Das Festmedium enthält 1,5\% (w/v) Agar 


\subsubsection{Plattierung einer cDNA-Phagenbank}

Neben der selbst erstellten NM 1149- $\lambda$-Phagen-cDNA-Bank, wurde eine weitere $\lambda$ Phagen-cDNA-Bank (Dr. N. Sandal; Laboratory of Gene Expression; University of Aarhus; Denmark) aus Wurzelgewebe von Beta vulgaris L. in das Screening mit einbezogen. Diese cDNA-Bank wurde mit dem Lambda ZAP II ${ }^{\circledR}$ System der Firma Stratagene erstellt.

NZY-Platten wurden $1 \mathrm{~h}$ bei $37^{\circ} \mathrm{C}$ vorgewärmt. $\lambda$-Top-Agar wurde geschmolzen und in einem Wasserbad auf $42^{\circ} \mathrm{C}$ temperiert. $150 \mu 1 \lambda$-Kompetente Zellen (E. coli, XL1 Blue MRF') wurden mit einer geeigneten Menge der Phagensuspension (für $90 \mathrm{~mm} \varnothing$ Platten ca. 5000-10000 pfu, durch Testplattierungen ermittelt) gemischt und $15 \mathrm{~min}$ bei RT inkubiert. Die Phagen-Bakterien-Suspension wurde mit 4,5 ml Top-Agar pro Platte gemischt und auf die NZY-Platten gegossen. Nach dem Erkalten des Top-Agars wurden die Platten mit der Agarseite nach oben bei $37^{\circ} \mathrm{C}$ für $16 \mathrm{~h}$ inkubiert und anschließend für 12 Stunden bei $4^{\circ} \mathrm{C}$ gekühlt.

$$
\begin{array}{ll}
\text { Top Agar: } & \text { NZY-Flüssigmedium } \\
& \text { Agarose } \quad(0,7 \% \mathrm{w} / \mathrm{v})
\end{array}
$$

\subsubsection{Herstellung von Nitrocellulose Replika-Filtern}

Auf die Agaroberfläche der Platten wurden BA 85 Nitrocellulose-Rundfilter $(82 \mathrm{~mm} \varnothing$, Schleicher \& Schüll) gelegt und dort 15 min bei RT belassen. Die Phagenpartikel binden an die Nitrocellulose. Mit einer großen Kanüle wurden zur späteren richtigen Orientierung drei Löcher in asymmetrischem "L"-Muster (ca. 3 x $5 \mathrm{~cm}$ "L") durch die Nitrocellulose in den Agar gestochen. Die Filter wurden von den Platten entfernt und entsprechend ihren Platten beschriftet.

Die Filter wurden mit der Phagen-Seite nach oben luftblasenfrei auf zwei Lagen mit Southern I durchtränktem Whatman 3MM Papier (oder vergleichbar starkes Filterpapier) gelegt und 5 min dort belassen. In der alkalischen Lösung zerfallen die Phagenpartikel. Die DNA wird freigesetzt, denaturiert und durch die hohe Natriumkonzentration gebunden. 
Die Filter wurden dann für 5 min auf zwei Lagen mit Southern II durchtränktem Whatman 3MM gelegt (Neutralisierung) und anschließend für 15 min auf mit 2 x SSC durchtränktem Whatman 3MM (Entsalzung). Danach wurden die Filter für $1 \mathrm{~h}$ bei $80^{\circ} \mathrm{C}$ gebacken (irreversible Bindung der DNA an die Nitrocellulose).

$\begin{array}{lrl}\text { Southern I: } & \begin{array}{r}0,5 \mathrm{M} \\ 1 \mathrm{M}\end{array} & \mathrm{NaOH} \\ & & \mathrm{NaCl} \\ & & \\ \text { Southern II: } & 3 \mathrm{M} & \mathrm{NaCl} \\ & 0,5 \mathrm{M} & \mathrm{Tris} / \mathrm{HCl}(\mathrm{pH} 7) \\ & & \\ & 3 \mathrm{M} & \mathrm{NaCl} \\ & & \mathrm{Na}-\mathrm{Citrat}(\mathrm{pH} 7)\end{array}$

\subsubsection{Sondenmarkierung}

Es wurden ca. $100 \mathrm{ng}$ der Sonden-DNA (GS1-cDNA aus Nicotiana tabacum, B. Hirel, INRA de Versailles, France), $5 \mu$ l Hexanukleotide (Hexanucleotid Mixture 10xconc., Boehringer Mannheim) und $5 \mu 110 \times$ Reaktionspuffer (MBI Fermentas) gemischt und mit $\mathrm{H}_{2} \mathrm{O}$ bidest auf $41 \mu \mathrm{l}$ aufgefüllt und anschließend 10 min bei $95^{\circ} \mathrm{C}$ denaturiert. Der Ansatz wurde für 5 min auf Eis gestellt. Danach wurden $3 \mu \mathrm{l}$ des Nukleotidmixes -A (je $5 \mathrm{mM}$ dCTP, dGTP und dTTP) sowie $5 \mu 1 \alpha^{32} \mathrm{P}-\mathrm{dATP}(50 \mu \mathrm{Ci})$ und $1 \mu \mathrm{l}$ Klenow-Fragment (5U/ $\mu 1$, Klenow Fragment, exo-, MBI Fermentas) hinzugegeben und für $15 \mathrm{~min}$ bei $37^{\circ} \mathrm{C}$ inkubiert. Die Reaktion wurde durch Zugabe von $1 \mu$ l 0,5 M EDTA-Lösung (pH 8,0) gestoppt.

Anschließend wurde die markierte DNA durch Gelfiltration mit einer Sephadex G 50Säule von den nicht eingebauten Nukleotiden getrennt. Die spezifische Aktivität der Sonde wurde mit Hilfe eines Scintillationszählers bestimmt. 


\subsubsection{Hybridisierung}

Die Nitrocellulosefilter wurden zusammen in einer verschließbaren Kunststoffschale mit $3 \mathrm{ml}$ Vorhybridisierungslösung pro Rundfilter, $50 \mu \mathrm{l} / \mathrm{ml}$ Denhardt und $50 \mu \mathrm{l} / \mathrm{ml}$ frisch denaturiertem Heringssperma mindestens 2 Stunden bei $61^{\circ} \mathrm{C} \mathrm{im}$ Wasserbad geschüttelt. Die Vorhybridisierungslösung wurde abgegossen und durch Hybridisierungslösung (1,5 ml Hybridisierungslösung pro Filter, $61^{\circ} \mathrm{C}$ ) ersetzt, der die gleichen Mengen an DenhardtLösung und denaturiertem Heringssperma zugesetzt waren. Die denaturierte radioaktive Tabak-GS1-Sonde (ca. $10^{6} \mathrm{cpm} / \mathrm{ml}$ Hybridisierungslösung) wurde als letzte Komponente hinzugefügt. Die heterologe Hybridisierung erfolgte für $16 \mathrm{~h}$ bei $61^{\circ} \mathrm{C}$ im Schüttelwasserbad.

Die radioaktive Hybridisierungslösung wurde entsorgt und die Filter 2 mal mit vorgewärmter Waschlösung 1 kurz abgespült, um den größten Teil der ungebundenen Radioaktivität zu entfernen. Danach wurden die Filter für $15 \mathrm{~min}$ in ca. $200 \mathrm{ml}$ Waschlösung 1 und anschließend ebenfalls $15 \mathrm{~min}$ in Waschlösung 2 bei jeweils $61^{\circ} \mathrm{C}$ im Schüttelwasserbad gewaschen. Die Filter wurden an der Luft getrocknet auf Whatman 3MM Papier befestigt und in Haushaltsfolie eingewickelt. In der Dunkelkammer wurde ein Röntgenfilm (Hyperfilm $\beta$-max, Amersham) passender Größe auf die Filter gelegt und in einer lichtdichten Kassette für 16 h exponiert. Anschließend wurde der Film entwickelt.

$\begin{array}{ll}\text { Vorhybridisierungslösung: } & 6 \times \mathrm{SSPE} \\ & 0,1 \%(\mathrm{w} / \mathrm{v}) \mathrm{SDS} \\ & 5 \times \mathrm{Denhardt} \\ & 500 \mu \mathrm{g} / \mathrm{ml} \text { denat. Heringssperma } \\ & \\ & 3 \times \mathrm{SSPE} \\ & 0,1 \%(\mathrm{w} / \mathrm{v}) \mathrm{SDS} \\ & 5 \times \mathrm{Denh} \text { Herdt } \\ & 500 \mu \mathrm{g} / \mathrm{ml} \text { denat. Heringssperma } \\ & \\ & 2 \times \mathrm{SSPE} \\ & 0,1 \%(\mathrm{w} / \mathrm{v}) \mathrm{SDS}\end{array}$




\begin{tabular}{|c|c|c|}
\hline \multirow[t]{2}{*}{ Waschlösung 2: } & \multicolumn{2}{|l|}{$1 \times$ SSPE } \\
\hline & \multicolumn{2}{|c|}{$0,1 \%(\mathrm{w} / \mathrm{v}) \mathrm{SDS}$} \\
\hline \multirow[t]{3}{*}{$20 \times$ SSPE: } & $3 \mathrm{M}$ & $\mathrm{NaCl}$ \\
\hline & $0,2 \mathrm{M}$ & $\mathrm{NaH}_{2} \mathrm{PO}_{4} \times \mathrm{H}_{2} \mathrm{O}$ \\
\hline & $0,02 \mathrm{M}$ & EDTA \\
\hline \multirow[t]{3}{*}{50 x Denhardt: } & $0,2 \%(\mathrm{w} / \mathrm{v})$ & Ficoll 400 \\
\hline & $0,2 \%(\mathrm{w} / \mathrm{v})$ & PVP \\
\hline & $0,2 \%(\mathrm{w} / \mathrm{v})$ & BSA \\
\hline
\end{tabular}

\subsection{DNA aus $\lambda$-Minilysaten}

Nach dem "Erst-Screening" wurden die Plaques, die einem Signal auf der Autoradiographie zuzuordnen waren, aus dem Agar ausgestochen und in $700 \mu 1$ SM-Puffer überführt. Da die Plaques bei der "Erst-Plattierung" sehr dicht beieinander liegen und eine exakte Signal-Zuordnung in der Regel nicht möglich ist, wurden die Plaques mit der weiten Öffnung einer Pasteurpipette ausgestanzt, wobei es möglich war, daß sich mehrere Plaques auf einem ausgeschnittenem Agarstück befanden (Multiplaque). Um einen reinen Phagenklon zu erhalten, wurde nach einer 30 minütigen Inkubation bei RT ein Aliquot der Phagen-SM-Pufferlösung 1:1000 (in SM-Puffer) verdünnt. Von dieser Verdünnung wurden $1 \mu \mathrm{l}$ und $10 \mu \mathrm{l}$ mit je $100 \mu \mathrm{l} \lambda$-kompetenter E. coli (XL1 Blue MRF') Zellen vermischt und für 15 min bei RT inkubiert. Die Plattierung erfolgte wie unter Kap. 2.2.2 beschrieben. Die Anzahl der Plaques pro Platte sollte zwischen 10 und 100 liegen. Von diesen Platten wurden Replika-Filter erstellt und wie unter Kap. 2.2.5 beschrieben hybridisiert.

Die Einzelplaques der "Zweit-Plattierung", die auf der Autoradiografie positive Signale zeigten, wurden mit dem spitzen Ende einer Pasteurpipette ausgestochen und in je $200 \mu 1$ SM-Medium überführt, davon wurden $20 \mu$ l entnommen und mit $30 \mu \mathrm{l} \lambda$-kompetenter $E$. 
coli (XL1 Blue MRF') Zellen vermischt. Diese Suspension wurde 15 min bei RT inkubiert und anschließend in ein Reagenzglas mit $5 \mathrm{ml} \mathrm{NZY-Medium} \mathrm{transferiert.} \mathrm{Bei} 37^{\circ} \mathrm{C}$ unter kräftigem Schütteln wurde für $16 \mathrm{~h}$ inkubiert.

$\mathrm{Zu}$ dem Lysat wurden 2-3 Tropfen Chloroform gegeben, um die nicht durch Phagen lysierten Bakterien abzutöten. Das Lysat wurde 5 min bei $5000 \mathrm{~g}$ zentrifugiert und der Überstand in ein frisches Reagenzglas überführt. Luftdicht verschlossen ist das Minilysat bei $4^{\circ} \mathrm{C}$ mehrere Jahre stabil.

In ein Eppendorfgefäß wurden $500 \mu$ Minilysat pipettiert. DNAse und RNAse wurden auf eine Endkonzentration von je $10 \mu \mathrm{g} / \mathrm{ml}$ hinzugeben und 30 min bei $37^{\circ} \mathrm{C}$ inkubiert. Anschließend wurden $25 \mu \mathrm{l}$ 0,5 M EDTA pH 8,0 hinzugeben und sofort vermischt (inaktiviert reversibel DNAsen und RNAsen und die Phagenpartikel zerfallen).

Proteinase K wurde zu einer Endkonzentration von $40 \mu \mathrm{g} / \mathrm{ml}$ hinzugegeben und $30 \mathrm{~min}$ bei $37^{\circ} \mathrm{C}$ inkubiert. Danach wurden $50 \mu 13 \mathrm{M} \mathrm{NaAc}(\mathrm{pH}$ 6,5) und $500 \mu$ Phenol/Chloroform hinzupipettiert, geschüttelt und $5 \mathrm{~min}$ in einer Eppendorfzentrifuge bei RT zentrifugiert. Die wässrige obere Phase wurde in ein neues Eppendorfgefäß überführt, mit $300 \mu 1$ Isopropanol gemischt und $10 \mathrm{~min}$ in einer Eppendorfzentrifuge bei RT zentrifugiert.

Der Überstand wurde verworfen, das Pellet mit $70 \%$ EtOH gewaschen und der Überstand vollständig entfernt. Das DNA-Pellet wurde $10 \mathrm{~min}$ an der Luft getrocknet und in $50 \mu \mathrm{l}$ $\mathrm{H}_{2} \mathrm{O}$ (bidest) gelöst.

Die DNA aus den NM 1149 Lambda Phagen wurde mit dem Restriktionsenzym EcoR I verdaut, elektrophoretisch in einem Agarosegel aufgetrennt, die Inserts aus dem Gel isoliert und in den Plasmidvektor pBluescript SK (-) (Stratagene) ligiert (siehe Kapitel 2.6.).

Die cDNA-Inserts der Phagen-DNA der Lambda ZAP II Bank wurden mit Hilfe der in vivo Excision als Bestandteil eines pBluescript-Phagemid isoliert. 


\subsubsection{In vivo Excision}

Für die in vivo Excision wurden $200 \mu 1 \lambda$-kompetente E. coli (XL1-Blue MRF') Bakterien mit $250 \mu \mathrm{l}$ des Phagen-Minilysats (ca. $10^{5}$ pfu) und $1 \mu \mathrm{l}$ des ExAssist Helfer-Phagen (ca. $10^{6} \mathrm{pfu} / \mathrm{ml}$ ) gemischt und für $15 \mathrm{~min}$ bei $37^{\circ} \mathrm{C}$ inkubiert. Danach wurden $3 \mathrm{ml}$ LB Medium hinzugegeben und für weitere $2,5 \mathrm{~h}$ bei $37^{\circ} \mathrm{C}$ inkubiert. Die Zellen wurden dann 15 min bei $2000 \mathrm{x} \mathrm{g}$ abzentrifugiert, der Überstand für $15 \mathrm{~min}$ bei $70^{\circ} \mathrm{C}$ erhitzt und bei $4000 \mathrm{xg}$ 15 min zentrifugiert. $100 \mu 1$ des Überstands mit dem filamentösen pBluescript Phagemid wurden mit $200 \mu \mathrm{l}$ frisch gewachsenen $\left(\mathrm{OD}_{600}=0,5-1,0\right)$ SOL R Bakterienzellen (Stratagene) gemischt und für $15 \mathrm{~min}$ bei $37^{\circ} \mathrm{C}$ inkubiert. Anschließend wurden $25 \mu \mathrm{lder}$ Bakteriensuspension auf eine LB-Ampicilin $(50 \mu \mathrm{g} / \mathrm{ml})$ Agarplatte ausplattiert und für $16 \mathrm{~h}$ bei $37^{\circ} \mathrm{C}$ inkubiert. Die gewachsenen Kolonien enthielten nun den doppelsträngigen pBluescript Vektor mit dem cDNA-Insert.

\subsection{DNA Sequenzierung}

Die Sequenzierungen der cDNA-Inserts wurden von der Firma SEQLAB Sequence Laboratories Göttingen GmbH (Göttingen) durchgeführt.

\subsubsection{DNA Sequenzvergleiche}

Die Sequenzvergleiche mit verschiedenen Datenbanken erfolgten über Internet mit Programmen der folgenden Anbieter:

National Center for Biotechnology Information (http://www.ncbi.nlm.gov/cgi-bin/blast/nph-newblast)

Human Genome Center, Baylor College of Medicine (http://dot.imgen.bcm.tcm.edu:9331/cig-bin) 


\subsection{In vitro Transkription/Translation}

Die in vitro Transkription/Translation erfolgte mit dem Linked in vitro SP6/T7 Transcription/Translation Kit- radioactive (Boehringer Mannheim). $\mathrm{Zu} \quad 5 \quad \mu 1$ T7 Transcription buffer (Kit) wurden $0,5 \mu \mathrm{g}$ Ausgangs-cDNA zugegeben und mit $\mathrm{H}_{2} \mathrm{O}$ (Kit) auf $20 \mu \mathrm{l}$ aufgefüllt. Nachdem das Reaktionsgemisch bei $30^{\circ} \mathrm{C}$ für 30 min inkubierte, wurden $10 \mu \mathrm{l}$ davon mit 1,6 $\mu \mathrm{l}$ radioaktivem ${ }^{35}$ S-Methionin und 38,4 $\mu 1$ des Translation mix (Kit) gemischt und für $1 \mathrm{~h}$ bei $30^{\circ} \mathrm{C}$ inkubiert.

\subsection{Subklonierung}

\subsubsection{Vektoren}

Folgende Plasmid-Vektoren wurden bei den Subklonierungen eingesetzt:

pBluescript SK (-) (Stratagene)

BIN 19 (Clontech)

pBI 121 (Clontech)

Top Free OCS-Term ( Prof. Dr. Gatz, A. v. H. Inst., Göttingen)

\subsubsection{Bakterien}

Für die Subklonierungen wurden die Bakterienstämme E. coli XL 1 Blue MRF' (Stratagene) und A. tumefaciens PGV 2260 C58 verwendet.

\subsubsection{Anzucht eines Plasmidklons}

Eine auf LB-Festmedium vereinzelte Bakterien-Kolonie wurde mit einem sterilem Zahnstocher abgenommen und in $5 \mathrm{ml}$ LB-Flüssigmedium mit dem entsprechendem 
Antibiotikum überführt. Die Flüssigkultur wurde bei $37^{\circ} \mathrm{C}$ in einem Schüttler für $16 \mathrm{~h}$ inkubiert.

$\begin{array}{lll}\text { LB- (Luria-Bertani) Medium: } & 1 \%(\mathrm{w} / \mathrm{v}) & \text { Trypton } \\ 0,5 \%(\mathrm{w} / \mathrm{v}) & \text { Hefeextrakt } \\ 1 \%(\mathrm{w} / \mathrm{v}) & \mathrm{NaCl} \\ & \\ & \text { Das Festmedium enthält 1,5\%(w/v) Agar. }\end{array}$

\begin{tabular}{|c|c|c|}
\hline Antibiotika: & Arbeitskonz.: & Stock-Lösungen: \\
\hline Ampicillin & $50 \mathrm{mg} / \mathrm{l}$ & $50 \mathrm{mg}$ in $1 \mathrm{ml} \mathrm{H}_{2} \mathrm{O}$ \\
\hline Kanamycin & $50 \mathrm{mg} / \mathrm{l}$ & $50 \mathrm{mg}$ in $1 \mathrm{ml} \mathrm{DMSO}$ \\
\hline Tetracyclin & $10 \mathrm{mg} / \mathrm{l}$ & $1 \mathrm{~g}$ in $10 \mathrm{ml} \mathrm{EtOH}$ \\
\hline Rifampicin & $50 \mathrm{mg} / \mathrm{l}$ & $1 \mathrm{~g}$ in $20 \mathrm{ml} \mathrm{H}_{2} \mathrm{O}$ \\
\hline
\end{tabular}

\subsubsection{Plasmidisolierung}

\subsubsection{CTAB-Minipräparation}

(modifiziert nach DEL SAL et al., 1989)

Von einer $5 \mathrm{ml}$ E. coli Kultur $\left(\mathrm{OD}_{600}=1,0\right)$ wurden 1,5 $\mathrm{ml}$ in ein Eppendorfgefäß überführt und 3 Minuten bei 4000 x g und Raumtemperatur zentrifugiert. Das Pellet wurde in $200 \mu \mathrm{l}$ STET Puffer mit frisch zugegebenem Lysozym $(0,1 \mathrm{mg} / \mathrm{ml})$ resuspendiert und für 10 Minuten bei RT inkubiert.

Die Suspension wurde 90 Sekunden bei $95^{\circ} \mathrm{C}$ einem Hitzeschock ausgesetzt und 10 Minuten bei 20000 x g zentrifugiert. Das Pellet mit Zellresten und genomischer BakterienDNA wurde anschließend mit einem Zahnstocher entfernt und die RNA mit $10 \mu 1$ RNAse $(10 \mu \mathrm{g} / \mu \mathrm{l})$ für $15 \mathrm{~min}$ bei $37^{\circ} \mathrm{C}$ verdaut.

Nach Zugabe von $10 \mu \mathrm{l}$ CTAB erfolgte die selektive Fällung der Plasmid-DNA. Der CTAB-DNA Komplex wurde nach 10 Minuten bei 20000 x g pelletiert. Das Pellet wurde dann in $300 \mu \mathrm{l} 1,2 \mathrm{M} \mathrm{NaCl}$ gelöst und mit $700 \mu \mathrm{l} 96 \%$ Ethanol $\left(-20^{\circ} \mathrm{C}\right)$ für 20 Minuten bei 
$-20^{\circ} \mathrm{C}$ gefällt. Die Plasmid-DNA wurde danach durch eine 15 minütge Zentrifugation bei $20000 \mathrm{x} \mathrm{g}$ und $4^{\circ} \mathrm{C}$ pelletiert.

Das Pellet wurde für $10 \mathrm{~min}$ an der Luft getrocknet und in 10-20 $\mu 1 \mathrm{H}_{2} \mathrm{O}$ (bidest) aufgenommen.

$\begin{array}{lll}\text { STET-Puffer: } & 8 \%(\mathrm{w} / \mathrm{v}) & \text { Saccharose } \\ & 50 \mathrm{mM} & \text { Tris/HCl }(\mathrm{pH} 8) \\ & 50 \mathrm{mM} & \text { EDTA } \\ & 0,1 \%(\mathrm{w} / \mathrm{v}) & \text { Triton } \mathrm{X}-100 \\ & & \\ \text { CTAB: } & 5 \%(\mathrm{w} / \mathrm{v}) & \mathrm{CTAB} \\ & 0,2 \mathrm{M} & \mathrm{NaCl}\end{array}$

\subsubsection{Plasmid Midipräparation}

Die Suspension einer $25 \mathrm{ml}$ E.coli Kultur, die für $16 \mathrm{~h}$ bei $37^{\circ} \mathrm{C}$ inkubierte $\left(\mathrm{OD}_{600}=0,5\right.$ 1,0), wurde bei 5000 x g 10 min zentrifugiert, der Überstand abgenommen und das Bakterien-Pellet in $4 \mathrm{ml}$ Puffer P1 resuspendiert. Die Zell-Lyse erfolgte bei RT nach Zugabe von $4 \mathrm{ml}$ Puffer P2, welche durch $4 \mathrm{ml}$ Puffer P3 $\left(4^{\circ} \mathrm{C}\right)$ nach 5 min abgestoppt wurde. Das Gemisch wurde für $20 \mathrm{~min}$ auf Eis gestellt und anschließend über einen Faltenfilter in ein neues Gefäß überführt. Zum Aussalzen der Proteine wurden dem Eluat 4 ml gesättigter NaCl-Lösung zugesetzt und bei 20000 x g für 30 min zentrifugiert. Der Überstand wurde abgenommen und mit 0,7 Vol. Isopropanol versetzt. Erneut wurde bei 20000 x g für 30 min zentrifugiert. Das Plasmid-Pellet wurde dann in $200 \mu \mathrm{l} \mathrm{H}_{2} \mathrm{O}$ aufgenommen.

$\begin{array}{lll}\text { P1: } & 50 \mathrm{mM} & \text { Tris/HCl }(\mathrm{pH} 8) \\ & 10 \mathrm{mM} & \text { EDTA } \\ & 100 \mu \mathrm{g} / \mathrm{ml} & \text { RNAse A }\end{array}$




$$
\begin{array}{lll}
\text { P2: } & 200 \mathrm{mM} & \mathrm{NaOH} \\
& 1 \%(\mathrm{w} / \mathrm{v}) & \mathrm{SDS} \\
\text { P3: } & 3,0 \mathrm{M} & \mathrm{KAc}(\mathrm{pH} \mathrm{5,5)}
\end{array}
$$

\subsubsection{Konzentrationsbestimmung von Nukleinsäuren}

Die Nukleinsäure-Konzentration und -Reinheit einer Probe wurde durch Messung der Extinktion in einem Spektralphotometer bei den Wellenlängen 280, 260 und $230 \mathrm{~nm}$ bestimmt.

Die Konzentration für doppelsträngige DNA berechnet sich nach:

$\mathrm{c}_{\mathrm{DNA}}[\mu \mathrm{g} / \mu \mathrm{l}]=\left(50 \times \mathrm{OD}_{260} \times\right.$ Verdünnungsfaktor $) / 1000$

Für RNA gilt:

$\mathrm{c}_{\mathrm{RNA}}[\mu \mathrm{g} / \mu \mathrm{l}]=\left(42 \times \mathrm{OD}_{260} \times\right.$ Verdünnungsfaktor $) / 1000$

Der Quotient von $\mathrm{OD}_{260} / \mathrm{OD}_{280}$ erlaubt eine Abschätzung der Nukleinsäure-Reinheit. Wenn der Wert unter 1,8 liegt, ist die Probe mit Protein- oder Phenolresten kontaminiert. Ein Verhältnis von $\mathrm{OD}_{260} / \mathrm{OD}_{230}<2$ zeigt eine Verunreinigung durch Polysaccharide an.

\subsubsection{Reinigung und Konzentrierung von Nukleinsäuren}

Um Proteine zu entfernen, wurde eine Phenolisierung durchgeführt. Dazu wurde die Nukleinsäurelösung, welche mit Wasser auf mindestens $200 \mu$ l aufgefüllt wurde, mit dem gleichen Volumen Phenol/Chloroform versetzt und kurz gevortext. Zur Phasentrennung wurde die Emulsion 5 min bei 15000 x g und RT zentrifugiert. 
Zur wäßrigen Oberphase, die die Nukleinsäuren enthält, wurde das gleiche Volumen Chloroform/Isoamylalkohol hinzugefügt. Erneut wurde gevortext und zentrifugiert ( $5 \mathrm{~min}$, 15000 x g, RT). Die obere Phase, mit der gereinigten Nukleinsäure, wurde dann in ein neues Reaktionsgefäß überführt.

Um Nukleinsäuren zu konzentrieren, wurde sie mit 1/20 Vol. 3 M NaAc und 2 Vol. $96 \%$ EtOH $\left(-20^{\circ} \mathrm{C}\right)$ versetzt und bei $-20^{\circ} \mathrm{C}$ für 30 min gefällt. Der Ansatz wurde dann bei $4^{\circ} \mathrm{C}$, 15 min zentrifugiert.

Abschließend wurde das Pellet an der Luft getrocknet und in einem geeigneten Volumen $\mathrm{H}_{2} \mathrm{O}$ (bidest) resuspendiert (Standardkonzentration ca. 1,0 $\mu \mathrm{g} / \mu \mathrm{l}$ ).

Phenol/Chloroform: $\quad$ Phenol/Chloroform/Isoamylalkohol 25/24/1 (v/v/v); pH 8

Chloroform/Isoamylalkohol: Chloroform/Isoamylalkohol 24/1 (v/v); pH 8

\subsubsection{Restriktionsverdau von Plasmid-DNA}

\subsubsection{Komplettverdau}

Bei einem Komplettverdau wurde die DNA in allen möglichen Schnittorten eines entsprechenden Enzyms gespalten. Dieses Verfahren wurde angewandt, wenn innerhalb des zu isolierenden DNA-Fragments keine weiteren Schnittstellen derjenigen Enzyme lokalisiert waren, mit denen das Fragment herausgeschnitten werden sollte.

Die Verdaue wurden mit handelsüblichen Enzymen und den dazu jeweils empfohlenen Restriktionspuffern bei angegebener Temperatur durchgeführt.

$\begin{array}{lll}\text { Standard Reaktionsansatz: } & 1 \mu \mathrm{g} & \text { DNA } \\ & 2 \mu \mathrm{l} & 10 \mathrm{x} \text { Reaktionspuffer } \\ 2-3 \mathrm{U} & \text { Enzym } \\ & \mathrm{x} \mu \mathrm{l} & \mathrm{H}_{2} \mathrm{O}(\mathrm{zu} 20 \mu \mathrm{l})\end{array}$

Der Ansatz wurde für $1-2 \mathrm{~h}$ bei $37^{\circ} \mathrm{C}$ (enzymabhängig) inkubiert. 


\subsubsection{Partialverdau}

Besaß das $\mathrm{zu}$ isolierende Fragment weitere Schnittstellen der Enzyme, welche zum Herausschneiden erforderlich waren, so wurde die DNA partiell verdaut.

Bei einem Partialverdau wurde weniger Enzym eingesetzt, als für einen Komplettverdau notwendig ist, so daß sich mehrere Fragmentfraktionen aus unverdautem, teilverdautem und vollständig verdautem Plasmid ergaben.

Da die Kinetik des Verdaus vom jeweils eingesetzten Enzym und Plasmid abhängt, mußte die, für das gewünschte Fragment, optimale Enzymmenge und Inkubationszeit speziell ermittelt werden.

Hierzu wurde als Grundansatz verwendet: $\quad 5 \mu \mathrm{g} \quad$ DNA

$$
\begin{array}{ll}
5 \mu \mathrm{l} & 10 \mathrm{x} \text { Reaktionspuffer } \\
0,3 \mathrm{U} & \text { Enzym/ } \mu \mathrm{g} \text { DNA } \\
\mathrm{x} \mu \mathrm{l} & \mathrm{H}_{2} \mathrm{O}(\mathrm{zu} 50 \mu \mathrm{l})
\end{array}
$$

Nach je 1, 2, 5, 10 und 15 min wurde die Reaktion abgestoppt, indem ein Aliquot $(10 \mu \mathrm{l})$ des Ansatzes auf Eis gestellt und mit Gelladepuffer versetzt wurde.

Nachdem die Proben in einem Agarosegel aufgetrennt wurden, konnte beurteilt werden, nach welcher Inkubationszeit sich die größte Menge an dem zu isolierendem Fragment gebildet hatte. Diese Reaktionszeit wurde dann für den kompletten Ansatz gewählt.

\subsubsection{Agarose-Gelelektrophorese}

(modifiziert nach SAMBROOK et al., 1989)

Die Auftrennung der DNA-Fragmente nach ihrer Länge erfolgte in einem Agarosegel durch Anlegen einer elektrischen Spannung. Verwendet wurden Agarosegele die je nach Anforderung 0,7 \% - 1,2\% Agarose in 1 x TAE-Puffer enthielten. Zur Detektion der DNA-Fragmente unter UV-Licht $(254 \mathrm{~nm}$ ) wurden den Gelen $3 \mu \mathrm{l} \mathrm{EtBr/100} \mathrm{ml} \mathrm{Gel}$ hinzugeben.

Es wurden ca. 100 ng DNA pro erwarteter DNA-Bande mit $3 \mu 16$ x Ladepuffer (MBI Fermentas) versetzt, mit $\mathrm{H}_{2} \mathrm{O}$ auf $18 \mu \mathrm{l}$ aufgefüllt und auf das Gel aufgetragen. 
Die Elektrophorese erfolgte bei einer Spannung von 4 -5 Volt pro Zentimeter Gellänge.

$\begin{array}{lll}50 \times \text { TAE Puffer: } & 40 \mathrm{mM} & \text { Tris/HCl }(\mathrm{pH} 8) \\ & 20 \mathrm{mM} & \text { Eisessig } \\ 1 \mathrm{mM} & \text { EDTA } \\ & & \\ & & \\ \text { EtBr: } & 0,5 \%(\mathrm{w} / \mathrm{v}) & \text { Ethidium Bromid }\end{array}$

\subsubsection{DNA Isolierung aus LMP-Agarose}

Für die Isolation von DNA-Fragmenten aus Agarosegelen wurde direkt unter (pluspolseitig) der zu isolierenden DNA-Bande, ein Trog aus dem Gel geschnitten und dieser mit 0,8\% (w/v) LMP-Agarose aufgefüllt.

Nach dem Auspolymerisieren der LMP-Agarose wurde die Elektrophorese soweit fortgesetzt, bis die Bande in die LMP-Agarose eingewandert war. Die Bande wurde aus dem Gel ausgeschnitten und in einem Eppendorfgefäß bei $65^{\circ} \mathrm{C}$ geschmolzen. Das gleiche Volumen an Phenol (80\% w/v, pH 8) wurde dazupipettiert und gründlich gemischt. Die Suspension wurde dann für $10 \mathrm{~min}$ bei $-70^{\circ} \mathrm{C}$ eingefroren, bei $37^{\circ} \mathrm{C}$ wieder aufgetaut und für 15 min zentrifugiert. Die wäßrige Oberphase wurde abgenommen und durch Phenolisierung mit Phenol/Chloroform und Chloroform gereinigt. Danach wurde die DNA gefällt und in $10 \mu \mathrm{l}-20 \mu \mathrm{l} \mathrm{H}_{2} \mathrm{O}$ aufgenommen.

\subsubsection{PCR-Mutagenese}

Die Methode der PCR-Mutagenese wurde eingesetzt, um zusätzliche Restriktionsschnittstellen in einem zu amplifizierenden cDNA-Fragment einzufügen. Dazu wurden Primer verwendet, welche gegenüber den Template-Sequenzen, leicht veränderte Basensequenzen aufwiesen. Diese abgewandelte Basensequenzen entsprachen den Erkennungssequenzen für bestimmte Restriktionsenzyme. Die amplifizierte DNA wurde 
mit diesen Enzymen verdaut und anschließend in einen entsprechend geschnittenen Vektor ligiert.

Primer1 (BamH I): $\quad$ 5' TTT TTA CCA AAG GA $\underline{\text { T }}$ CCA TCA TAT TAA $\quad 3{ }^{\prime}$

Template (GS1 BV): $\quad$ 5' TTT TTA CCA AAG $\underline{\mathbf{A}} \mathbf{A} \underline{\mathbf{G}} \mathbf{C C A}$ TCA TAT TAA 3'

Primer2 (Xba I): $\quad$ 5' TCC TCG GAA AG

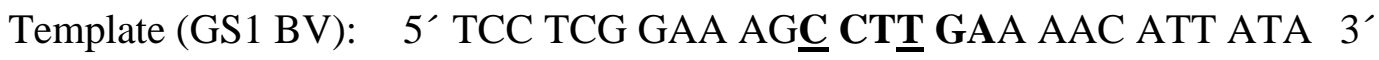

Die Synthese der Primer erfolgte durch die Firma Biometra, Göttingen.

Die Annealing-Temperatur der Primer wurde nach folgender Formel näherungsweise berechnet:

$$
\begin{aligned}
& \text { Anlagerungstemperatur }=\mathrm{T}_{\mathrm{M}^{-}} 5^{\circ} \mathrm{C} \\
& \qquad \mathrm{T}_{\mathrm{M}}=\left[(\text { Anzahl } \mathrm{A}+\mathrm{T}) \times 2^{\circ} \mathrm{C}+(\text { Anzahl } \mathrm{G}+\mathrm{C}) \times 4^{\circ} \mathrm{C}\right]
\end{aligned}
$$

Da die Basensequenz aber nicht homolog war, wurde die berechnete AnnealingTemperatur um $10^{\circ} \mathrm{C}$ reduziert.

PCR-Ansatz:

$\begin{array}{ll}\text { Ausgangslösung: } & \text { Endkonzentration: } \\ 10 \times \text { PCR-Pufferlsg. } & 1 \times \text { Pufferlsg. } \\ \mathrm{MgCl}_{2}(25 \mathrm{mM}) & 1,6 \mathrm{mM} \mathrm{MgCl}_{2} \\ \text { dNTPs }(\text { je } 5 \mathrm{mM}) & 0,2 \mathrm{mM} \text { dNTPs (jeweils) } \\ \text { Primer1 } & 0,1-1,0 \mu \mathrm{M} \\ \text { Primer2 } & 0,1-1,0 \mu \mathrm{M} \\ \text { Taq-DNA-Polymerase } & 1-5 \mathrm{U} / 100 \mu \mathrm{l} \\ \text { Template-DNA } & \leq 10 \mathrm{ng} / \mu \mathrm{l}\end{array}$

mit $\mathrm{H}_{2} \mathrm{O}$ bidest auf das jeweilige Endvolumen auffüllen 
Die PCR wurde mit dem PTC-200 Peltier Thermal Cycler (MJ Research) durchgeführt. Folgendes PCR-Programm wurde für die PCR-Mutagenese eingesetzt:

\begin{tabular}{lll} 
1. Denaturieren & $7 \mathrm{~min}$ & $95^{\circ} \mathrm{C}$ \\
2. Denaturieren & $45 \mathrm{sec}$ & $95^{\circ} \mathrm{C}$ \\
3. Primer-Annealing & $30 \mathrm{sec}$ & $55^{\circ} \mathrm{C}$ \\
4. Polymerase-Reaktion & $30 \mathrm{sec}$ & $72^{\circ} \mathrm{C}$ \\
5. Schritte 2-4 & \multicolumn{2}{c}{$30 \mathrm{mal}$} \\
6. Endreaktion & $5 \mathrm{~min}$ & $72^{\circ} \mathrm{C}$
\end{tabular}

\subsubsection{Ligation von DNA-Fragmenten}

\subsubsection{Ligation kompatibler DNA-Enden}

(modifiziert nach SAMBROOK et al., 1989)

Kompatible kohäsive und stumpfe DNA Enden werden durch die $\mathrm{T}_{4}$-Ligase kovalent verbunden.

Für eine Ligation mit kompatiblen kohäsiven Enden (sticky ends), wurden 50 - 100 ng Vektor und eine äquimolare Menge Fragment zusammengegeben und mit $\mathrm{H}_{2} \mathrm{O}$ auf 8,5 $\mu 1$ aufgefüllt. Das Gemisch wurde für 5 min bei $45^{\circ} \mathrm{C}$ erwärmt um eventuelle Fehlpaarungen $\mathrm{zu}$ lösen und anschließend für 2 min auf Eis abgekühlt. Danach wurden $1 \mu 110 \mathrm{x}$ Ligasepuffer und 0,5 $\mu 1 \mathrm{~T}_{4}$-Ligase (3 U/ $\mu 1$, Boehringer Mannheim) hinzupipettiert und für $16 \mathrm{~h}$ bei $16^{\circ} \mathrm{C}$ inkubiert.

Für "Blunt End"-Ligationen wurden $6 \mathrm{U} \mathrm{T}_{4}$-Ligase bei gleicher DNA-Menge eingesetzt.

\subsubsection{Ligation nicht kompatibler DNA-Enden}

Bei nicht kompatiblen DNA-Enden wurden entweder mit Hilfe des Klenow-Enzyms (Große Untereinheit der DNA-Polymerase) und den Nukleotiden die 5' überstehenden Enden aufgefüllt oder bei 3' überstehenden Enden die einzelsträngigen DNA-Bereiche durch die Mung-Bean-Nuklease abverdaut. Die so entstandenen stumpfen DNA-Enden 
(blunt ends) konnten dann ebenfalls ligiert werden. Für die Auffüllreaktion wurden 0,5 $\mu \mathrm{g}$ DNA mit 0,5 $\mu$ l Klenow-Enzym (5 U/ $\mu 1$, Boehringer Mannheim), $2 \mu 1 \mathrm{dNTPs}$ (je $5 \mathrm{mM}$ ) und $2 \mu \mathrm{l} 10 \mathrm{x}$ Klenow Puffer in einem Gesamtvolumen von $20 \mu \mathrm{l}\left(\mathrm{H}_{2} \mathrm{O}\right)$ für $15 \mathrm{~min}$ bei $37^{\circ} \mathrm{C}$ inkubiert. Die Reaktion der Mung-Bean-Nuklease (Promega) erfolgte mit $1 \mathrm{U} / \mu \mathrm{g}$ DNA für eine Stunde bei $37^{\circ} \mathrm{C}$.

\subsubsection{Dephosphorylierung mit alkalischer Phosphatase}

Bei ungerichteten Ligationen, d.h. wurden Vektor und Fragment mit nur einem Restriktionsenzym geschnitten, wurde der Vektor, um eine Rezirkularisierung zu verhindern, zuvor dephosphoryliert.

Die Dephosphorylierung wurde mit 3,5 U alkalischer Phosphatase (Boehringer Mannheim) pro $\mu \mathrm{g}$ linearisierter Plasmid-DNA und $5 \mu \mathrm{l}$ des dazugehörigen $10 \mathrm{x}$ Puffers in einem Gesamtvolumen von $50 \mu \mathrm{l}$ durchgeführt. Die Reaktion erfolgte bei $37^{\circ} \mathrm{C}$ für $30 \mathrm{~min}$. Das Enzym wurde inaktiviert, indem der Ansatz mit $2 \mu$ l Proteinase K $(10 \mu \mathrm{g} / \mu \mathrm{l})$ versetzt, 15 min bei $37^{\circ} \mathrm{C}$ inkubiert und für 10 Minuten auf $75^{\circ} \mathrm{C}$ erhitzt wurde.

Die DNA wurde anschließend phenolisiert, gefällt und in einem, für die anschließende Ligation, günstigen Volumen $(0,1 \mu \mathrm{g} / \mu \mathrm{l})$ in $\mathrm{H}_{2} \mathrm{O}$ aufgenommen.

\subsubsection{Bakterien-Transformation}

\subsubsection{Chemisch-kompetente Zellen}

Aus einer E. coli Übernacht-Kultur wurden $1 \mathrm{ml}$ in $100 \mathrm{ml}$ LB-Medium überführt und solange bei $37^{\circ} \mathrm{C}$ inkubiert, bis die Kultur eine $\mathrm{OD}_{600}$ von 0,5 erreicht hatte.

Die Zellen wurden 10 min bei $5000 \mathrm{x} \mathrm{g}\left(4^{\circ} \mathrm{C}\right)$ abzentrifugiert, das Pellet in $25 \mathrm{ml}$ Puffer A resuspendiert und für 1 Stunde auf Eis gestellt. Die Zellen wurden erneut pelletiert und in 4 ml Puffer B aufgenommen.

Diese Suspension wurde zu je $100 \mu$ l Aliquots in kalte Reaktionsgefäße pipettiert. In flüssigem Stickstoff wurden sie schockgefroren und bei $-70^{\circ} \mathrm{C}$ gelagert. 


\begin{tabular}{|c|c|c|}
\hline \multirow[t]{5}{*}{ Puffer A: } & $30 \mathrm{mM}$ & KAc \\
\hline & $10 \mathrm{mM}$ & $\mathrm{CaCl}_{2} \times 2 \mathrm{H}_{2} \mathrm{O}$ \\
\hline & $100 \mathrm{mM}$ & $\mathrm{KCl}$ \\
\hline & $2,5 \% \quad(\mathrm{v} / \mathrm{v})$ & Glycerin \\
\hline & $50 \mathrm{mM}$ & $\mathrm{MnCl}_{2} \times 2 \mathrm{H}_{2} \mathrm{O}$ \\
\hline \multirow[t]{4}{*}{ Puffer B: } & $10 \mathrm{mM}$ & MOPS \\
\hline & $10 \mathrm{mM}$ & $\mathrm{CaCl}_{2} \times 2 \mathrm{H}_{2} \mathrm{O}$ \\
\hline & $10 \mathrm{mM}$ & $\mathrm{KCl}$ \\
\hline & $2,5 \% \quad(\mathrm{v} / \mathrm{v})$ & Glycerin \\
\hline
\end{tabular}

\subsubsection{Kompetente Zellen für Elektroporation}

Bakterienzellen (A. tumefaciens) einer Übernacht-Kultur wurden in $100 \mathrm{ml}$ LB-Medium verdünnt $(1 / 100)$ und bis zu einer $\mathrm{OD}_{600}=0,5-1$ weiter inkubiert.

Die Zellen wurden bei $5000 \mathrm{x} \mathrm{g}, 15$ min und $4^{\circ} \mathrm{C}$ zentrifugiert und das Pellet in $100 \mathrm{ml}$ $\mathrm{H}_{2} \mathrm{O}$ (bidest) resuspendiert. Um eine für die Elektroporation notwendige geringe Ionenkonzentration im Medium zu erreichen, wurde dieser Waschschritt noch zweimal wiederholt, wobei das Pellet beim letzten Schritt in $5 \mathrm{ml} \mathrm{H}_{2} \mathrm{O}$ (bidest) mit $10 \%$ (v/v) Glycerin aufgenommen wurde.

Diese Suspension wurde zu je $50 \mu$ l Aliquots in kalte Reaktionsgefäße überführt und in flüssigem Stickstoff eingefroren. Die Zellen wurden bei $-70^{\circ} \mathrm{C}$ gelagert.

\subsubsection{Transformation von chemisch-kompetenten Bakterien}

(modifiziert nach MANDEL, M. und HigA, A., 1970)

Kompetente E. coli Zellen wurden auf Eis aufgetaut, mit dem halben Ligationsansatz rekombinanter Plasmide versetzt und 20 min auf Eis gestellt. Die Zellen wurden dann für 90 Sekunden einem Hitzeschock bei $42^{\circ} \mathrm{C}$ ausgesetzt und für 3 min auf Eis abgekühlt.

Dem Reaktionsgefäß mit den kompetenten Zellen wurde anschließend $800 \mu$ L LB-Medium zugegeben und die Zellen für $1 \mathrm{~h}$ bei $37^{\circ} \mathrm{C}$ inkubiert. 
Aliquots von $200 \mu 1$ wurden auf selektive LB-Platten ausgestrichen. Bei $37^{\circ} \mathrm{C}$ erfolgte dort für 16 h die Selektion der Rekombinanten.

\subsubsection{Transformation mit Elektroporation}

Elektrokompetente A. tumefaciens Zellen wurden auf Eis aufgetaut und mit ca. $50 \mathrm{ng}$ Plasmid-DNA versetzt. Das Bakteriengemisch $(50 \mu \mathrm{l})$ wurde in eine vorgekühlte $0,2 \mathrm{~cm}$ Küvette des Elektroporations-Geräts Gene Pulser II (Biorad) pipettiert.

Die Einstellungen für die Elektroporation betrugen: $\quad R=200 \Omega$

$25 \mu \mathrm{F}$

$2,5 \mathrm{kV}$

Nach dem Elektro-Impuls wurden sofort $1 \mathrm{ml}$ LB-Medium in die Küvette gegeben. Das Gemisch wurde in ein Eppendorfgefäß überführt, für $2 \mathrm{~h}$ bei $25^{\circ} \mathrm{C}$ inkubiert und $100 \mu \mathrm{l}$ davon auf LB-Platten (Kanamycin/Rifampicin) ausgestrichen. Die Selektion erfolgte für 3 $\mathrm{d}$ bei $25^{\circ} \mathrm{C}$.

\subsection{Transformation von Zuckerrüben}

Für die Co-Transformation von Zuckerrüben mit A. tumefaciens PGV 2260 C58, und A. rhizogenis wurden die beiden Stämme in LB-Medium bei $25^{\circ} \mathrm{C}$ angezogen $\left(\mathrm{OD}_{600}=0,5\right)$. Von der Suspension mit den A. tumefaciens Bakterien, die den Binärvektor (BIN 19) mit dem zu transformierenden Gen enthielten, wurden $2 \mathrm{ml}$, von $\operatorname{der} A$. rhizogenis-Kultur $6 \mathrm{ml}$ in eine Petrischale $\mathrm{zu} 4 \mathrm{ml}$ LB-Medium hinzugegeben und vermischt. Als Kontrolle wurde eine Transformation nur mit dem A. rhizogenis-Stamm durchgeführt. 
Von steril angezogenen drei Wochen alten Zuckerrüben-Klonen der Sorte 2B 0035 (KWS) wurden die Blattstiele herauspräpariert und kurz in das Bakteriengemisch getaucht. Die Blattstiele wurden dann auf sterilem Filterpapier abgetrocknet und auf MS-Agarplatten überführt, die 0,5 mg/l des Pflanzen-Hormons BAP enthielten,. Die nachfolgende Regeneration erfolgte bei $26^{\circ} \mathrm{C}$ im Dunkeln. Nach Wurzelausbildung (ca. 3 - 4 Wochen) wurden die Transformanten zur Selektion auf MS-Platten mit 50 mg/l Kanamycin ohne

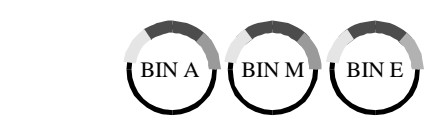

Binärvektoren

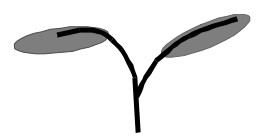

Zukerrübenpfanze

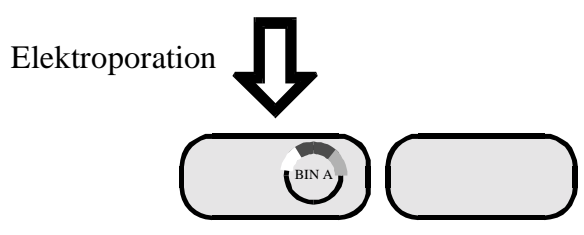

A. tumefaciens
A. rhizogenis

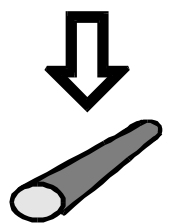

Blattstiel

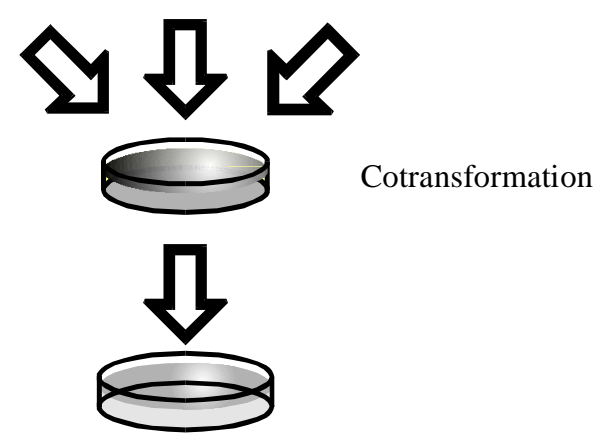

Selektionsmedium

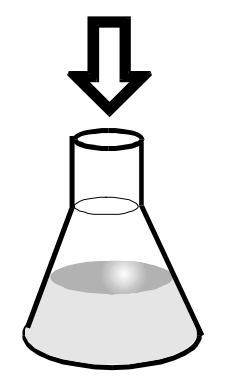

Regeneration und Selektion

Flüssigmedium

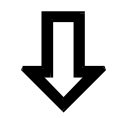

molekularbiologische und physiologische Untersuchungen
Hormonzusatz und $300 \mathrm{mg} / \mathrm{l}$

Betabactyl (Smith Kline Beecham

Pharma GmbH, München) überführt. Die Transformation, Regeneration und Selektion wurde bei der Firma Planta (KWS) in Einbeck durchgeführt. Nach erfolgter Selektion (ca. 5 6 Wochen) wurden die Transformanten auf Betabactyl MS-Platten ohne Kanamycin kultiviert. Für die Nukleinsäurenund Protein-Extraktionen wurden die Wurzel-Kulturen in flüssigem Betabactyl MS-Medium in 100 $\mathrm{ml}$ Erlenmeyerkolben auf einem Schüttler $(25 \mathrm{rpm})$ bei $26^{\circ} \mathrm{C}$ im Dunkeln herangezogen.

Abb. 1: Arbeitsschema der Cotransformation. 
MS-Medium (modifiziert nach Murashige und Skoog, 1962):

Stammlösungen:

\begin{tabular}{|c|c|c|}
\hline \multirow[t]{5}{*}{ Makroelemente (100 x ): } & $250 \mathrm{~g} / 1$ & $\mathrm{KNO}_{3}$ \\
\hline & $25 \mathrm{~g} / 1$ & $\mathrm{MgSO}_{4} \times 7 \mathrm{H}_{2} \mathrm{O}$ \\
\hline & $13,4 \mathrm{~g} / 1$ & $\left(\mathrm{NH}_{4}\right)_{2} \mathrm{SO}_{4}$ \\
\hline & $15 \mathrm{~g} / \mathrm{l}$ & $\mathrm{Na}_{2} \mathrm{PO}_{4} \times \mathrm{H}_{2} \mathrm{O}$ \\
\hline & $15 \mathrm{~g} / 1$ & $\mathrm{CaCl}_{2} \times 2 \mathrm{H}_{2} \mathrm{O}$ \\
\hline \multirow[t]{6}{*}{ Mikroelemente $(100 \mathrm{x})$ : } & $300 \mathrm{mg} / \mathrm{l}$ & $\mathrm{H}_{3} \mathrm{BO}_{3}$ \\
\hline & $1000 \mathrm{mg} / \mathrm{l}$ & $\mathrm{MnSO}_{4} \times \mathrm{H}_{2} \mathrm{O}$ \\
\hline & $200 \mathrm{mg} / \mathrm{l}$ & $\mathrm{ZnSO}_{4} \times 7 \mathrm{H}_{2} \mathrm{O}$ \\
\hline & $75 \mathrm{mg} / \mathrm{l}$ & $\mathrm{KJ}$ \\
\hline & $25 \mathrm{mg} / 1$ & $\mathrm{Na}_{2} \mathrm{MoO}_{4} \times 2 \mathrm{H}_{2} \mathrm{O}$ \\
\hline & $2,5 \mathrm{mg} / 1$ & $\mathrm{CuSO}_{4} \times \mathrm{H}_{2} \mathrm{O}$ \\
\hline \multirow[t]{2}{*}{ Eisen-EDTA (100 x ): } & $3,73 \mathrm{~g} / \mathrm{l}$ & $\mathrm{Na}_{2}$ EDTA \\
\hline & $2,78 \mathrm{~g} / 1$ & $\mathrm{FeSO}_{4} \times 7 \mathrm{H}_{2} \mathrm{O}$ \\
\hline \multirow[t]{3}{*}{ Vitamine $(1000 \mathrm{x})$ : } & $1 \mathrm{~g} / 1$ & Nikotinsäure \\
\hline & $10 \mathrm{~g} / 1$ & Thiamin- $\mathrm{HCl}$ \\
\hline & $1 \mathrm{~g} / \mathrm{l}$ & Pyridoxin- $\mathrm{HCl}$ \\
\hline Myo-Inositol (100 x ): & $10 \mathrm{~g} / \mathrm{l}$ & Myo-Inositol \\
\hline
\end{tabular}


Zusammensetzung für 11 MS-Medium:

$\begin{array}{ll}\text { Makroelemente: } & 10 \mathrm{ml} \\ \text { Mikroelemente: } & 10 \mathrm{ml} \\ \text { Eisen-EDTA: } & 10 \mathrm{ml} \\ \text { Vitamine: } & 1 \mathrm{ml} \\ \text { Myo-Inositol: } & 10 \mathrm{ml} \\ \text { Saccharose: } & 20 \mathrm{~g} \\ & \mathrm{pH} \mathrm{5,5}\end{array}$

Das Festmedium enthält: Agar: $\quad 7 \mathrm{~g}$

\subsection{Southern Blot-Analyse}

\subsubsection{Extraktion Genomischer-DNA}

Die Extraktion der genomischen DNA aus Feinwurzeln erfolgte mit dem Nucleon PhytoPure Kit der Firma Amersham.

In flüssigem Stickstoff wurden $100 \mathrm{mg}$ Wurzelgewebe zu feinem Pulver zermörsert und mit $600 \mu 1$ der Reagent 1-Lösung (Kit), die mit 1 \% (v/v) Mercaptoethanol und RNase (20 $\mu \mathrm{g} / \mathrm{ml}$ ) versetzt worden war, vermischt und für $30 \mathrm{~min}$ bei $37^{\circ} \mathrm{C}$ inkubiert. Anschließend wurden $200 \mu \mathrm{l}$ Reagent 2 (Kit) hinzupipettiert, gemischt und für $10 \mathrm{~min}$ bei $65^{\circ} \mathrm{C}$ inkubiert. Das Gemisch wurde für 20 min auf Eis gestellt und dann mit $500 \mu$ l Chloroform $\left(-20^{\circ} \mathrm{C}\right)$ und $100 \mu \mathrm{l}$ DNA Extraction Resin (Kit) versetzt und für $10 \mathrm{~min}$ auf einer Wippe bei RT sanft geschwenkt. Danach wurde das Gemisch bei 1300 x g zentrifugiert und die Oberphase abgenommen, zu der das gleiche Volumen Isopropanol $\left(-20^{\circ} \mathrm{C}\right)$ gegeben wurde. Durch Zentrifugation $\left(5000 \mathrm{x}\right.$ g) wurde die DNA pelletiert und mit $70 \% \mathrm{EtOH}\left(-20^{\circ} \mathrm{C}\right)$ gewaschen. Nach erneuter Zentrifugation wurden die EtOH-Reste vollständig entfernt, das Pellet für 10 min an der Luft getrocknet und in $50 \mu 1 \mathrm{H}_{2} \mathrm{O}$ (bidest) aufgenommen. 


\subsubsection{Southern Blot}

Je $25 \mu \mathrm{g}$ genomische DNA wurden mit ausgewählten Restriktionsenzymen vollständig verdaut und in einem Agarosegel elektrophoretisch aufgetrennt. Zur Dokumentation wurde das Gel zusammen mit einem Lineal unter UV-Licht abfotografiert (Polaroid TA 40 CRT). Der Transfer der DNA auf eine Nylonmembran (Hybound N, Schleicher und Schüll) erfolgte nach der Methode von SOUTHERN (1975) in einem alkalischen Kapillarblot. Um einen gleichmäßigen Transfer der unterschiedlich großen DNA-Fragmente zu erreichen wurde das Gel vor dem Blotten für 5 min in 0,25 M HCl depuriniert (WAHL et al., 1979; MEINKOTH und WAHL, 1984).

In einer Schale mit Transferlösung (1,5 M NaCl, 0,5 M NaOH) wurde die Transferbrücke aufgebaut. Auf die Transferbrücke wurde ein Filterstreifen (Whatman $3 \mathrm{MM}$ ) gelegt, der mit seinen Enden in die Transferlösung tauchte. Das Gel wurde, mit der Unterseite nach oben auf das Filterpapier gelegt. Anschließend wurde das Gel luftblasenfrei mit der Nylonmembran und drei Lagen Whatman 3 MM Filtern bedeckt. Darauf wurde ein ca. 10 $\mathrm{cm}$ hohen Stapel aus Saugpapier aufgeschichtet und mit einem $500 \mathrm{~g}$ Gewicht beschwert. Der Transfer erfolgte für $16 \mathrm{~h}$ bei RT.

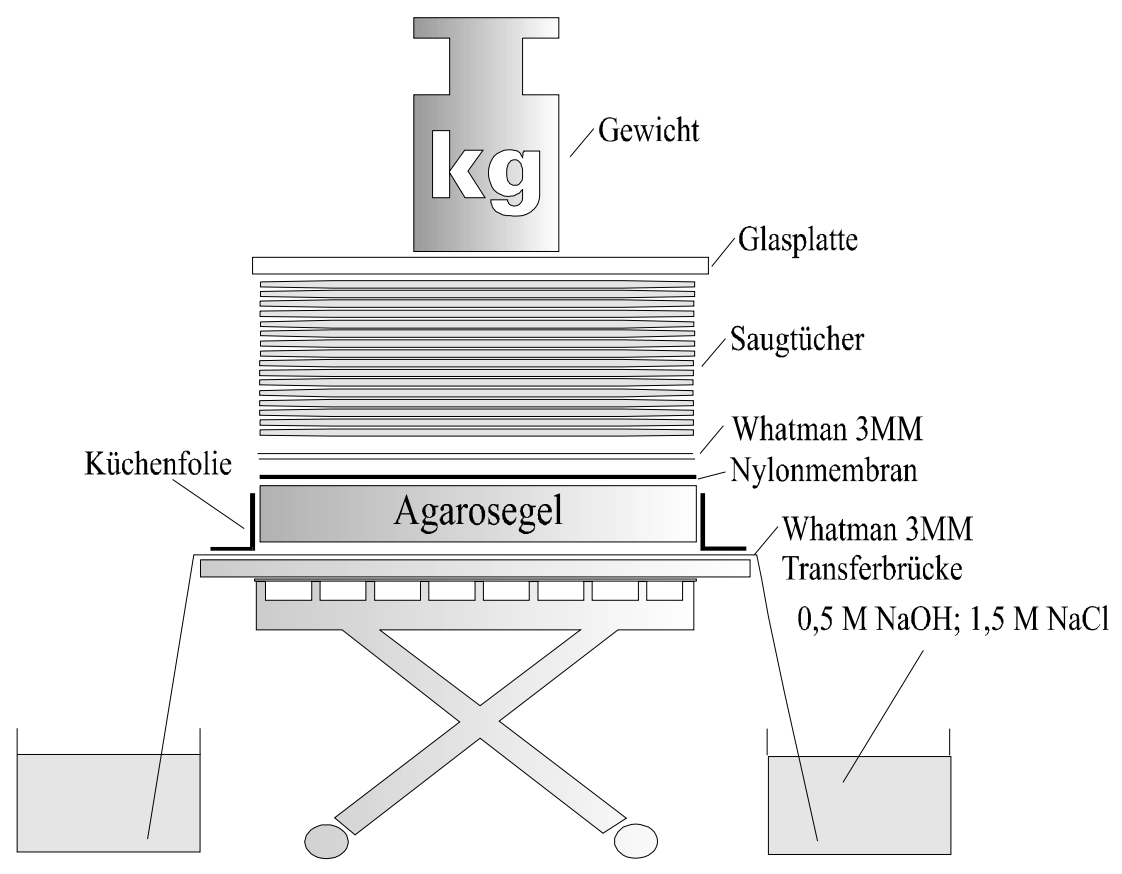

Abb. 2: Aufbau eines Kapillarblots 
Um die DNA kovalent an die Nylonmembran zu binden, wurde die Membran für 15 Sekunden einer UV-Strahlung ( $\lambda 254 \mathrm{~nm}$ ) ausgesetzt. Danach wurde die Nylonmembran zur Neutralisation kurz in 2 x SSC geschwenkt und dann an der Luft getrocknet.

Die anschließende Hybridisierung erfolgte wie unter Kapitel (2.2.5.) angegeben.

Von der radioaktiv markierten Nylonmembran wurde eine Autoradiografie erstellt.

Verwendet wurden hierfür Röntgen-Filme (BioMax MS, Kodak), die in einer lichtdichten Kassette und mit Verstärkerfolie (BioMax MS TranScreen intensifying screen system, Kodak) bei $-70^{\circ} \mathrm{C}$ je nach Strahlungsintensität mehrere Tage exponiert und anschließend entwickelt wurden.

\subsection{Northern Blot-Analyse}

\subsubsection{Extraktion von Gesamt-RNA}

(modifiziert nach LOGEMANN, SCHELL und WILLMITZER, 1987)

Für die Northern Blot-Analyse wurden $200 \mathrm{mg}$ Wurzelgewebe in flüssigem Stickstoff zu feinem Pulver gemörsert und mit $1 \mathrm{ml}$ Z-6-Puffer (mit $1 \%$ (v/v) Mercaptoethanol) versetzt. Die Suspension wurde phenolisiert (Kapitel 2.6.6.) und die RNA nach Zugabe von $1 / 20$ Vol. $1 \mathrm{M}$ Essigsäure und $0,7 \mathrm{Vol}$. EtHO $\left(-20^{\circ} \mathrm{C}\right)$ bei $-70^{\circ} \mathrm{C}$ für $1 \mathrm{~h}$ gefällt. Die RNA wurde dann durch Zentrifugation bei $20000 \mathrm{x}$ g pelletiert und mit $150 \mu 13 \mathrm{M} \mathrm{NaAc}$ $(\mathrm{pH} 5,0)$ gewaschen, erneut zentrifugiert, mit $200 \mu \mathrm{l} \mathrm{EtOH}(70 \%)$ gewaschen und nach der anschließenden Zentrifugation 10 min an der Luft getrocknet. Das RNA-Pellet wurde in $50 \mu 1 \mathrm{H}_{2} \mathrm{O}$ (bidest) aufgenommen.

$\begin{array}{lll}\text { Z-6-Puffer: } & 8 \mathrm{M} & \text { Guanidinhydrochlorid } \\ & 20 \mathrm{mM} & \text { MES }(\mathrm{pH} 7,0) \\ & 20 \mathrm{mM} & \text { EDTA }\end{array}$




\subsubsection{Formaldehyd-Agarosegel}

Gesamt-RNA wurde in einem denaturierendem Formaldehyd-Agarosegel (1 \% (w/v) Agarose, 1 x RB-Puffer, 2,5 M Formaldehyd) elektrophoretisch aufgetrennt.

Je $15 \mu$ g RNA wurden mit $15 \mu$ l RNA-Farbmix und $\mathrm{H}_{2} \mathrm{O}$ auf ein Endvolumen von $25 \mu \mathrm{l}$ gemischt und für 15 min bei $65^{\circ} \mathrm{C}$ denaturiert. Das Gemisch wurde für 2 min auf Eis gestellt und auf das Gel aufgetragen. Die Elektrophorese erfolgte in 1 x RB-Puffer bei einer Spannung von $5 \mathrm{~V} / \mathrm{cm}$ Gellänge.

$\begin{array}{lll}\text { 10 x RB-Puffer: } & 200 \mathrm{mM} & \text { MOPS ( pH 7) } \\ & 50 \mathrm{mM} & \text { NaAc } \\ & 0,2 \mathrm{mM} & \text { EDTA } \\ & & \\ \text { RNA-Farbmix: } & 10 \mu \mathrm{l} & 10 \mathrm{x} \mathrm{RB} \\ & 175 \mu \mathrm{l} & \text { Formaldehyd (37 \%) } \\ & 500 \mu \mathrm{l} & \text { DMF } \\ & 25 \mu \mathrm{l} & \text { Farbmix } \\ & 10 \mu \mathrm{l} & \text { EtBr }(5 \mathrm{mg} / \mathrm{ml}) \\ & & \\ & 0,25 \%(\mathrm{w} / \mathrm{v}) & \text { Bromphenolblau } \\ & 40 \%(\mathrm{w} / \mathrm{v}) & \text { Glycerin } \\ & 80 \mathrm{mM} & \text { EDTA }\end{array}$

\subsubsection{Northern Blot}

Der Northern Blot wurde als alkalischer Kapillarblot nach gleichem Schema wie der Southern Blot ( Kapitel 2.8.2.) durchgeführt, wobei das Gel zuvor nicht depuriniert wurde. 


\subsection{Western Blot-Analyse}

\subsubsection{Proteinextraktion}

Das Pflanzenmaterial wurde mit Extraktionspuffer im Verhältnis 2/1 (Extraktionspuffer [ml]/FG [g]) auf Eis gemörsert. Der Rohextrakt wurde zuerst für $10 \mathrm{~min}$ bei $20000 \mathrm{x} \mathrm{g}$ und der Überstand für 30 min bei 100000 x g (Beckmann Optima TLX Ultrazentrifuge, TL 100.3 Rotor) und $4^{\circ} \mathrm{C}$ zentrifugiert. Der Überstand enthält die löslichen Proteine.

$\begin{array}{lll}\text { Extraktionspuffer: } & 50 \mathrm{mM} & \text { Imidazol } \\ & 5 \mathrm{mM} & \text { Glutamat } \\ 1 \mathrm{mM} & \mathrm{MgCl}_{2} \\ 0,5 \%(\mathrm{v} / \mathrm{v}) & \mathrm{ME} \\ & \mathrm{pH} \mathrm{7,5}\end{array}$

\subsubsection{Proteinbestimmung}

Die Proteinbestimmung erfolgte nach BRADFORD (1976). Dazu wurden $5 \mu 1-10 \mu 1$ des abzentrifugierten Rohextrakts mit $\mathrm{H}_{2} \mathrm{O}$ zu $100 \mu \mathrm{l}$ aufgefüllt und mit $1 \mathrm{ml}$ BradfordReagenz versetzt. Nach 10 minütiger Inkubation bei RT erfolgte die photometrische Messung der Extinktion gegen einen Blindwert (100 $\mu 1 \mathrm{H}_{2} \mathrm{O}$ in $1 \mathrm{ml}$ Bradford-Reagenz) bei $\lambda 595 \mathrm{~nm}$. Für die Quantifizierung diente Rinderserumalbumin (Boehringer Mannheim) als Standard.

\subsubsection{Anionenaustauschchromatographie}

Um die Glutaminsynthetase aus einem Rohextrakt anzureichern, wurde eine Anionenaustauschchromatographie durchgeführt. Verwendet wurde dazu eine Porus Q Anionenaustausch-Säule (PerSetptive Biosystems), die mit einem FPLC System der Firma Pharmacia betrieben wurde. 
Die Probe wurde auf die Säule geladen und dann mit einem kontinuierlich steigendem $\mathrm{NaCl}$ Gradienten (0 M-1 M) eluiert. Die Flußrate betrug $2 \mathrm{ml} / \mathrm{min}$. Die Fraktionen wurden $\mathrm{zu} 1 \mathrm{ml}$ in einem Fraktionssammler aufgefangen, wovon je $50 \mu \mathrm{l}$ einem Glutaminsynthetase-Test unterzogen wurden. Die Fraktionen, die GS-Aktivität aufwiesen, wurden vereinigt und durch eine Membranfiltration bei einer Ausschlußgrenze von 100 $\mathrm{kDa}$ mit einem Centricon 100 (Amicon, USA) bei $3000 \mathrm{x}$ g eingeengt.

$\begin{array}{llll}\text { Elutionspuffer: } & \underline{\mathrm{A}} & \underline{\mathrm{B}} & \\ & 50 \mathrm{mM} & 50 \mathrm{mM} & \text { Imidazol, } \mathrm{pH} \mathrm{7,5} \\ 5 \mathrm{mM} & 5 \mathrm{mM} & \text { Glutamat } \\ 1 \mathrm{mM} & 1 \mathrm{mM} & \mathrm{MgCl}_{2} \\ 0,5 \%(\mathrm{v} / \mathrm{v}) & 0,5 \%(\mathrm{v} / \mathrm{v}) & \mathrm{ME} \\ & 1 \mathrm{M} & \mathrm{NaCl}\end{array}$

\subsubsection{SDS-PAGE}

Die SDS-Polyacrylamid-Gradientengelelektrophorese erfolgte mit einem diskontinuierlichen Puffersystem nach LÄMMLI (1970). Die Polymerisation des Acrylamids (Verhältnis Acrylamid / N, N-Methylenbisacrylamid = 37,5 / 1) wurde mit APS und TEMED gestartet. Der Gradient des Trenngels verlief von 7,5\% - $20 \%$ Acrylamid.

Die Proben wurden im Verhältnis 1/1 mit 8 x SDS-Probenpuffer versetzt und auf das Gel geladen. Zur Bestimmung der Molekulargewichte wurden zusätzlich Markerproteine des LMW Calibration Kit (Pharmacia Biotech) eingesetzt. Die Elektrophorese erfolgte bei 140 $\mathrm{V}$ für $2 \mathrm{~h}$.

$\begin{array}{lll}\text { SDS-Probenpuffer }(8 \mathrm{x}): & 20 \mathrm{mM} & \text { Tris/HCl }(\mathrm{pH} 6,8) \\ & 8 \%(\mathrm{w} / \mathrm{v}) & \mathrm{SDS} \\ & 20 \%(\mathrm{v} / \mathrm{v}) & \text { Glycerin } \\ & 80 \mathrm{mM} & \mathrm{ME} \\ & 0,1 \%(\mathrm{w} / \mathrm{v}) & \text { Bromphenolblau }\end{array}$




$\begin{array}{lll}\text { Laufpuffer }(10 \mathrm{x}): & 0,25 \mathrm{M} & \text { Tris } \\ & 2 \mathrm{M} & \text { Glycin } \\ & 1 \%(\mathrm{w} / \mathrm{v}) & \mathrm{SDS}\end{array}$

\subsubsection{Zweidimensionale Gelelektrophorese}

Bei der zweidimensionalen Gelelektrophorese wurden die Proteine zuerst einer isoelektrischen Fokussierung (modifiziert nach DUNBAR et al, 1990) in einem Harnstoffkapillargel unterzogen (1. Dimension) und anschließend in einem SDS-PAGE ihrer Größe nach aufgetrennt (2. Dimension).

Für die erste Dimension wurden 1,7 g Harnstoff, $1,2 \mathrm{ml} \mathrm{H}_{2} \mathrm{O}$ und $400 \mu \mathrm{l}$ einer Acrylamid $(30 \% \mathrm{w} / \mathrm{v}) / \mathrm{N}, \mathrm{N}-$ methylenbisacrylamid (1,8 \% w/v)-Lösung mit $60 \mu \mathrm{l}$ Nonidet P 40 vermischt und nach Zugabe von $66 \mu$ l Trägerampholine pH 3 - 10 (Serva, Heidelberg), 25 $\mu 15 \%$ iges (w/v) APS und $5 \mu 110 \%$ iges (v/v) TEMED, in eine $100 \mu$ l Glaskapillare aufgezogen. Nach dem Auspolymerisieren wurden die Kapillare senkrecht in die Elektrophorese-Apparatur eingesetzt und mit den Proben beladen, welche zuvor mit Harnstoffbeladungspuffer im Verhältnis 1/1 gemischt wurden. Die Proben wurden dann mit 5 fach verdünnten Harnstoffbeladungspuffer überschichtet und die Apparatur mit 50 $\mathrm{mM} \mathrm{H} \mathrm{H}_{3} \mathrm{PO}_{4}$ (Anodenpuffer) und mit Methylrot angefärbter $50 \mathrm{mM} \mathrm{NaOH-Lösung}$ (Kathodenpuffer) befüllt. Die isoelektrische Fokussierung erfolgte bei $190 \mathrm{~V}$ für $16 \mathrm{~h}$.

Die Gele wurden anschließend aus den Glaskapillaren entfernt, für $10 \mathrm{~min}$ in SDSBeladungspuffer inkubiert und der Länge nach auf ein SDS-Gradientengel (ohne Sammelgel) aufgebracht. Die Auftrennung erfolgte bei $140 \mathrm{~V}$ für $2 \mathrm{~h}$.

$\begin{array}{lll}\text { Harnstoffbeladungspuffer: } & 9 \mathrm{M} & \text { Harnstoff } \\ & 4 \%(\mathrm{v} / \mathrm{v}) & \text { Nonidet P } 40 \\ 2 \%(\mathrm{v} / \mathrm{v}) & \mathrm{ME} \\ 2 \%(\mathrm{v} / \mathrm{v}) & \text { Ampholine }(\mathrm{pH} 3-10)\end{array}$




\subsubsection{Western Blot}

Der Western Blot erfolgte in einer Trans-Blot cell Elektrophorese-Einheit (BioRad) nach Towbin et al. (1979). Dabei wurden die Proteine aus dem Acrylamidgel auf eine Nitrocellulose-Membran (11307-41BL, Satorius) übertagen. Die Elektrophorese erfolgte bei $500 \mathrm{~mA}$ für $1 \mathrm{~h}$.

Nach dem Blotten wurde die Membran für $10 \mathrm{~min}$ bei RT in eine 0,5 \%ige Ponceau S-Lösung in $1 \%(\mathrm{v} / \mathrm{v})$ HAc gelegt, die die übertragenen Proteine reversibel anfärbte. Die Banden der Markerproteine wurden eingezeichnet und die Membran anschließend durch waschen mit $\mathrm{H}_{2} \mathrm{O}$ entfärbt.

Blotting Puffer:

$$
\begin{aligned}
& 23 \mathrm{mM} \\
& 200 \mathrm{mM} \\
& 20 \%(\mathrm{v} / \mathrm{v})
\end{aligned}
$$

Tris/ $\mathrm{HCl}(\mathrm{pH} 8,3)$

Glycin

Methanol

\subsubsection{Immunodetektion}

Die markierte Nitrocellulosemembran des Western Blots wurde für $2 \mathrm{~h}$ in Blocking Medium und anschließend für $16 \mathrm{~h}$ mit dem primären Antikörper (1/3000 in Blocking Medium) inkubiert. Der polyklonale Antikörper (Dr. R. Wallsgrove, Rothamsted Experimental Station, England) ist aus Kaninchen gewonnen und war gegen Wurzelknöllchen GS gerichtet.

Die Blot-Membran wurde dreimal für 15 min in TBS gewaschen und dann mit dem zweiten Antikörper (1/2000 in Blocking Medium) für $1 \mathrm{~h}$ inkubiert. Der zweite Antikörper war ein handelsüblicher Goat Anti Rabbit IgG (H+L) Alkaline Phosphatase KonugatedAntikörper der Firma BioRad.

Nach der Inkubation wurde der Filter erneut dreimal, je 15 min, in TBS gewaschen und dann bis zur Entwicklung des Tetrazolium-Farbstoffes (ca. $15 \mathrm{~min}$ ) bei $37^{\circ} \mathrm{C}$ im Alkalische-Phosphatase-Puffer inkubiert. 
TBS:

$$
\begin{array}{ll}
0,02 \mathrm{mM} & \text { Tris } \\
0,5 \mathrm{mM} & \mathrm{NaCl} \\
& \mathrm{pH} \mathrm{7,5}
\end{array}
$$

Alkalische-Phosphatase-Puffer: $\quad 100 \mathrm{mM} \quad \mathrm{NaHCO}_{3}$

$\begin{array}{ll}1 \mathrm{mM} & \mathrm{MgCl}_{2} \\ 1 \mathrm{ml} / 100 \mathrm{ml} & 3 \% \mathrm{NBT} \text { in } 70 \% \mathrm{DMF} \\ 1 \mathrm{ml} / 100 \mathrm{ml} & 1,5 \% \mathrm{BCIP} \text { in DMF } \\ & \text { pH } 9,8\end{array}$

\subsection{Bestimmung der GS-Aktivität}

Der colorimetrische in vitro Test, zur Bestimmung der Glutaminsynthetase-Aktivität, erfolgte nach MäcK (1988) in Anlehnung an SHAPIRO und STADTMAN (1970), RHODES et al. (1975) und STEWART und RHODES (1977).

Für den Test wurden $10 \mu \mathrm{l}$ des Rohextrakts mit $40 \mu \mathrm{l} \mathrm{H}_{2} \mathrm{O}$ und $250 \mu \mathrm{l}$ Synthetase Medium versetzt und für $1 \mathrm{~h}$ bei $37^{\circ} \mathrm{C}$ inkubiert. Das Abstoppen der Reaktion erfolgte durch Zugabe von $250 \mu \mathrm{l}$ Fe-Mix, wobei das synthetisierte $\gamma$-GHA mit den Fe (III)-Ionen einen braunen Farbkomplex bildete. Die Lösung wurde mit $500 \mu 1 \mathrm{H}_{2} \mathrm{O}$ verdünnt, bei $20000 \mathrm{x}$ g für 5 min zentrifugiert und die Extinktion des Überstands bei $\lambda 498 \mathrm{~nm}$ in einem Photometer gegen einen Blindwert gemessen.

Die Aktivität berechnet sich nach:

$$
\text { Aktivität } \frac{\mu \text { mol } \gamma \text {-GHA }}{h}=\frac{(\mathrm{E}(\mathrm{TA})-\mathrm{E}(\mathrm{BW})) \times \mathrm{V}}{\operatorname{Ekff}(\mathrm{GHA})} \times \frac{60}{\mathrm{dt}}
$$

$\mathrm{E}(\mathrm{TA})=$ Extinktion des Testansatzes bei $\lambda 498 \mathrm{~nm}$

$\mathrm{E}(\mathrm{BW})=$ Extinktion des Blindwertes bei $\lambda 498 \mathrm{~nm}$

$\operatorname{Ekff}(\mathrm{GHA})=\mu$ molarer Extinktionskoeffizient von $\gamma$-GHA $=0,848$

$\mathrm{V}=$ Volumen des Testansatzes [ml]

$\mathrm{dt} \quad=$ Inkubationszeit [min] 
MATERIAL UND METHODEN

$\begin{array}{lll}\text { Synthetase Medium: } & 200 \mathrm{mM} & \text { Imidazol } \\ & 160 \mathrm{mM} & \text { Glutamat } \\ 60 \mathrm{mM} & \mathrm{MgSO}_{4} \\ 6,25 \mathrm{mM} & \mathrm{NH}_{2} \mathrm{OHCl} \\ 20 \mathrm{mM} & \mathrm{ATP} \\ & \\ \text { Fe-Mix: } & 88 \mathrm{mM} & \mathrm{Fe}(\mathrm{III}) \mathrm{Cl} 3 \\ & 200 \mathrm{mM} & \text { Trichloressigsäure } \\ & 670 \mathrm{mM} & \mathrm{HCl}\end{array}$




\section{ERGEBNISSE}

\subsection{Präparation einer cDNA-Bank}

\subsubsection{Gesamt RNA}

Für die cDNA-Bank wurden aus $20 \mathrm{~g}$ seneszentem Blattmaterial von Zuckerrüben $5 \mathrm{mg}$ Gesamt-RNA gewonnen. Die photometrische Messung der Gesamt-RNA ergab bei $\lambda 260$ $\mathrm{nm}$ eine Konzentration von 2,5 $\mu \mathrm{g} / \mu \mathrm{l}$. Die Quotienten der Messungen von $\lambda 280 \mathrm{~nm} / 260$ $\mathrm{nm}$ und $\lambda 230 \mathrm{~nm} / 260 \mathrm{~nm}$ waren 1,9 und 2,1. Von der RNA wurden außerdem $5 \mu \mathrm{g}$ in einem Agarosegel elektrophoretisch aufgetrennt, um die Unversehrtheit der RNA zu überprüfen. Die rRNAs, die 80 - $85 \%$ der Gesamt-RNA ausmachen (HEMLEBEN, 1990), waren unter UV-Licht als deutliche Banden zu erkennen (Abb. 1). Distinkte rRNA-Banden treten nur bei intakter Gesamt-RNA auf.

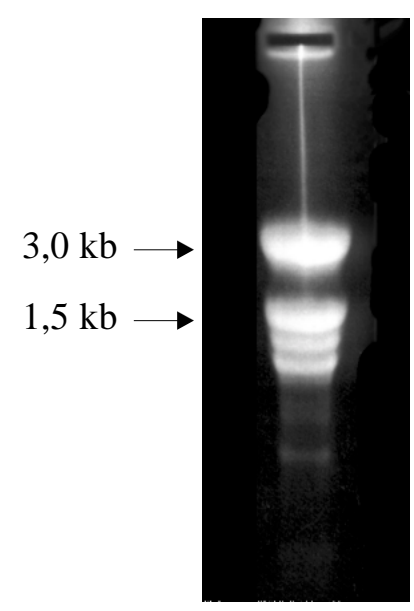

Abb. 1: $5 \mu \mathrm{g}$ Gesamt-RNA aus seneszenten Zuckerrüben Blättern in einem FormaldehydAgarosegel elektrophoretisch aufgetrennt.

\subsection{2 mRNA}

Nach zweimaliger Reinigung der Gesamt-RNA mit einer Oligo-dT-Cellulose Säule wurden $35 \mu \mathrm{g}$ mRNA $(0,7 \%$ der Gesamt-RNA) gewonnen und in einer Konzentration von $1 \mu \mathrm{g} / \mu \mathrm{l}$ in TE aufgenommen. 


\subsection{3 cDNA}

Für die cDNA-Synthese wurden $5 \mu \mathrm{g}$ der mRNA eingesetzt. Die Kontrolle der Synthese erfolgte durch einen Parallelansatz mit radioaktivem ${ }^{32} \mathrm{P}$ dCTP. Von diesem Kontrollansatz wurde $1 \mu \mathrm{l}$ (ca. 100 ng cDNA) in einem Agarosegel elektrophoretisch aufgetrennt. Von dem getrockneten Gel wurde eine Autoradiographie erstellt (Abb. 2). Die Hauptmasse der synthetisierten cDNA lag in einem Größenbereich von 0.5 - 3,0 kb. Dieser Größenbereich entspricht dem der mRNAs in eukariotischen Zellen (ALBERTS, 1986).

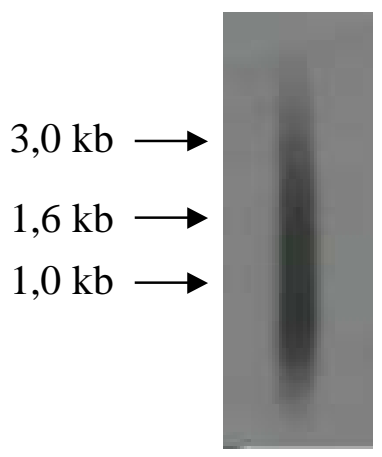

Abb.2: Autoradiographie von radioaktiv markierter cDNA (ca. $100 \mathrm{ng}$ ) in einem Agarosegel elektrophoretisch aufgetrennt. Die Expositionszeit betrug drei Tage

\subsubsection{Phagen-Titer}

Nachdem die cDNA mit den Eco RI/Not I Adapter versehen und in die Vektorarme ligiert wurde, erfolgte die Verpackung in die Phagen. Die Bestimmung des Phagen-Titers ergab 6100 pfu/ $\mu 1$, somit ca. 1,4 mill. pfu für die gesamte Phagen-Bank.

\subsection{Screening von cDNA-Banken}

In höheren Pflanzen werden zwischen 10000 und 30000 Gene zur gleichen Zeit exprimiert (HEMleben, 1990). Um alle exprimierten Gene erfassen zu können, wurden für ein ErstScreening ca. 120000 pfu auf 12 Petrischalen (9 x 13 mm) ausplattiert und die PhagenDNA auf GS1-Homolgie überprüft. Dazu wurde die Phagen-DNA auf Nitrocellulose übertragen und mit einer GS1-cDNA aus Tabak (B. HIREL, INRA de Versailles, France) als heterologe Sonde hybridisiert. In mehreren Versuchen wurden die Hybridisierungsgsbedingungen den speziellen Eigenschaften der Sonde und der Phagen- 
DNA angepasst. Die Stringenz der heterologen Hybridisierung wurde so gewählt, daß die Sonde Hybribisierungssingnale lieferte, aber die Anzahl an Signalen möglichst gering blieb, d.h. nicht mehr als 20 Signale pro Erst-Screening auftraten. Die besten Ergebnisse wurden erzielt, mit einer 2stündigen Vorhybridisierung bei $61^{\circ} \mathrm{C}$, einer Hybridisierung bei $61^{\circ} \mathrm{C}$ für $16 \mathrm{~h}$ und anschließendem einmaligem Waschen mit den Waschlösungen 1 und 2 für je $15 \mathrm{~min}$.

Die Plaques, die beim Erst-Screening auf dem Röntgenfilm Signale erzeugten, wurden durch ein zweites Ausplattieren vereinzelt und die Nitrocellulose Replika-Filter einer erneuten Hybridisierung unterzogen. Die Phagen von Einzelplaques, von denen Hybridisierungssignale ausgingen, wurden durch Minilysate vermehrt. Die Phagen-DNA der Lambda ZAP II cDNA-Bank wurde einer in vivo Excision unterzogen, um PlasmidDNA (pBluescript SK (-)) zu erhalten. Die DNA der NM 1149 Phagen-cDNA-Bank wurde aus den Minilysaten extrahiert und einem Eco RI Restriktionsverdau unterzogen. Nach Auftrennung der DNA in einem Agarosegel wurde das Insert aus dem Gel isoliert und in einen Eco RI geschnittenen und dephosphorylierten pBluescript SK (-) Vektor ligiert. Die Plasmide wurden durch Transformation in E. coli XL 1 Blue MRF' vermehrt, durch Plasmid Midipräparation aus den Bakterien isoliert und die Inserts ansequenziert. Die erhaltenen Sequenzdaten wurden über Internet mit Sequenzen verschiedener DNA/ProteinDatenbanken verglichen.

Die Sequenzen zweier Klone aus der Lambda ZAP II cDNA-Bank aus ZuckerrübenWurzelgewebe zeigten Übereinstimmungen mit cytosolischer Glutaminsynthetase (GS1) aus verschiedenen Pflanzen. Homologien zu plastidärer Glutaminsynthetase (GS2) konnten bei zwei Klonen aus der Lambda NM 1149 Phagen-Bank (seneszentes Blattgewebe) nachgewiesen werden. Alle vier Klone wurden vollständig, sowohl in 5'-, als auch in 3'Richtung durchsequenziert und die erhaltenen Sequenzen erneut mit Sequenzen aus verschiedenen DNA/Protein-Datenbanken verglichen. Dabei zeigte sich, daß ein Zuckerrüben GS1-Klon ein unvollständiges Sequenz-Artefakt war, dem ein Teil der Sequenz im Mittelstück fehlte und die anschließende Restsequenz nicht mehr im Leserahmen (,in Frame“) verlief. Der Zweite Klon der Wurzel-cDNA-Bank enthielt die vollständige GS1-Sequenz.

Die GS2-Sequenzen der beiden Klone aus der cDNA-Bank von seneszentem Blattgewebe waren identisch und vollständig.

Die Vollständigkeit der DNA-Sequenzen zeigte sich an Hand der jeweils gefundenen Start- 
und Stop-Codone und dem Vergleich mit den entsprechenden GS-Sequenzen anderer höherer Pflanzen.

\subsubsection{Die cDNA-Sequenz der GS1 aus der Zuckerrübe}

Die cDNA-Sequenz, von der hier nur der Sense-Strang in 5'- 3' -Richtung gezeigt wird, beginnt ab der Eco RI-Schnittstelle. Mit der Eco RI-Schnittstelle zu Beginn der Sequenz und der Not I-Schnittstellen am Ende wurde die cDNA in die Phagen-DNA einkloniert.

\section{5'-Eco RI}

GAATTCGTT GCTGTCGCCG TTGCTGTCGC CGTTGCTGTC GCCGTTGCTG

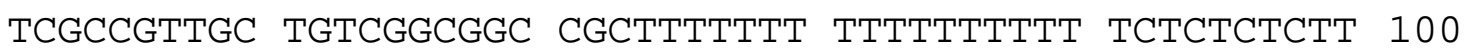
CAtтTTCTTC ACTTtTtCTT CTTCATAACA AAAAATCATC AATCATGGCT CTTCTTAACG ATCTAATtAA CCTTAATCTC TCAGAAACAT CTGACAAGAT 200 tAttgctgag tAtAtAtgga tCggaggatC tgggttggat AtgAgAagCA AAgCAAgGAC AttAACAgGg CCAAtAAgtg AtCCtgCAAA AttAcCAAAA 300 tgGAAttAcG AtggatcAag tActAAtCAA gCtCCtggtg AAgAtAgtgA AgtcAtttta tACCCtCAgg CtAttttcAA ggAtCCAttC AgAAgAggAg 400 ACAATATCCT AgtTATGTGT GATgCATACA CCCCAgCtgG AgAACCAATT CCAACAAACA AGAGgtACAA TGCTGAgAAA ATCTTCAgCC ACCCAGACGT 500 TGtCGCtGA GAgCCAtGgt AtgGAAtTGA ACAAGAAtAC ACACtTCtTC

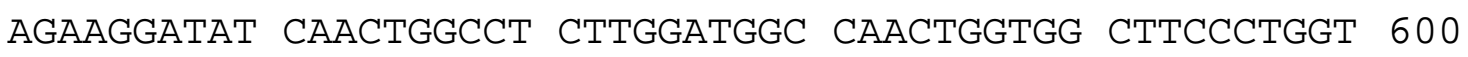
CCTCAGgGAC CAtACTAtTg TGgtgtAgGg GCtGAtAAAT CTtTCGgGCG AgACAtTgtA GAtgCtCACt AtAAggcttg CAtCtAtgCt GgtgtCAAtA 700

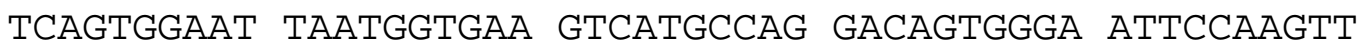
gGtCCtACtg ttgaAittc AtCtggtgat CAAgtCtggg ttgCtAgAtA 800 CAttcttgag AgAAttgctg AgAttgcCgg Agttgttgtg tCtTttgacC CCAAACCAgt GAAgggtgAt tgaAtggtg CTGgtgCtCA CACCAACtAC 900 AgCACtAAgt CGAtgAggga AgAtggtggg AtCAAtgttA tAAAggCtgC CAtCGAgAAg tTGAgtCTCC GTCACAAGgA GCACAtTgCt GCCTACGgGg 1000 AgGgCAACGA GAgGAgGCtC ACtgGtCGtC AtgAgAcAgC CGAtAtCACC 


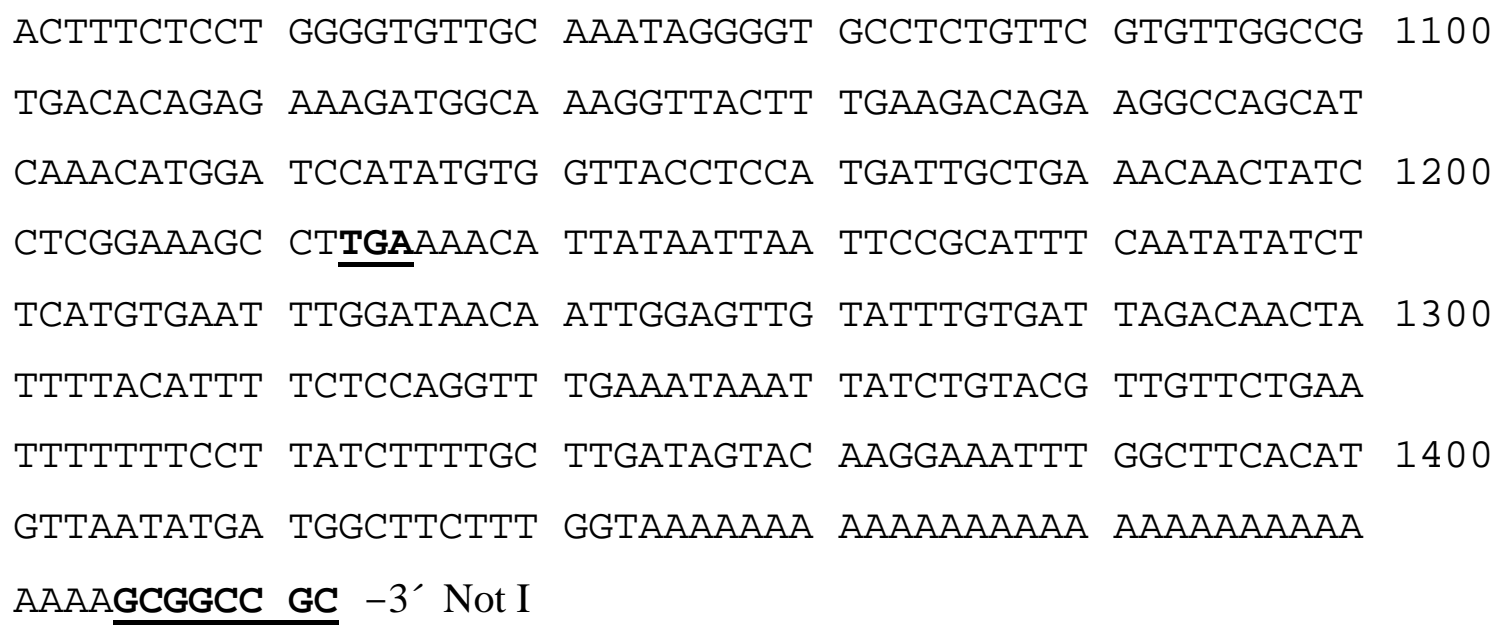

Bis zum ersten ATG-Triplet, die dem AUG-Startcodon der mRNA entspricht, enthält der untranslatierte Leader-Bereich 138 Basenpaare. Der translatierende Teil der Sequenz bis zum ersten TGA-Triplet, dem UGA-Stopcodon (Opal) der mRNA entsprechend, besteht aus $1068 \mathrm{bp}$. Es folgt eine $211 \mathrm{bp}$ lange untranslatierte Terminationssequenz an die sich eine 31 bp lange poly-A Sequenz (HuNT, 1994) anschließt.

\subsubsection{Die Aminosäure-Sequenz der GS1-Untereinheit der Zuckerrübe}

Die aus der cDNA abgeleitete Aminosäuresequenz enthält 356 AS. Die aufgeführte Sequenz beginnt am N-Terminus.

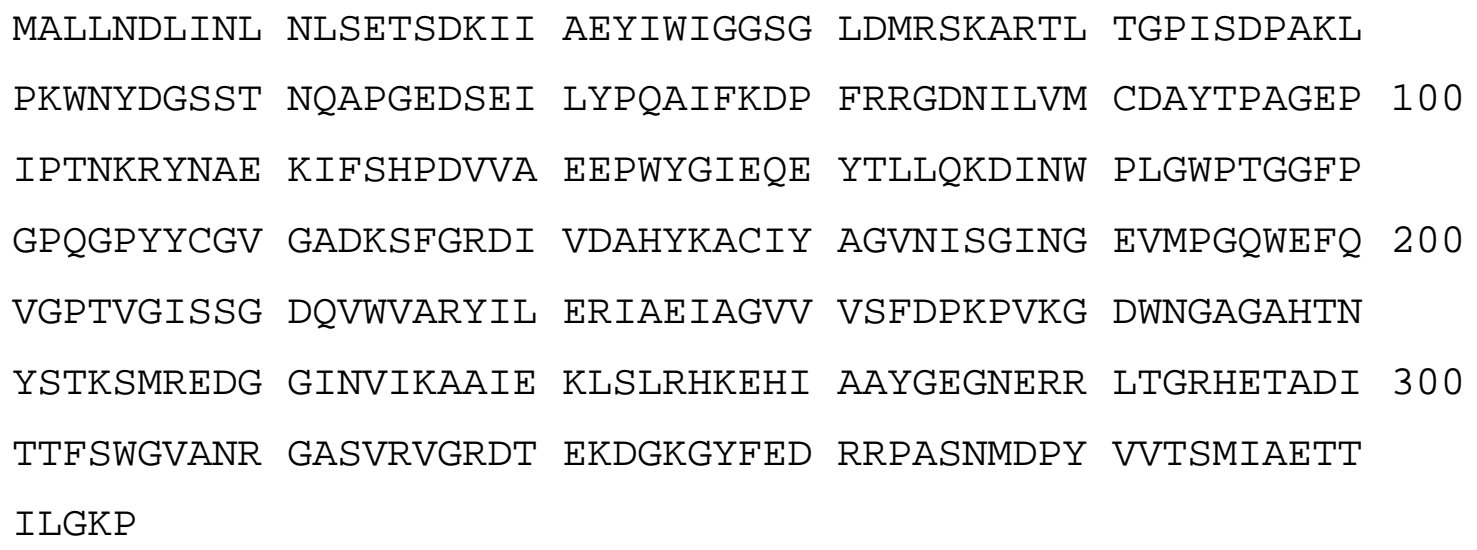




\subsubsection{Die cDNA-Sequenz der GS2 aus der Zuckerrübe}

Die cDNA-Sequenz der GS2 enthält ab dem Eco RI/Not I-Adapter bis zum ersten ATGTriplett 10 bp eines untranslatierten Leaders. Darauf folgen 1293 bp des translatierenden Bereichs und $209 \mathrm{bp}$ der untranslatierten Terminationssequenz, die mit einem UAAStopcodon (Ochre) auf der mRNA-Ebene beginnt.

\section{5'- Eco RI/Not I-Adapter}

\begin{tabular}{|c|c|c|c|c|c|}
\hline AATTCGCGG & CGCTT & & & & \\
\hline GCAATGTCAG & ATGAAACTAT & CAAAGAGCTT & GACAAACTCA & ATGATACCAA & 100 \\
\hline ACTCTTGGAC & СТССАТАТТА & CTGAAAGGAA & GTCAAAAGGG & ATCAATTAAG & \\
\hline TGCTCTACGA & AGTTTAAAGT & ATGTGCCGCT & CTCAAGACTG & AACATGGCAC & 200 \\
\hline TGTGAACAGG & ATGGAGCAAT & TACTCAATTT & GGATGTCACT & CСАТTTACTG & \\
\hline ACAAGATTAT & TGCAGAATAC & ATTTGGATTG & GAGGATCTGG & GATTGATCTT & 300 \\
\hline CGTAGCAAAT & CGAGGACACT & ATCACGACCT & GTTGAGGACC & CATCTGAGCT & \\
\hline TCCCAAGTGG & AACTATGATG & GGTCAAGCAC & AGGACAAGCA & CCTGGAGAAG & 400 \\
\hline CAGTGAAGT & AАТСТTATAC & CCCCAAGCAA & TTTTTAAGGA & TCCATTCCGT & \\
\hline GGTGGTAACA & ATATTTTGGT & AATATGTGAC & GCATACACAC & CAGCAGGTGA & 500 \\
\hline GCCGATCCCA & ACGAATAAAC & GACACAAAGC & TGCCGAGATC & TTCAGCAACC & \\
\hline CAAAGGTTGC & TTCTGAGGTT & CCATGGTTTG & GAATAGAGCA & AGAATACACG & 600 \\
\hline CTGCTTCAAC & CAAATGTTCA & ATGGCCCTTG & GGATGGCCTG & TCGGAGCCTA & \\
\hline TCCTGGTCCC & CAGGGACCAT & ATTACTGTGG & TGTTGGTGCT & GATAAATCGT & 700 \\
\hline TTGGACGTGA & CATATCTGAT & GCTCATTATA & AAGCTTGCCT & GTATGCTGGA & \\
\hline АТАААСАТАА & GTGGCACCAA & CGGGGAGGTC & ATGCCTGGCC & AGTGGGAATT & 800 \\
\hline TCAGGTTGGT & CCTAGTGTTG & GGATTGAAGC & TGGAGATCAT & ATCTGGTGTG & \\
\hline CCAGATATCT & TCTTGAGAGA & ATCACTGAGC & AAGCTGGTGT & AGTTTTGACA & 900 \\
\hline CTTGATCCGA & AGCCAATTGA & GGGTGATTGG & AACGGCGCAG & GTTGCCATAC & \\
\hline CAATTACAGT & ACAAAGACAA & TGAGAGAAGA & CGGTGGTTTT & GAAGTAATAA & 100 \\
\hline AGAAGGCCAT & TTTGAATCTA & TCATTACGCC & ATAAAGAACA & TATCAGTGCA & \\
\hline TATGGAGAAG & GGAATGAAAG & AAGACTGACA & GGGAAGCATG & AGACTGCCGA & \\
\hline CATCGACACA & TTCTCTTGGG & GTGTCGCCAA & TCGTGGTTGT & TCAATCCGTG & \\
\hline TGGGTCGTGA & TACGGAGAAG & GAAGGCAAAG & GTTACATGG & AGACAGGCGA & \\
\hline
\end{tabular}




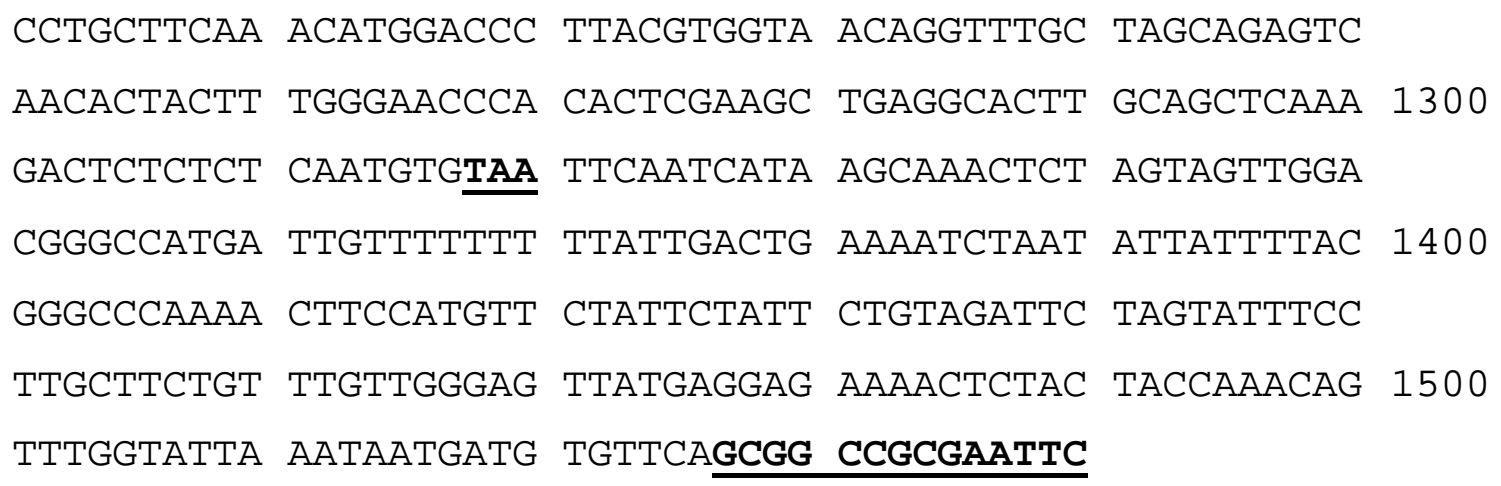

Eco RI/Not I-Adapter-3'

\subsubsection{Die Aminosäure-Sequenz der GS2-Untereinheit der Zuckerrübe}

Die aus der cDNA abgeleitete Aminosäuresequenz enthält 431 AS. Die aufgeführte Sequenz beginnt am N-Terminus.

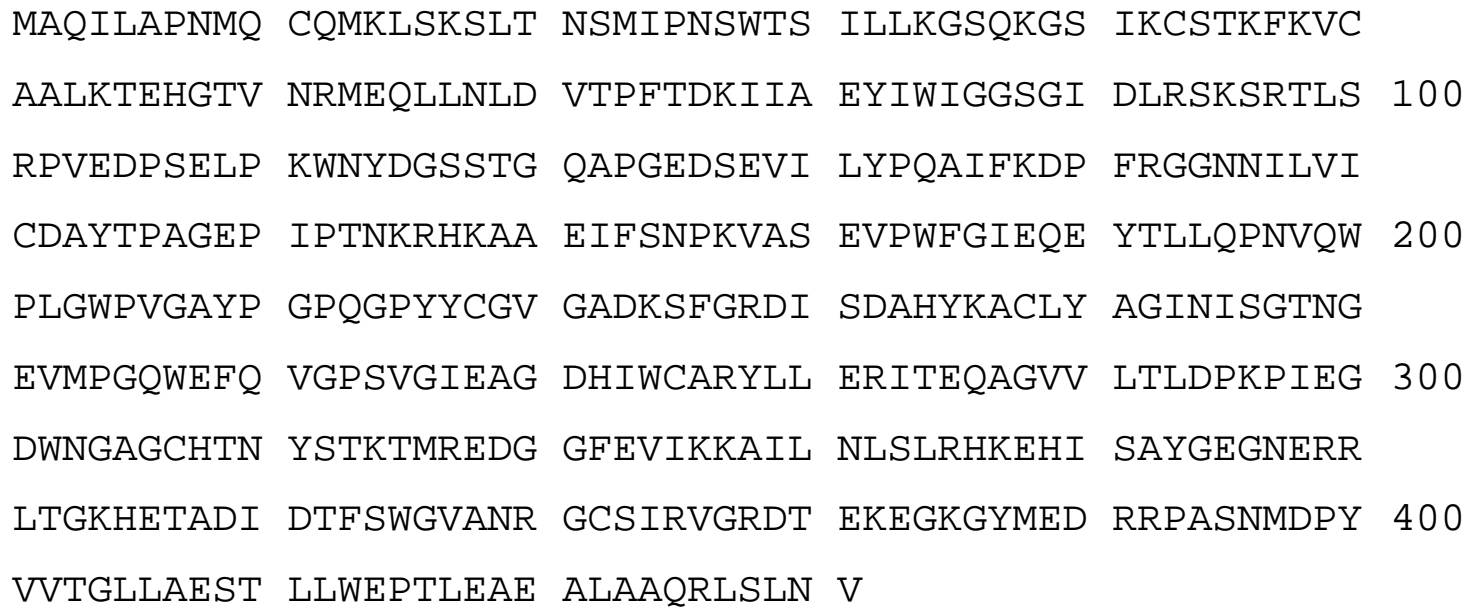




\subsubsection{Sequenzvergleiche}

Die Sequenzvergleiche (Tabelle 1) des codierenden Bereichs der GS1 aus Zuckerrübe (Beta vulgaris L.) auf DNA- und Protein-Ebene mit GS1-Sequenzen aus anderen Pflanzen (Vigna aconitifolia, Lin et al., 1992; Oryza sativa, Sakamoto et al., 1989; Lotus japonica, Thykjaer et al., 1997) ergaben folgende Homologien, die in Prozent (B. vulgaris-GS1 = $100 \%)$ angegeben sind. Auf Protein-Ebene wurde zusätzlich unterschieden in identische Aminosäuren (AS) und chemisch ähnliche Aminosäuren (+). Außerdem sind in der Tabelle 1 Homologievergleiche zur GS2 von Beta vulgaris L. dargestellt.

\begin{tabular}{|c|c|c|c|}
\hline Pflanze & DNA & AS & + \\
\hline Vigna aconitifolia & $81 \%$ & $88 \%$ & $95 \%$ \\
\hline Oryza sativa & $81 \%$ & $87 \%$ & $95 \%$ \\
\hline Lotus japonica & $80 \%$ & $88 \%$ & $95 \%$ \\
\hline Beta vulgaris (GS2) mit Precurser & $61 \%$ & $65 \%$ & - \\
\hline Beta vulgaris (GS2) ohne Precurser & $66 \%$ & $73 \%$ & - \\
\hline
\end{tabular}

Tabelle 1: Nukleotid- und Aminosäure-Übereinstimmungen der GS1 der Zuckerrübe zu anderen Pflanzen und der GS2 der Zuckerrübe (der Prozentsatz der AminosäurenÄhnlichkeit der GS1 zur GS2 wurde nicht ermittelt).

\subsection{In vitro Transkription/Translation}

$\mathrm{Da}$ es in der Literatur keine Hinweise gab, ob GS1-Sequenzunterschiede den verschiedenen GS1-Untereinheiten zugeordnet werden können, wurde mit der klonierten cDNA der Zuckerrüben-GS1 eine in vitro Transkription und Translation durchgeführt, um dann mit einer 2D-PAGE Analyse die klonierte cDNA einer der GS1-Untereinheiten zuzuordnen.

Die in vitro Transkription erfolgte nach dem Protokoll für den T7 Promoter (Linked in vitro SP6/T7 Transcription/Translation Kit - radioactive, Boehringer Mannheim), da die cDNA so in das Plasmid pBluescript einkloniert war, das der „Sense“-Strang in 5'- $3^{\prime}$ Richtung hinter (downstream) der T7 Promoterregion des Plasmids lag. 
Nach der Transkription wurden $10 \mu \mathrm{l}$ der Transkriptionslösung eingesetzt, die ca. $1 \mu \mathrm{g}$ mRNA enthielten, um die in vitro Translation durchzuführen. Zusätzlich wurden dem Reticulocyten Lysat des Translations-Mix $1,6 \mu l{ }^{35} \mathrm{~S}-$ Methionin $(1000 \mathrm{Ci} / \mathrm{mmol})$ hinzugegeben, um das neu synthetisierte Protein radioaktiv zu markieren.

Um einen direkten Vergleich zwischen dem in vitro translatierten und den in der Zuckerrübe natürlich vorkommenden GS1-Untereinheiten zu erhalten, wurden GS1Proteine aus einem Zuckerrübenblatt mit dem radioaktiven in vitro translatierten GS1Protein gemischt und mit dieser kombinierten Probe 2D-PAGEs durchgeführt. Die GS1 aus dem Blatt-Rohextrakt wurde dazu vorher über Anionenaustauschchromatographie gereinigt und durch Membranfiltration eingeengt. Für die isoelektrische Fokussierung (IEF) wurden $30 \mu \mathrm{l}(7,5 \mu \mathrm{g}$ Protein) dieser Lösung mit $5 \mu \mathrm{l}$ des radioaktiven Translationsgemisches zusammengegeben und auf ein Kapillargel aufgetragen.

Als Kontrollen wurden zusätzliche IEFs durchgeführt, die jeweils nur eine der beiden Probenlösungen enthielten, d. h. die Proben der GS1 aus dem Blattextrakt und die radioaktive in vitro translatierte GS1wurden einzeln aufgetrennt.

Nach der isoelektrischen Fokussierung, dem SDS-Gellauf und dem Western Blotting wurde zuerst eine Immunodetektion mit spezifischen GS-Antikörpern (R. WALLSGROVE, Rothamsted Experimental Station, England) durchgeführt. Anschließend wurden von den Membranen Autoradiographien erstellt.

Die Kontrolle, die nur mit dem Blattextrakt durchgeführt wurde, zeigte nach Immunodetektion die bekannte Proteinverteilung der GS von Zuckerrübe, wobei deutlich wurde, daß die GS1 Aufreinigung nicht vollständig war, da eine geringe Menge an GS2 auf der Membran nachweisbar war. Die Autoradiographie zeigte erwartungsgemäß keine radioaktiven Signale. Die Kontrolle mit dem in vitro Translationsgemisch zeigte bei der eingesetzten Menge keine Signale nach Immunodetektion. Auf der Autoradiographie ließ sich jedoch ein eindeutiges Signal ausmachen. Dieses Ergebnis zeigte, daß bei der Immunodetektion keine Kreuzreaktionen der Antikörper mit anderen Proteinen des Reticulocytenlysats, welches für die in vitro Translation eingesetzt wurde, auftraten. Um $\mathrm{zu}$ überprüfen, ob das in vitro translatierte Protein durch die GS-Antikörper überhaupt detektiert werden kann, wurde eine SDS-PAGE mit $30 \mu 1$ eines Translationsansatzes durchgeführt. Nach dem Western Blotting und der Immunodetektion war eine schwache Bande auf der Membran zu erkennen (nicht gezeigt). 
Die kombinierte Probe mit der Blatt-GS und der radioaktiven in vitro translatierten GS zeigten sowohl nach der Immunodetektion Farbsignale auf der Nitrocellulosemembran des Western Blot (Abb.6), als auch ein Signal auf dem entwickelten Röntgenfilm (Abb. 7). Der Röntgenfilm wurde auf die Nitrocellulosemembran gelegt und das Signal, das durch das in vitro translatierte Protein erzeugt wurde, konnte exakt einem Spot auf der Membran zugeordnet werden. Ein Vergleich mit der bekannten Proteinverteilung (BRECHLIN, 1995) ergab, daß das in vitro erzeugte GS1-Protein der GS1-Proteinuntereinheit mit der Bezeichnung , $\mathrm{P}$ “ entspricht.

In verschiedenen 2D-PAGEs, die mit in vitro translatierter GS1 durchgeführt wurden, zeigten sich auf den Röntgenfilmen neben dem Signal für die UE „P “ auch weitere, weniger starke Signale, die den anderen GS1-Spots, die bei der Immunodetektion auftraten, zugeordnet werden konnten. 


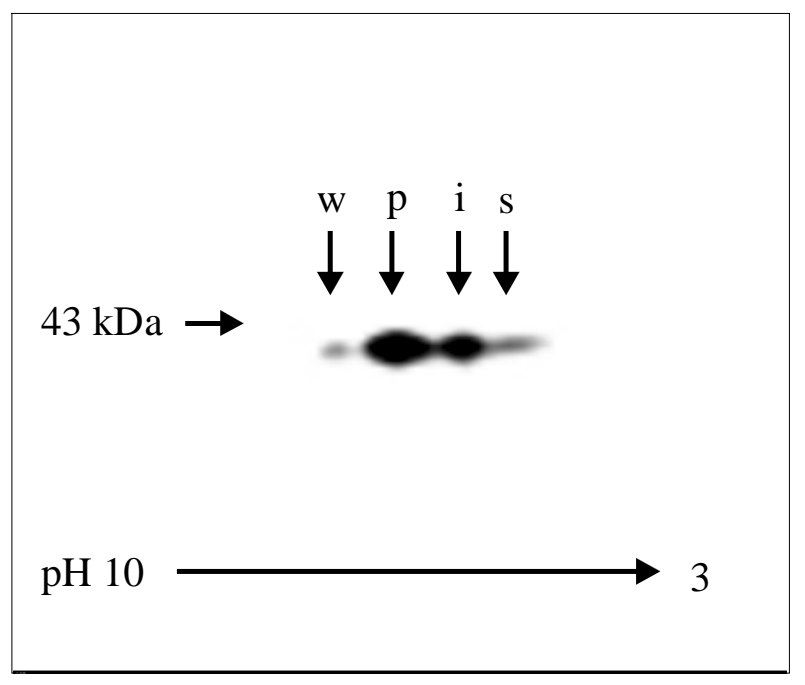

Abb. 6: Western Blot von einer 2D-PAGE mit den kombinierten Proben von $5 \mu 1$ des in vitro Translationsansatzes und $30 \mu \mathrm{l}$ (7,5 $\mu \mathrm{g}$ Protein) des Zuckerrübenblatt-Extrakts. Die Immunodetektion erfolgte mit GS-Antikörpern.

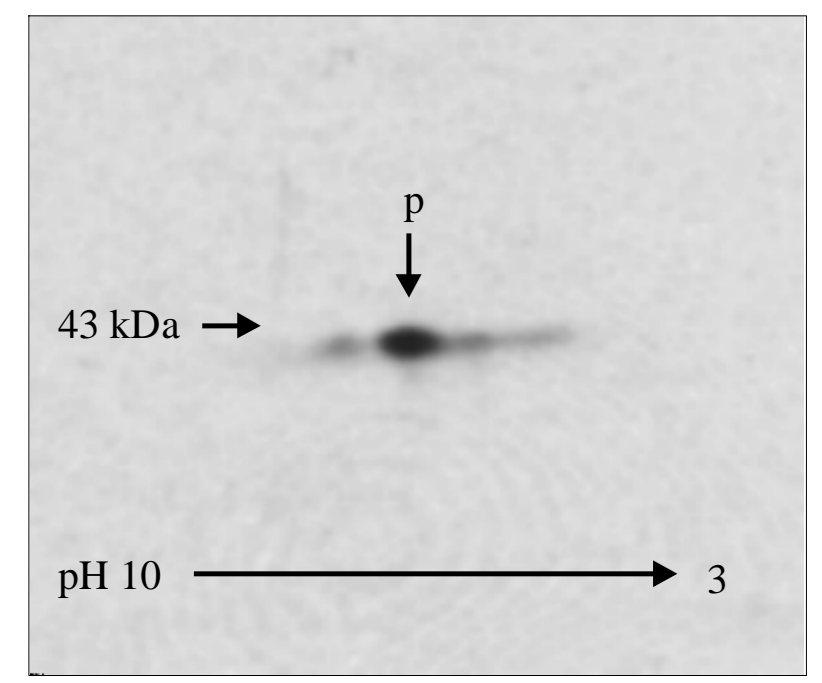

Abb. 7: Autoradiographie des Western Blot (Abb. 4) nach 16 h Exposition. 


\subsection{Subklonierungen}

\subsubsection{Erstellung des Anti-GS1 A Gen-Konstrukts}

Ausgehend von dem pBluescript Plasmid, das durch in vivo Excision aus der Lambda ZAP II Phagen-DNA gewonnen wurde und das die vollständige GS1-Sequenz enthielt, wurden drei Genkonstrukte mit unterschiedlichen Fragmenten der GS1-Sequenz in AntisenseOrientierung erstellt.

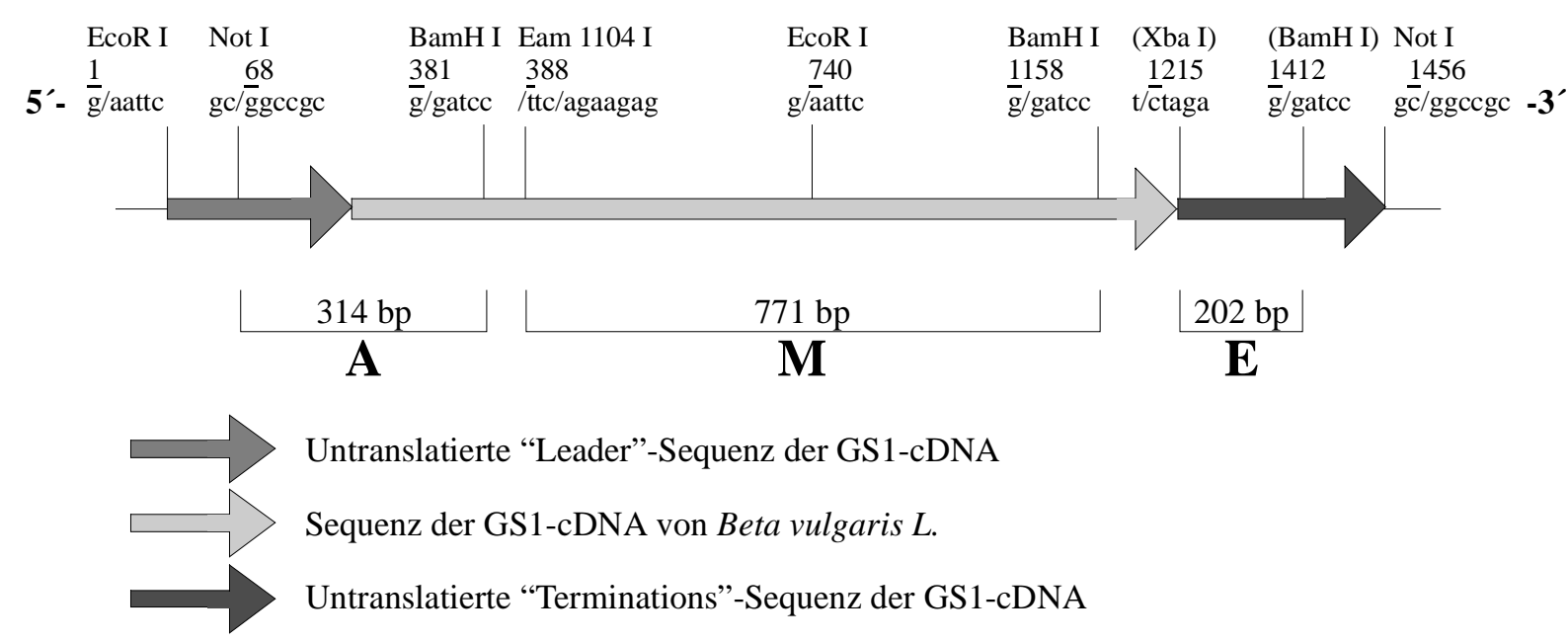

Abb. 8: Schema der GS1-cDNA (B. vulgaris L.) mit den Klonierungsschnittstellen. Die Restriktionsschnittstellen in Klammern wurden durch PCR-Mutagenese erzeugt und sind nicht Teil der Original-Sequenz.

Das erste Antisense-Konstrukt wurde auf folgende Weise kloniert. Der pBluescript Vektor wurde mit dem Restriktionsenzym Bam HI geschnitten, die DNA gefällt und anschließend mit Not I verdaut. Das 314 bp große DNA-Fragment (A) wurde nach Gelelektrophorese aus LMP-Agarose isoliert. Die Sequenz des Fragments beginnt mit Base 68 (ausgehend von der EcoR I-Sequenz der cDNA) und endet mit Base 381 (Abb. 8). Sie enthält eine 77 bp lange Sequenz des 5'-untranslatierten Leader, an die sich eine 237 bp lange Sequenz des Anfangsbereichs der translatierenden Sequenz anschließt. Einschließlich der kompletten Schnittstellensequenzen ist das Fragment 321 bp groß. Das DNA-Fragment wurde anschließend in einen original pBluescript Vektor (ohne Insert), der ebenfalls mit 
Bam HI und Not I geschnitten war, ligiert.

Dieses Plasmid (pBluescript A) wurde nach Transformation und Amplifizierung in E. coli XL1 Blue MRF' mit den Enzymen Bam HI und Sac I verdaut und das Insert isoliert. Das Insert wurde mit dem Vektor pBI 121, aus dem mit den gleichen Enzymen (Bam HI und Sac I) das GUS-Gen herausgeschnitten wurde, ligiert. Der neu entstandene pBI-Vektor (pBI anti-GS1 A) enthielt nun einen CaMV 35S Promoter, das 314 bp große Fragment aus dem Anfangsbereich der GS1-cDNA in antisense Orientierung und einen NOS-Terminator. Diese ca. 1530 bp große Gen-Kassette wurde mit den Enzymen Hind III und Eco RI aus dem Plasmid geschnitten und in den für die Zuckerrüben Cotransformation vorgesehenen Binärvektor Bin 19, der ebenfalls Hind III/Eco RI geschnitten war, ligiert. Dieser Vektor erhielt die Bezeichnung BIN A (Abb. 9).
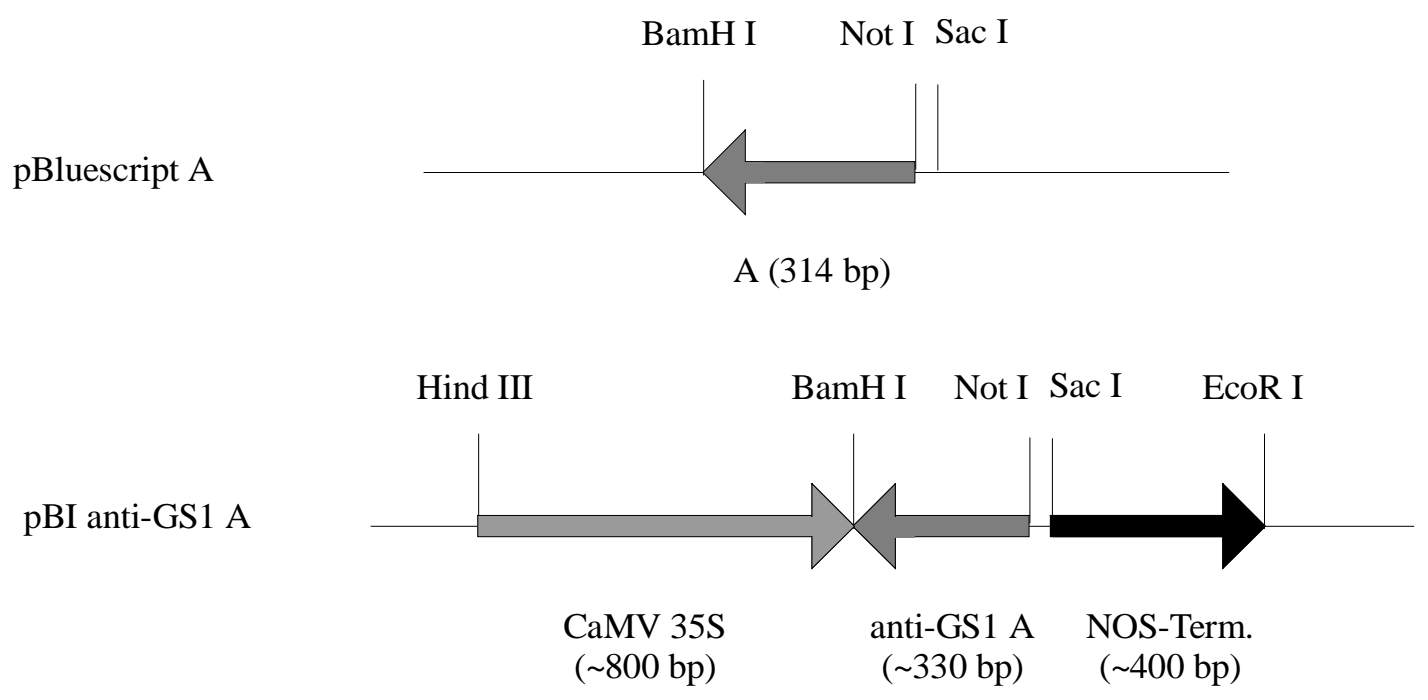

BIN A

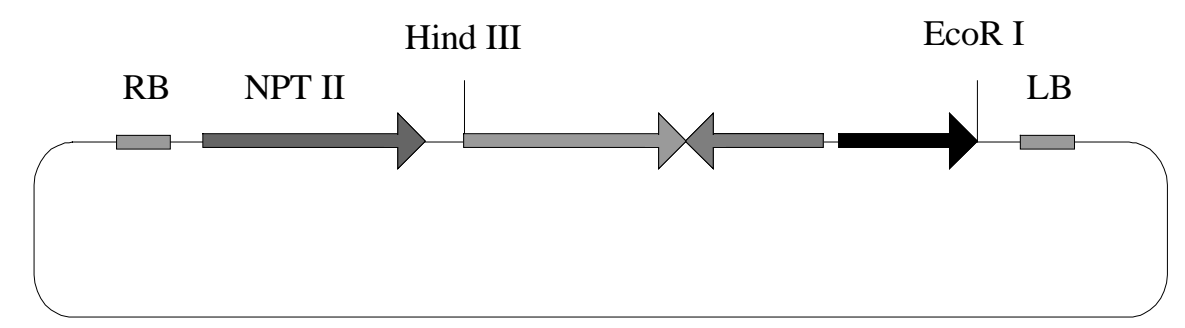

CaMV 35S: Promoter für die 35S RNA des Blumenkohlmosaikvirus

NOS-Term.: Terminationssequenz der Nopalinsynthetase von A. tumefaciens

NPT II: Gen für die Neomycin Phosphotransferase (Kanamycinresistenz)

RB: Rechte „Border“-Sequenz der T-DNA

LB: Linke „Border“-Sequenz der T-DNA

Abb. 9: Schema der Klonierung Des Binärvektors BIN A 


\subsubsection{Erstellung des Anti-GS1 M Gen-Konstrukts}

Das zweite Konstrukt wurde mit einem 771 bp großem Fragment (M) aus dem mittleren Bereich der GS1-cDNA erstellt. Dieses Fragment beginnt mit der Base 388 und endet mit der Base 1158 (Abb. 8). Mit den kompletten Schnittstellensequenzen ist das Fragment 776 bp groß.

Das Ausgangs-Plasmid, der pBluescript Vektor mit der inserierten cDNA, wurde mit dem Enzym Bam HI geschnitten, die DNA gefällt und mit dem Enzym Eam 1104 I nachgeschnitten. Das Plasmid Top Free OCS-Term wurde mit den Enzymen Bam HI und Pst I geschnitten. Das geschnittene Plasmid und das 767 bp cDNA-Fragment wurden in einen Gesamtvolumen von $10 \mu \mathrm{l}$ für $16 \mathrm{~h}$ bei RT ligiert. Da nur je eine Schnittstelle (Bam HI) der beiden DNAs kompatibel war und das Plasmid mit dem GS1 cDNA-Fragment nicht recirkularisieren konnte, wurden nach der Ligation die einzelsträngigen DNA-Enden mit Mung-Bean-Nuklease abverdaut und die „blunt ends“ anschließend ligiert. Das neu konstruierte Plasmids (Top Free anti-GS1 M) wurde in E. coli transformiert und amplifiziert. Um das ca. 970 bp große DNA-Fragment, das den Mittelteil der GS1 cDNA und den OCS-Terminator des Top Free Plasmids enthielt, zu isolieren, wurde zuerst mit dem Enzym Bam HI komplett und anschließend mit Eco RI partiell verdaut. Der partielle Verdau war notwendig, da sich in der Sequenz des GS1-Mittelstücks ebenfalls eine Eco RI Schnittstelle befand. In einem Vorversuch wurden die besten Bedingungen für den partiellen Verdau ermittelt. Dazu wurden $35 \mu \mathrm{g}$ der

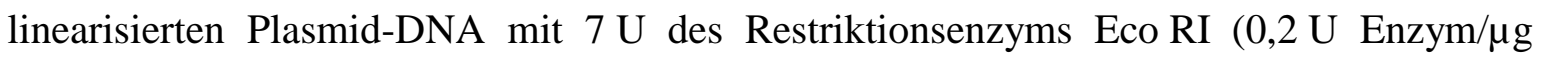
DNA) für 5 min bei $37^{\circ} \mathrm{C}$ in einem Gesamtvolumen von $70 \mu \mathrm{l}$ verdaut. Das 970 bp große Fragment wurde nach Gelelektrophorese aus LMP-Agarose isoliert.

Aus einen pBI 121 Vektor wurde mit den Restriktionsenzymen Bam HI und Eco RI das GUS-Gen zusammen mit dem NOS-Terminator herausgeschnitten. Das Restplasmid wurde isoliert und mit dem ca. 1020 bp Fragment ligiert. Zwischen zwei Hind III Schnittstellen enthält dieses Plasmid (pBI anti-GS1 M) einen CaMV 35S Promoter, das GS1 Mittelstück der cDNA in antisense Orientierung und einen OCS-Terminator. Diese ca. 1820 bp große Gen-Kassette wurde mit dem Enzym Hind III herausgeschnitten und nach Isolierung mit einem Bin 19 Vektor, der ebenfalls Hind III geschnitten und dephosphoryliert war, ligiert. Dieser Binärvektor, der für die Cotransformation eingesetzt wurde, erhielt die Bezeichnung BIN M (Abb. 10). 

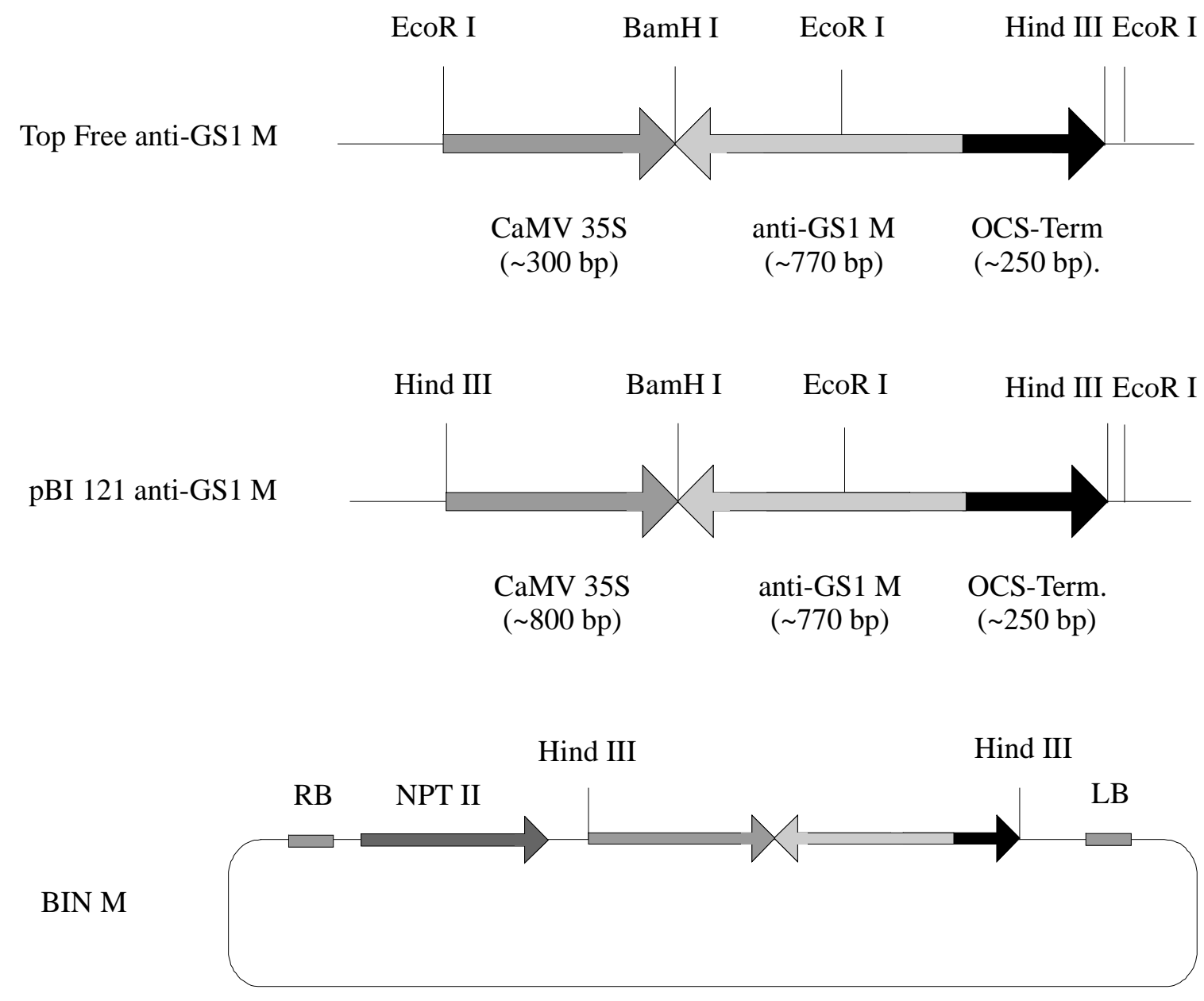

OCS-Term.: Terminationssequenz der Octopinsynthetase von A. tumefaciens

Abb. 10: Schema der Klonierung des Binärvektors BIN M

\subsubsection{Erstellung des Anti-GS1 E Gen-Konstrukts}

Das dritte Antisense-Konstrukt wurde mit einem 202 bp großem Fragment (E) des untranslatierten Terminationsbereichs konstruiert. Das Fragment beginnt mit Base 1211 und endet mit Base 1412 (Abb. 8). Einschließlich der Schnittstellensequenzen ist das Fragment 208 bp groß. Da in diesem Bereich der GS1 cDNA keine für die Klonierung günstigen Restriktionsschnittstellen vorhanden sind, wurde mit speziellen Primern über PCR dieser Sequenzabschnitt amplifiziert. Dabei wurden mit Hilfe der verwendeten Primer 
an beiden Enden der Sequenz je zwei Basen ausgetauscht (PCR-Mutagenese, siehe Kap. 2.6.10). An dem 5'-Ende wurde so eine Restriktionsschnittstelle für das Enzym Xba I erzeugte und am 3'-Ende eine Schnittstelle für Bam HI. Beide Primer sind 27mere und wurden so konstruiert, daß die leicht abweichenden Basensequenzen der einzubringenden Schnittstellen jeweils in der Mitte der Primer lagen, um eine möglichst stabile Anlagerung an die „Template“-DNA zu erzielen.

Für die Amplifikation mit PCR wurden 60 ng des Ausgangs-Plasmids, je 50 pmol der beiden Primer, $5 \mu \mathrm{l} \quad 10 \quad \mathrm{x}$ PCR-Puffer, $5 \mu \mathrm{l}$ dNTPs $\quad$ (je $5 \mathrm{mM}$ ) und $12,5 \mathrm{U}$ Taq-DNA-Polymerase zusammengegeben und mit $\mathrm{H}_{2} \mathrm{O}$ (bidest) auf $50 \mu \mathrm{l}$ aufgefüllt. Die PCR erfolgte wie unter Kap. 2.6.10 beschrieben.

Zur Kontrolle wurde ein Aliquot $(2 \mu \mathrm{l})$ des PCR-Ansatzes in einem Agarosegel elektrophoretisch aufgetrennt. Das amplifizierte PCR-Produkt hatte eine Länge von 230 bp. Der übrige Ansatze (ca. $20 \mu \mathrm{g}$ ) wurde phenolisiert, die DNA gefällt und anschließend mit den Restriktionsenzymen Bam HI und Xba I verdaut. Das 198 bp große DNA-Stück wurde über Gelelektrophorese von den abgeschnittenen DNA-Enden getrennt und aus LMP-Agarose isoliert. Anschließend wurde das DNA-Stück mit einem Bam HI/Xba I geschnittenen pBluescript Vektor ligiert (pBluescript E).

Aus diesem Plasmid wurde die Sequenz des Endbereichs der GS1 cDNA mit den Restriktionsenzymen Bam HI und Sac I herausgeschnitten und in einen pBI 121 Vektor, der ebenfalls Bam HI/Sac I geschnitten war, ligiert. Dieses Plasmid (pBI anti-GS1 E) enthielt einen CaVM 35S Promoter, die untranslatierte Terminationssequenz des GS1-Gens der Zuckerrübe in antisense Orientierung und einen NOS-Terminator. Die ca. 1430 bp große Gen-Kassette wurde mit den Enzymen Hind III und Eco RI aus dem Plasmid geschnitten und in einen ebenso verdauten Bin 19 Vektor ligiert. Dieser Vektor erhielt die Bezeichnung BIN E. 


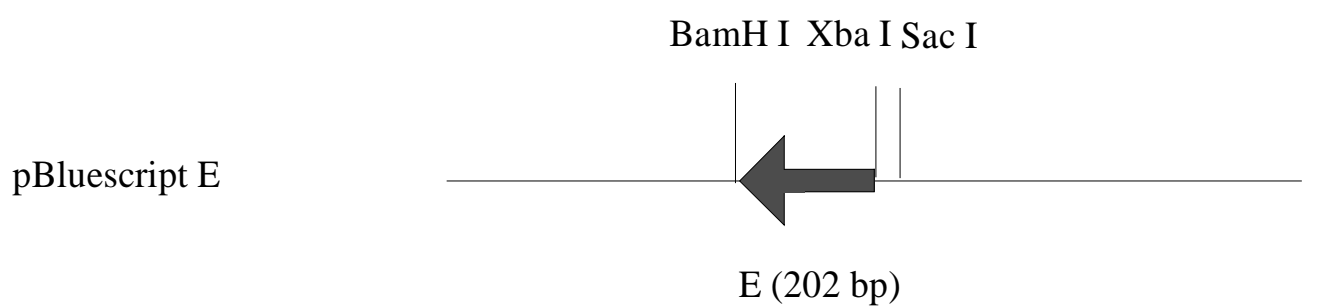

$\mathrm{E}(202 \mathrm{bp})$
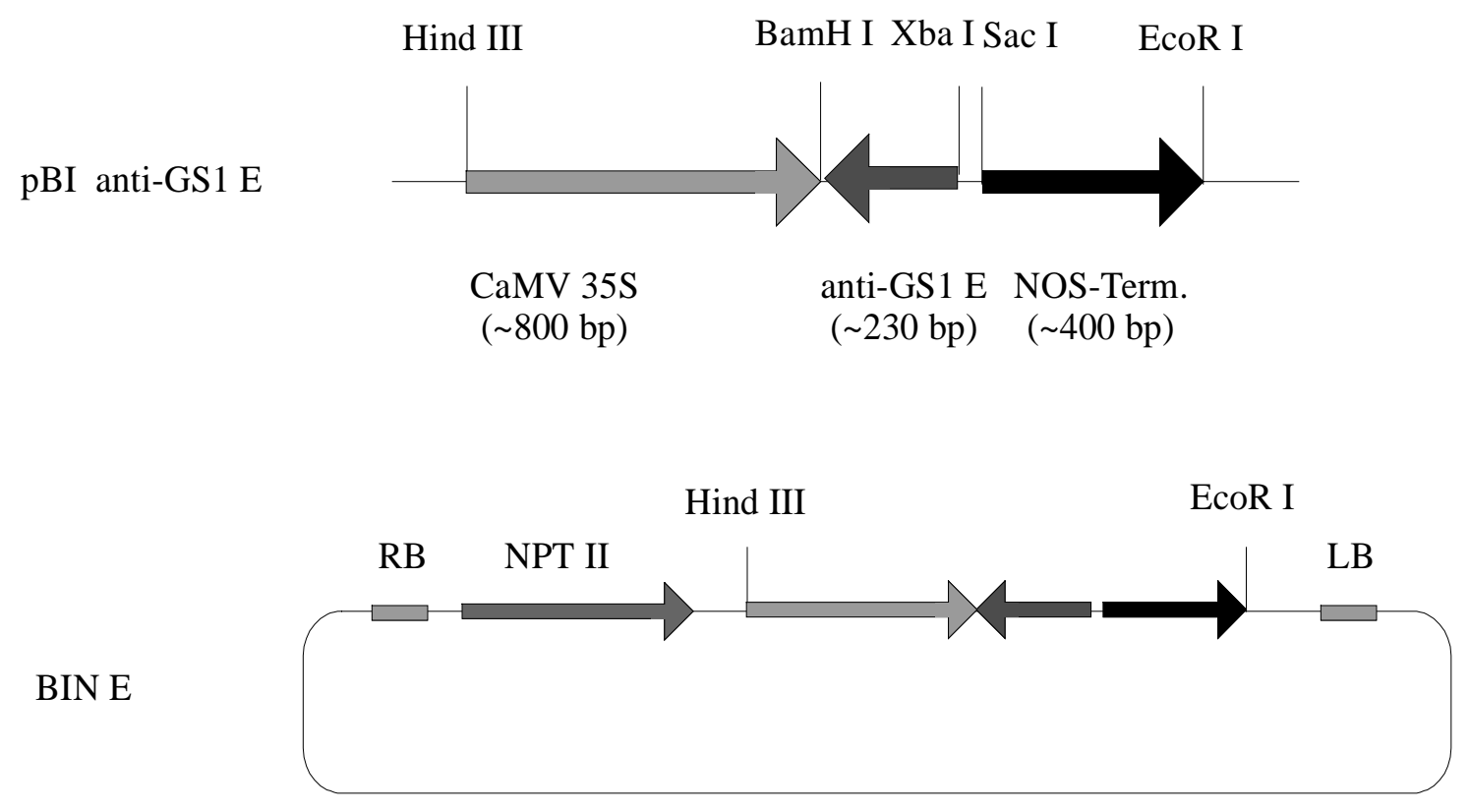

Abb. 11: Schema der Klonierung des Binärvektors BIN E

Die Binärvektoren wurden in E. coli amplifiziert und mit Midipräparation isoliert. Zur Überprüfung der Insertion der Gen-Kassetten wurden die Plasmide nach Restriktionsverdau in einem Agarosegel elektrophoretisch aufgetrennt (Abb. 12). BIN M wurde einmal mit Hind III und Eco RI und einmal nur mit Hind III verdaut. Die Plasmide BIN A und BIN E wurden mit Hind III und Eco RI geschnitten. Es entstehen bei allen Verdauen das ca. $13 \mathrm{~kb}$ großes Fragment des linearisierten BIN 19 Vektors und die entsprechenden Fragmente der Gen-Kassetten. Der Verdau von BIN M mit Hind III und Eco RI spaltet das Plasmid in drei Fragmente. Neben dem 13 kb-Fragment entstanden das 550 bp und das 1270 bp große Fragment (Spur 2) der 1820 bp großen Gen-Kassette, die bei dem Verdau mit Hind III entsteht (Spur 3). Der Hind III/Eco RI Verdau des BIN A Vektors zeigt neben der $13 \mathrm{~kb}$-Bande das $1530 \mathrm{bp}$ große DNA-Fragment der Gen-Kassette (Spur 4) und bei BIN E eine 1430 bp große Bande (Spur 5). 


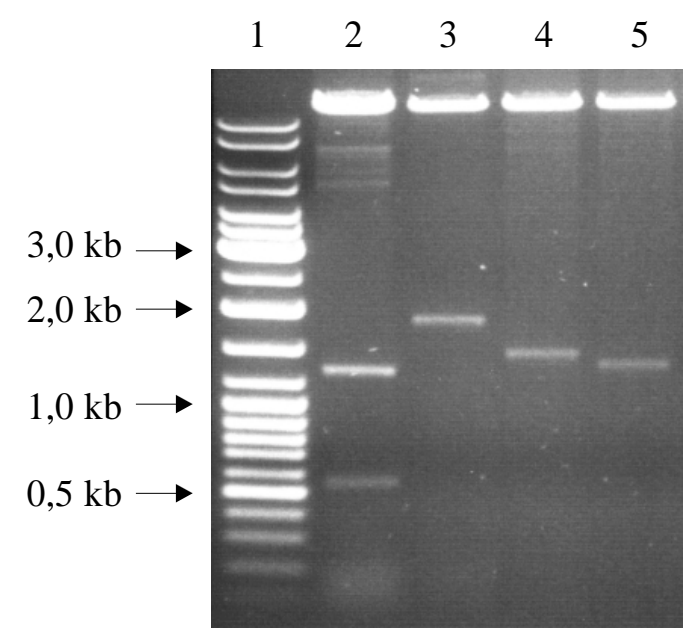

1) DNA Ladder Mix (MBI Fermentas)

2) $2 \mu \mathrm{g}$ BIN M mit Hind III und Eco RI verdaut

3) $2 \mu \mathrm{g}$ BIN M mit Hind III verdaut

4) $2 \mu \mathrm{g}$ BIN A mit Hind III und Eco RI verdaut

5) $2 \mu \mathrm{g}$ BIN E mit Hind III und Eco RI verdaut

Abb. 12: 1 \%iges Agarosegel mit restriktionsverdauten BIN 19 Konstrukten.

\subsection{Transformation}

Die Binärvektoren wurden mit Elektroporation in Agrobacterium tumefaciens (C 58) überführt und die Bakterien auf LB-Medium mit Kanamycin und Rifampicin selektiert.

Für die Erzeugung von „Hairy Roots“ wurden die drei transformierten Bakterienkulturen für ca. $2 \mathrm{~d}$ bei $25^{\circ} \mathrm{C}$ in flüssigem LB-Medium bis zu einer $\mathrm{OD}_{600}$ von 0,5 angezogen und zusammen mit A. rhizogenis wie unter Kap. 2.7. angegeben für die Cotransformation der Zuckerrübenblattstiele (Sorte 2B 0035, KWS) eingesetzt.

Nach der Cotransformation und Regeneration konnten 11 unabhängig transformierte Zuckerrübenwurzeln der Sorte A ( mit BIN A transformiert), 26 Transformanten der Sorte M und 10 Transformanten der Sorte E auf kanamycinhaltigem MS-Medium selektiert werden. Einige der Transformanten wuchsen im Vergleich zu anderen Transformanten sehr schlecht und konnten auch auf kanamycinfreiem MS-Medium nicht weiter kultiviert werden, so daß nur 10 Transformanten der Sorte A, 18 Transformanten der Sorte M und 10 Transformanten der Sorte E für die anschließenden Untersuchungen eingesetzt werden konnten. 


\subsection{Southern Blot}

Um den Nachweis über die erfolgte Transformation auf molekularbiologischer Ebene zu erhalten, wurde von ausgewählten Wurzeltransformanten genomische DNA isoliert und diese Restriktionsverdauen unterzogen. Die verdaute DNA wurde elektrophoretisch in einem Agarosegel aufgetrennt und die DNA in einem Southern Blot auf eine Nylonmembran übertragen. Die Hybridisierung erfolgte mit der homologen GS1-Sonde der Zuckerrüben cDNA bei $61^{\circ} \mathrm{C}$ für $16 \mathrm{~h}$.

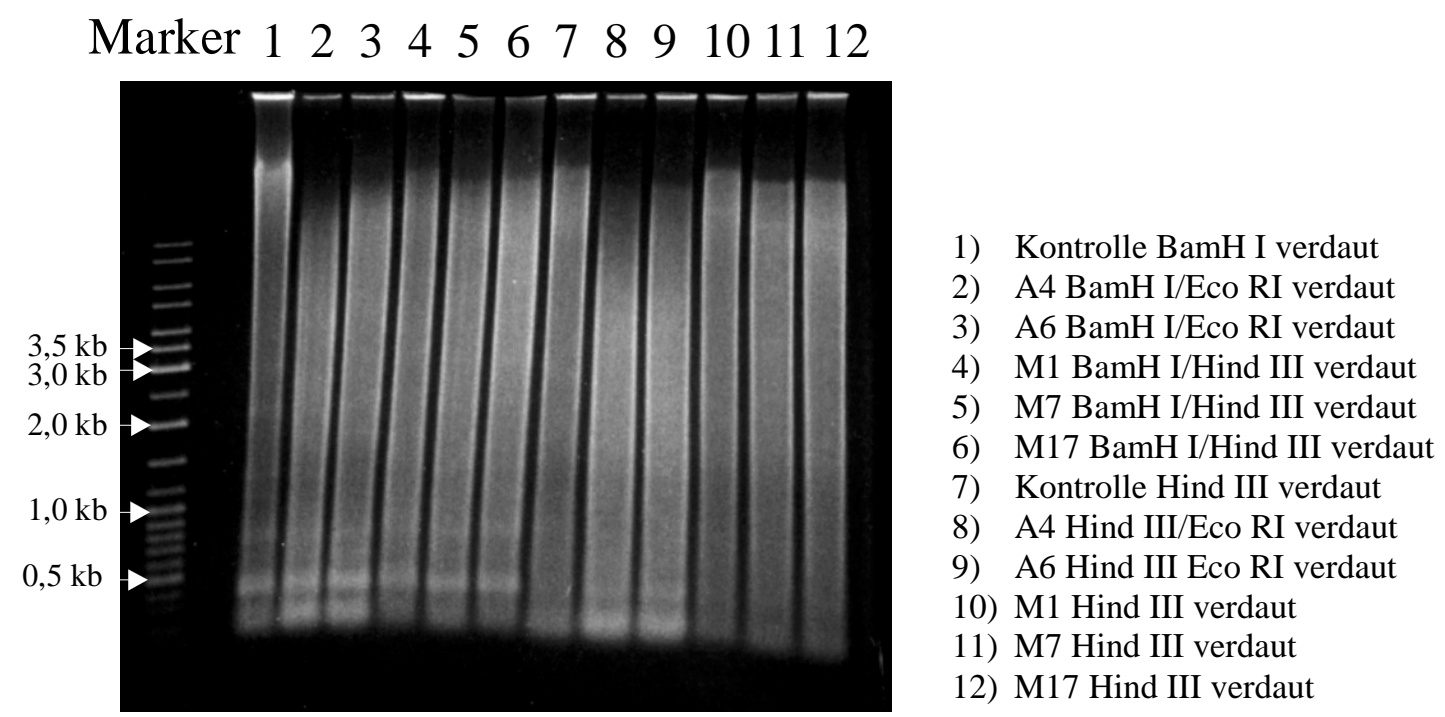

Abb. 13: 0,8 \%iges Agarosegel mit je $25 \mu \mathrm{g}$ restriktionsverdauter genomischer DNA der „Hairy Roots“.

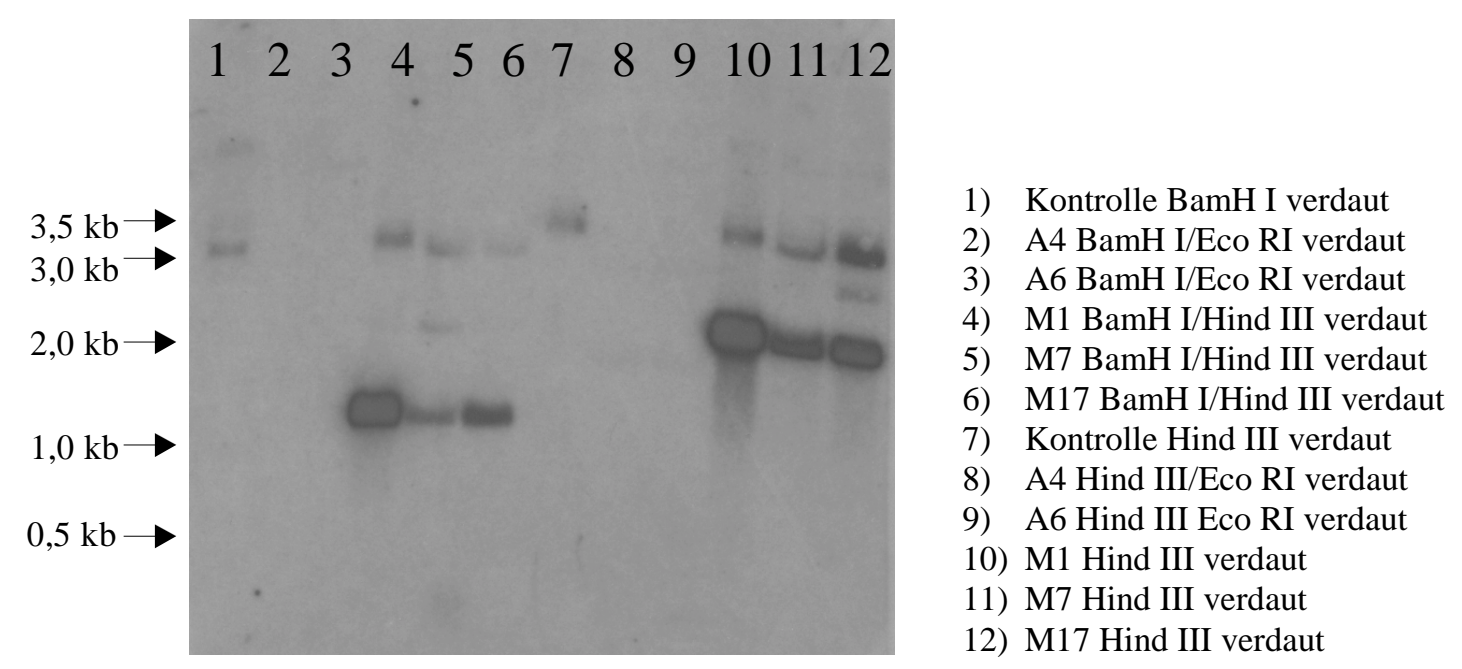

Abb. 14: Autoradiographie des Southern Blots (Exposition $6 \mathrm{~d}$ ) 
Die Autoradiographie (Abb. 14) zeigt in Spur 1 die mit Bam HI geschnittene DNA der Kontrollwurzel. Es erscheint eine Bande bei 3,2 kb. Diese Bande repräsentiert das Bam HI Fragment der genomische DNA der GS1. In den Spuren 2 und 3 der Transformanten A4 und A6 ist keine Bande zu erkennen. Die genomische GS1 wurde durch den Doppelverdau mit Bam HI und Eco RI in mindestens sechs Fragmente unterteilt, diese Aufteilung erschwert den Nachweis in der Autoradiographie. Auch das ca. 0,7 kb große Fragment des eingebrachten Antisense-Gens ist hier nicht zu erkennen. Die eingesetzte DNA-Menge war möglicherweise für diese Fragmentgröße zu gering, denn bei dem Hind III/Eco RI-Verdau (Spur 8 und 9) dieser Transformanten ist das ca. 1,5 kb große Fragment, das bei diesem Verdau aus dem eingebrachten Antisense-Gen (A) entsteht, auch nur schwach sichtbar. Die Spuren 4, 5 und 6 zeigen die 3,2 kb Bande der Hind III verdauten genomischen GS1 sowie die ca. $1 \mathrm{~kb}$ großen Fragmente des Antisense-Gens (M) der Transformanten M1, M7 und M17. In Spur 7 ist eine Bande bei 3,6 kb zu erkennen. Diese resultiert aus der Hind III geschnittenen genomischen DNA der Kontrollwurzel und entspricht der so geschnittenen genomischen GS1. Die Spuren 10, 11 und 12 zeigen die Banden der genomischen GS1 bei 3,6 kb und die Banden der Antisense-Gene (M) bei ca. 1,8 kb. Zusätzliche Banden erscheinen in Spur 5 (M7) bei ca. $2 \mathrm{~kb}$ und in Spur 12 (M17) bei ca. 2,5 kb. Diese Banden sind auf unvollständigen Verdau dieser DNAs zurückzuführen, da in den jeweils anderen Verdauen dieser Transformanten keine zusätzlichen Banden auftreten.

\subsection{Northern Blot}

Das Expressionsverhalten der GS1-Antisense-Gene der transformierten Zuckerrübenwurzeln wurde durch Northern Blots analysiert. Bei Expression von Antisense-Genen wird das entstehende doppelsträngige mRNA-Hybrid von Nukleasen degradiert und die Menge an Sense-mRNA wird reduziert (BouRQUE, 1995; JIANG et al, 1994). In einem denaturierenden Agarosegel wurden je $25 \mu \mathrm{g}$ Gesamt-RNA von ausgewählten Wurzel-Transformanten elektrophoretisch aufgetrennt (Abb. 15a) und die RNA durch Northern Blot auf eine Nylonmembran übertragen. Die Hybridisierung mit homologer GS1-cDNA-Sonde erfolgte bei $61^{\circ} \mathrm{C}$ für $16 \mathrm{~h}$. Das Autoradiogramm (Abb. 15b) zeigt nur in Spur 1, die die Gesamt-RNA der Kontrollwurzel enthielt, eine deutliche Bande 
bei 1,4 kb. Diese Größe entspricht der Größe der GS1-mRNA. Die Bahnen auf denen die RNA der Transformanten aufgetrennt wurden zeigen keine distinkte Banden der GS1mRNA. Dieses Ergebnis zeigt, daß die GS1-Antisense-Gene der untersuchten Transformanten in einem so hohem Ausmaß exprimiert werden, daß ein Nachweis an GS1mRNA nicht mehr möglich ist.
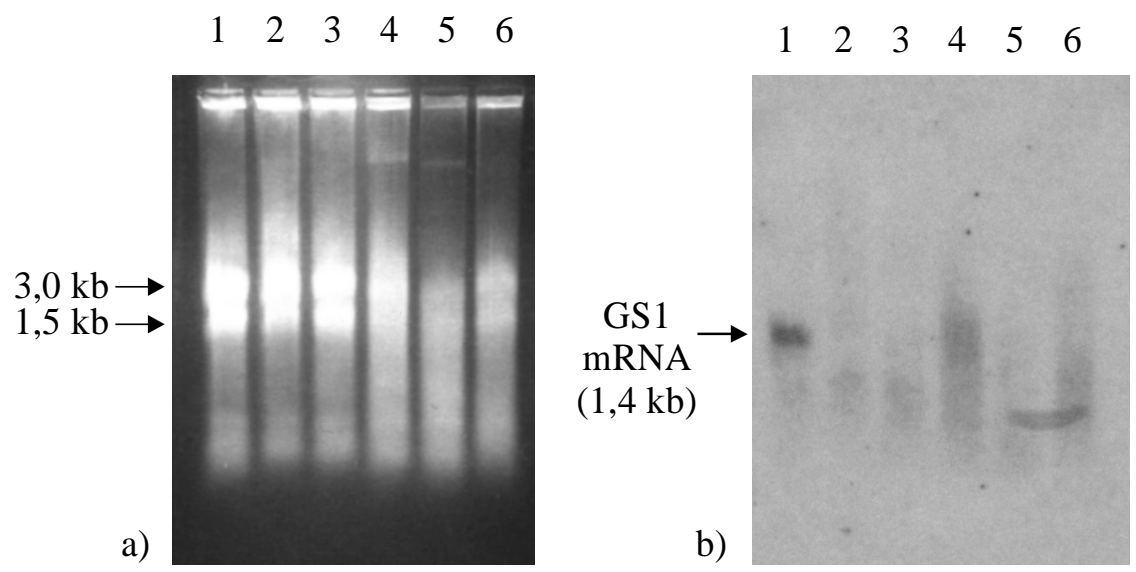

Abb. 15: a) denaturierendes Formaldehydagarosegel mit je $25 \mu \mathrm{g}$ Gesamt-RNA pro Spur:

1) Kontrolle; 2) A4; 3) A6; 4) M1; 5) M7; 6) M17

b) Autoradiographie des RNA-Gels (Exposition 6d)

\subsection{Western Blot}

\subsubsection{SDS-Gele}

Proteine mit einer geringen „Turn Over“-Rate benötigen nur wenig mRNA um ihren Gehalt in der Zelle aufrechtzuerhalten. Bei Antisense-Reduktion von translatierbarer mRNA eines Proteins ist es daher möglich, daß der natürlich in einer Zelle vorkommende Proteingehalt erhalten bleibt, obwohl keine oder nur geringe mRNA des entsprechenden Proteins im Northern Blot nachgewiesen werden konnte (TEMPLE et al., 1998). Um die Wirksamkeit der Antisense-Konstrukte auf Protein-Ebene zu untersuchen wurden SDSGelelektrophoresen von Protein-Rohextrakten der Transformanten im Vergleich zu denen der Kontrollwurzel durchgeführt. Nach Western Blotting und Immunodetektion mit GSAntikörpern wurden die GS-Proteingehalte der Rohextrakte sichtbar gemacht (Abb. 16 a und $b$ ). 

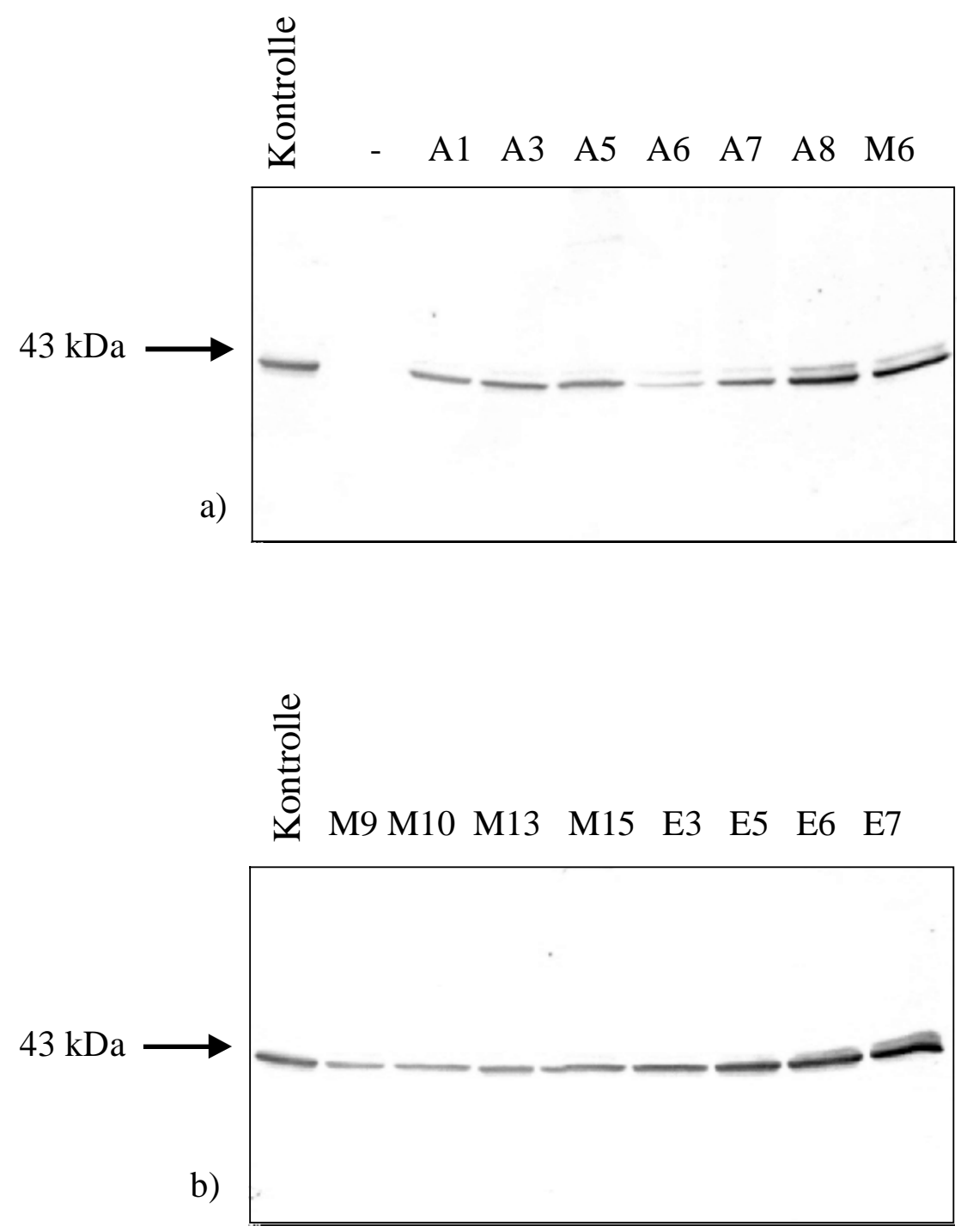

Abb. 16a) und b): Western Blots nach Immunodetektion durch polyklonale GS-Antikörper. Aufgetragen wurden je $25 \mu \mathrm{g}$ löslichem Gesamt-Proteins der Rohextrakte

Im Vergleich zu den Kontrollwurzeln zeigt die Transformante A6 eine stark reduzierte Menge an GS1 Protein. Die Transformanten A1, A3, A5, A7, M9, M10, M13, M15 und E3 zeigen eine leichte Reduktion des GS1 Proteingehalts. Die Transformanten E5, E6 und E7 weisen keine Verminderung des GS1-Protein auf. 


\subsubsection{D-PAGE}

2D-PAGE-Analysen führten zu der Vermutung, daß das Oktamer der cytosolischen Glutaminsynthetase zu unterschiedlichen Entwicklungsstadien aus verschiedenen ProteinUntereinheiten aufgebaut ist (BRECHLIN, 1995). Um zu überprüfen, ob die Reduktion des GS1-Proteingehalts Auswirkungen auf die Zusammensetzung der Protein-Untereinheiten hat, wurden 2D-PAGEs durchgeführt. Zuerst wurden 2D-PAGEs von der Kontrollwurzel und von der Wurzel-Transformante A6 durchgeführt. Dabei wurden je $35 \mu \mathrm{g}$ Protein für die erste Dimension in einem IEF-Kapillargel eingesetzt. Nach der Größenauftrennung in einem SDS-Gel, Western Blotting und Immunodetektion mit GS-Antikörpern zeigte der Blot der Kontrollwurzel das erwartete GS-Spotmuster (Abb. 17a). Der Blot der Transformante A6 zeigte nach Immunodetektion nur einen Spot (Abb. 17b), die vorhandene Gesamt-GS-Proteinmenge war entsprechend dem Ergebnis der SDS-PAGEUntersuchung (Abb. 16 a) gegenüber der Kontrolle deutlich geringer.

Um den Protein-Spot der A6-Transformante einem Spot der Kontrolle zuordnen zu können, wurden drei 2D-PAGEs durchgeführt, in denen unterschiedliche Mengen an Gesamt-Protein aus Kontroll-Rohextrakt und eine gleichbleibende Menge an GesamtProtein der Transformante A6 zusammengegeben wurden. Durch die Abnahme des Proteingehalts der Kontrollwurzel zeigt sich, daß der Spot der Transformante A6 mit dem Spot übereinstimmt, der im Wildtyp die Bezeichnung „P“ (BRECHLIN, 1995) erhalten hat (Abb. 16 a-c).
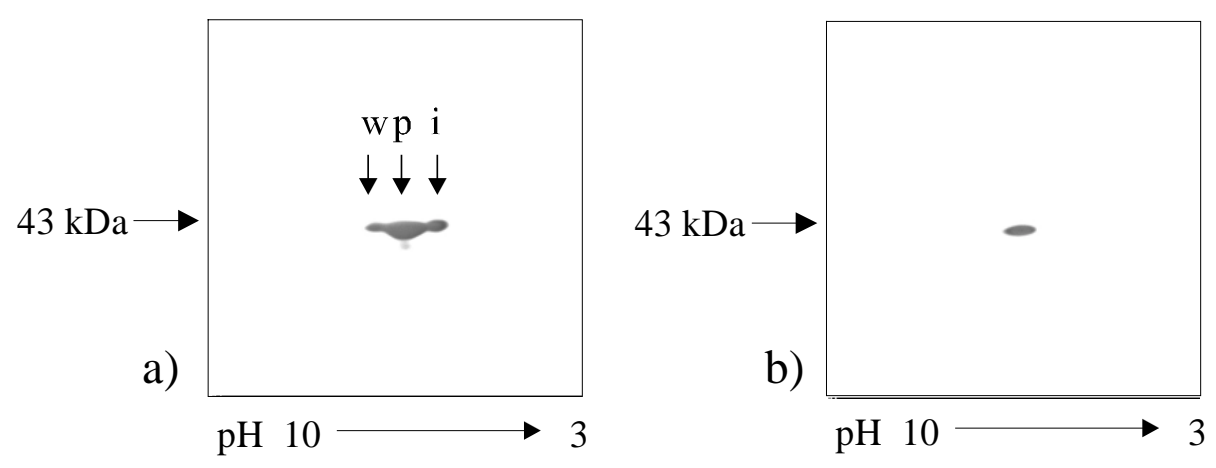

Abb. 17: a) $35 \mu$ g Protein des Rohextrakts der Kontrollwurzel

b) $35 \mu \mathrm{g}$ Protein des Rohextrakts der Transformante A6 
a)

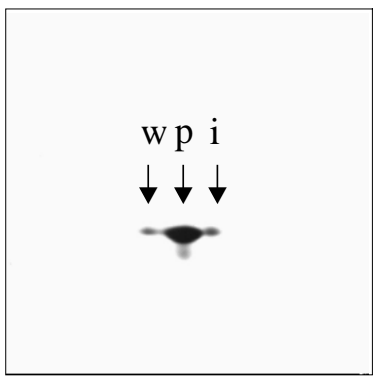

b)

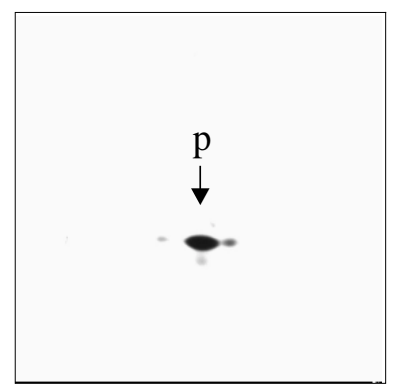

c)

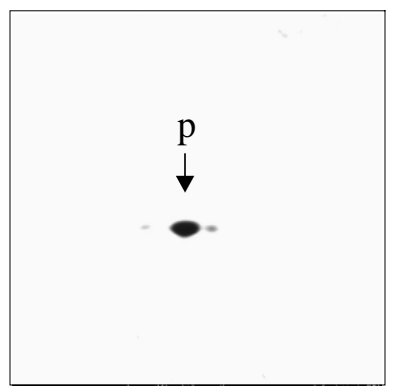

$18 \mathrm{a}-\mathrm{c}) 35 \mu \mathrm{g}$ Gesamt-Protein der Transformante A6

a) $+14 \mu \mathrm{g}$ Gesamt-Protein der Kontrollwurzel

b) $+7 \mu \mathrm{g}$ Gesamt-Protein der Kontrollwurzel

c) $+3,5 \mu \mathrm{g}$ Gesamt-Protein der Kontrollwurzel

Abb. 18a-c): 2D-PAGEs von kombinierten Protein-Proben der Transformante A6 und der Kontrollwurzel

\subsection{GS-Aktivität}

Die Höhe der Aktivität der Glutaminsynthetase ist ein entscheidender Faktor für die physiologischen Auswirkungen der in der Pflanze. Da für die Regulation der GS1-Aktivität in Pflanzen auch posttranslationale Mechanismen diskutiert werden (KAMACHI et al., 1992; TEMPLE et al., 1998), wurden GS-Aktivitätstests durchgeführt.

Es sollte dabei untersucht werden, ob die Reduktion des GS1-Transkripts und Proteins in den GS1-Antisense-Transformanten zu einer Verringerung der GS-Aktivität (GSA) führt oder diese durch posttranslationale Effekte ausgeglichen werden kann.

Zunächst wurden alle Transformanten (10 des Typs A, 18 des Typs $M$ und 10 Transformanten des Typs E) untersucht. Die GSA wurde zum Einen auf den GesamtProteingehalt bezogen ( $\mu$ mol gebildetes GHA/mg Protein $x \mathrm{~h}$ ), zum Anderen auf das Frischgewicht ( $\mu$ mol gebildetes GHA/g Frischgewicht (FG) $x$ h). Wie in den Western Blots gezeigt werden konnte, sind in den „Hairy Roots“ nur geringe Mengen an GS2 
vertreten, so daß die gemessene Aktivität fast ausschließlich der GS1 zugeordnet werden kann. Um die einzelnen GS-Aktivitätstests miteinander vergleichen zu können, wurde bei jedem Test die Aktivität der Kontrollwurzel mitbestimmt. Die Absolutwerte der verschiedenen Messungen zeigen große Unterschiede der einzelnen Transformanten (Abb. 19 und 20). Ungewöhnlich erscheinen die hohen Werte des Typs E, die zum Teil über doppelt so groß sind, wie die der Kontrolle. Werden die Meßwerte eines Testansatzes auf den jeweiligen Kontrollwert $($ Kontrolle $=100 \%)$ bezogen und prozentual angegeben, dann sind alle Meßwerte aus verschiedenen Tests miteinander vergleichbar (Abb. 21 und 22). Bei dieser Darstellung zeigt sich, daß die Abweichungen der GS-Aktivitäten der Transformanten des Typs E gegenüber den Aktivitäten der Kontrolle nicht so groß (bis 30 $\%$ ) sind. Je nachdem, wie die Messungen berechnet wurden, ergeben sich Unterschiede der GSA in den vier Graphiken. Für eine Beurteilung der GSA wurden daher alle vier Graphiken berücksichtigt. Zwei Transformanten des Typs A, mit dem integrierten antisense DNA-Fragment des GS1-Anfangsbereichs (A4 und A6) sowie fünf Transformanten des Typs M, mit dem Mittelteil des GS1-Gens in antisense Orientierung (M1, M3, M7, M8 und M17) zeigten die niedrigsten GS-Aktivitäten. Diese Transformanten wurden für weitere GSA-Tests ausgewählt. Die Transformanten M3 und M8 hatten jedoch ein so geringes Wachstum, daß sie sich nicht mehr regenerieren ließen. Für eine statistische Auswertung wurden daher nur die Transformanten A4, A6, M1, M7 und M17 herangezogen (Abb. 23a-d). Da alle Transformanten des Typs E eine ähnlich hohe GS-Aktivität wie die Kontrollen aufwiesen, wurden mit diesem Typ keine weiteren Untersuchungen durchgeführt. 


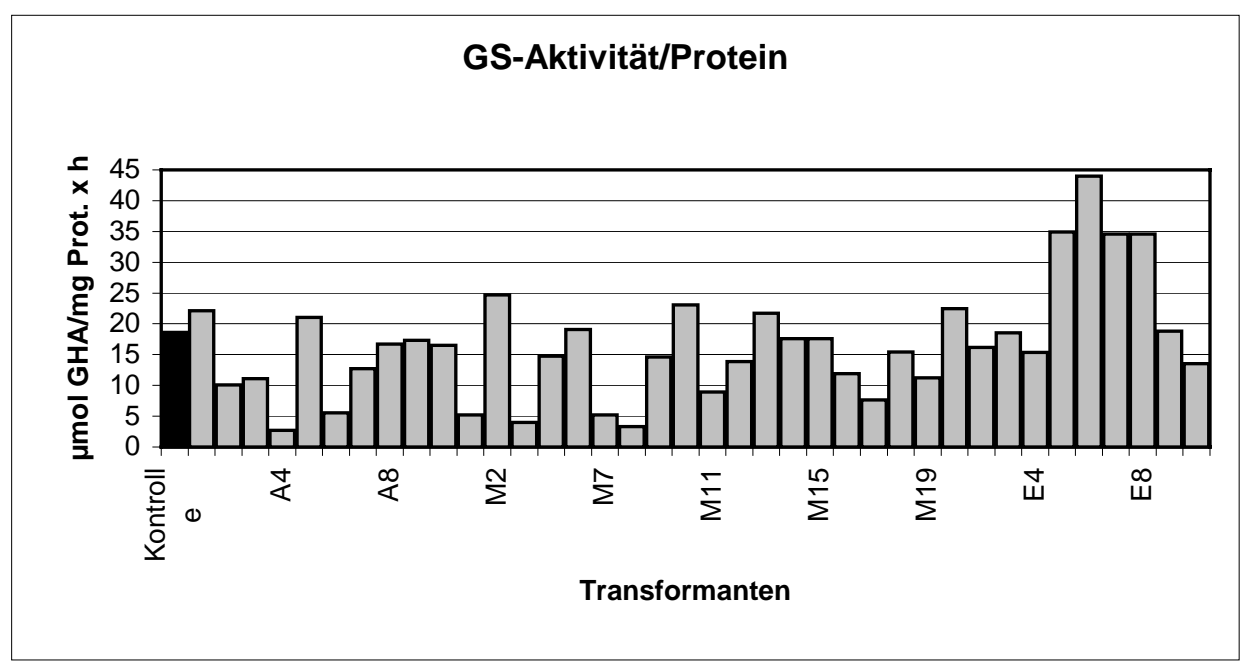

Abb. 19: GS-Aktivitäten bezogen auf das Gesamtprotein. Dargestellt sind die Mittelwerte der GS-Aktivitäten der Kontrollwurzel und der folgenden Transformanten von links nach rechts: A1; A2; A3; A4; A5; A6; A7; A8; A9; A10; M1; M2; M4; M5; M6; M7; M8; M9; M10; M11; M12; M13; M14; M15; M16; M17; M18; M19; E1; E2; E3; E4; E5; E6; E7; E8; E9; E10.

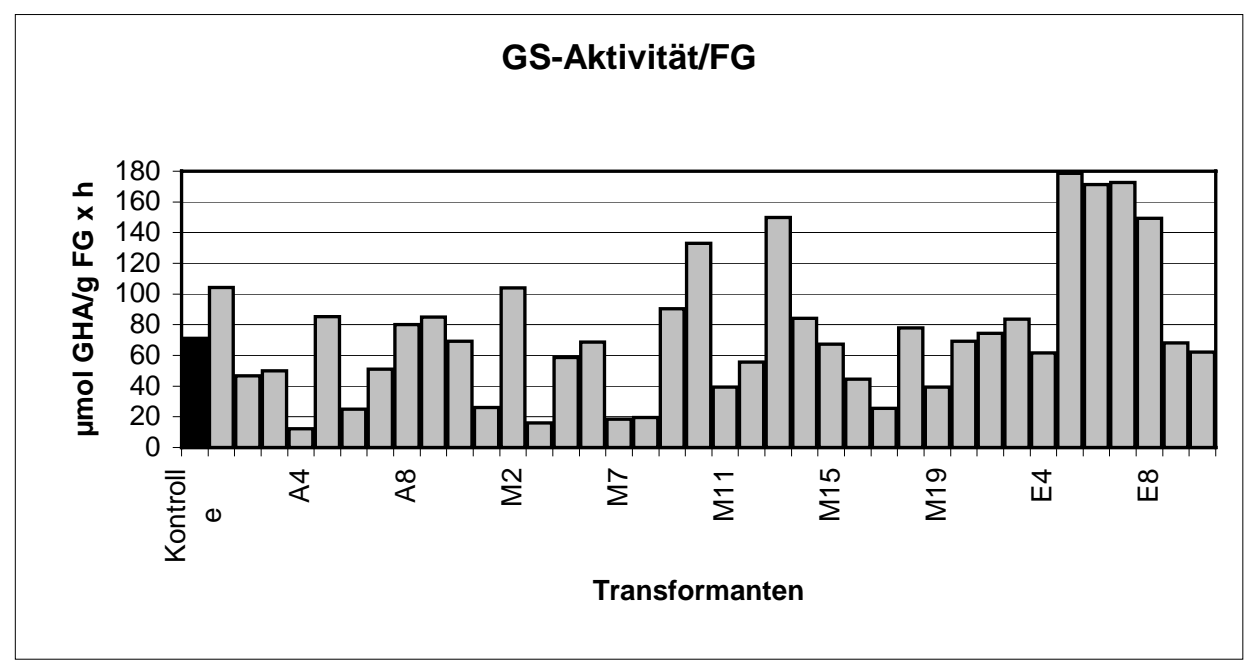

Abb. 20: GS-Aktivitäten bezogen auf das Frischgewicht. Die Darstellung entspricht Abb. 19 


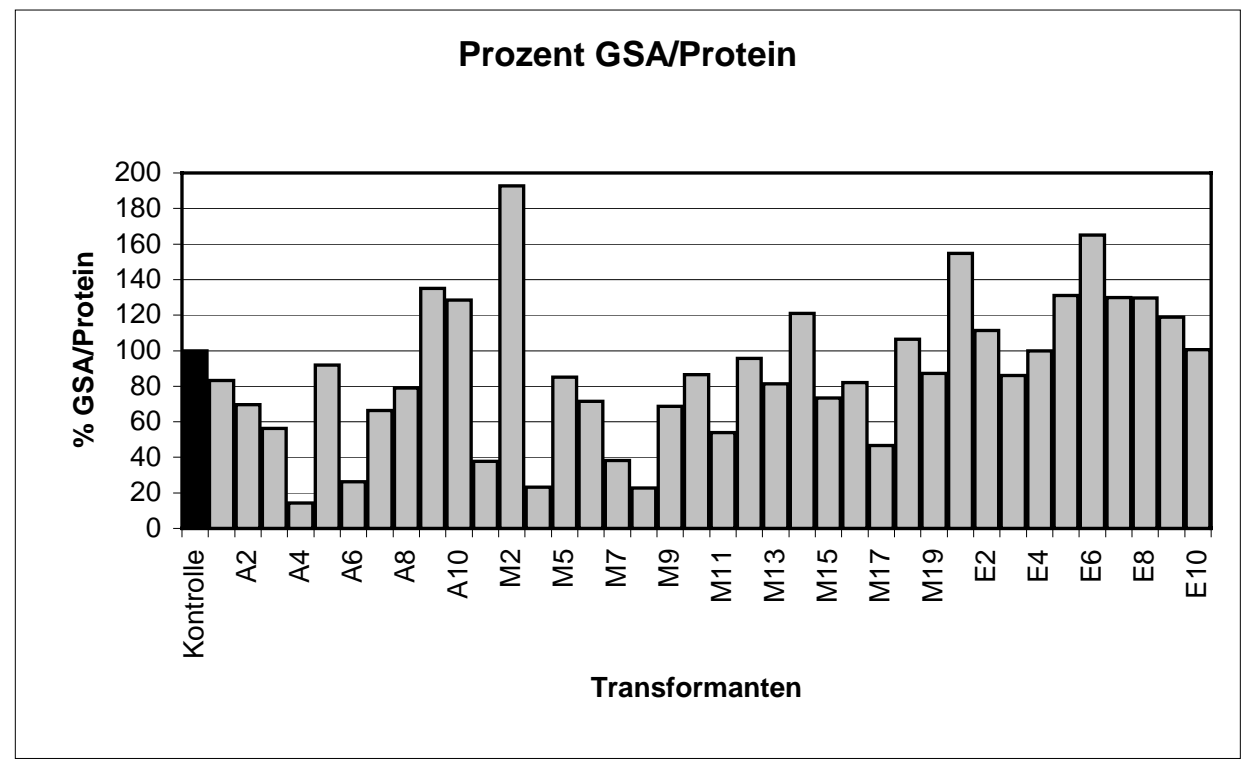

Abb. 21: GSA/Gesamtprotein in Prozent bezogen auf die jeweilige Kontrolle (100 \%). Die Darstellung entspricht Abb. 19.

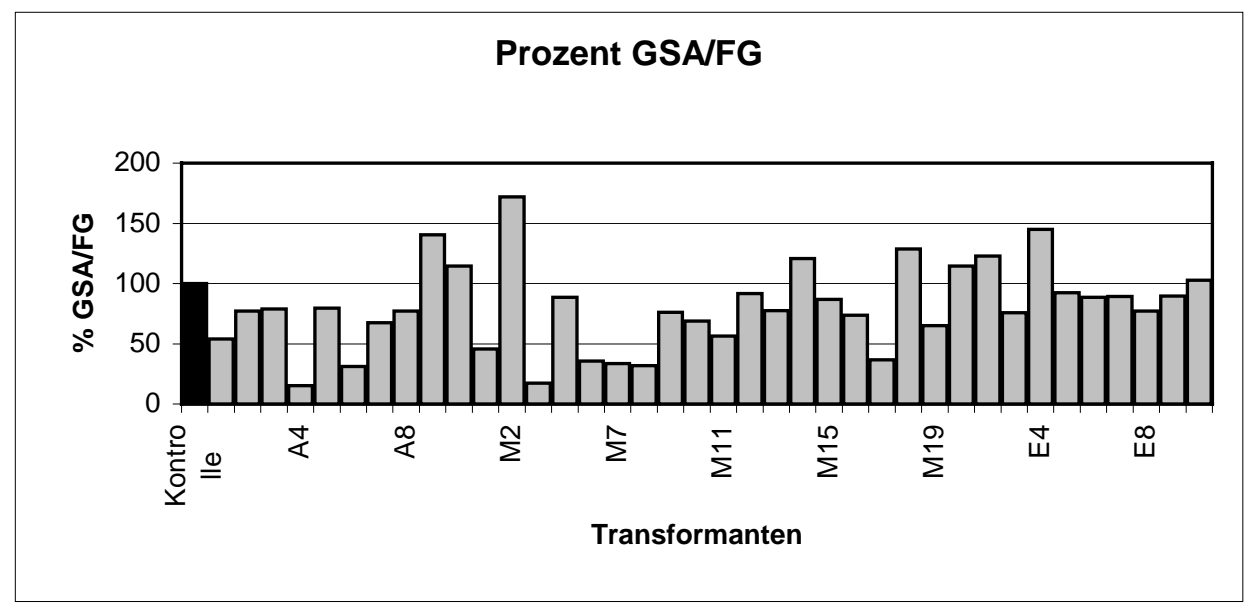

Abb. 22: GSA/Frischgewicht in Prozent bezogen auf die jeweilige Kontrolle (100\%).

Die Darstellung entspricht Abb. 19. 

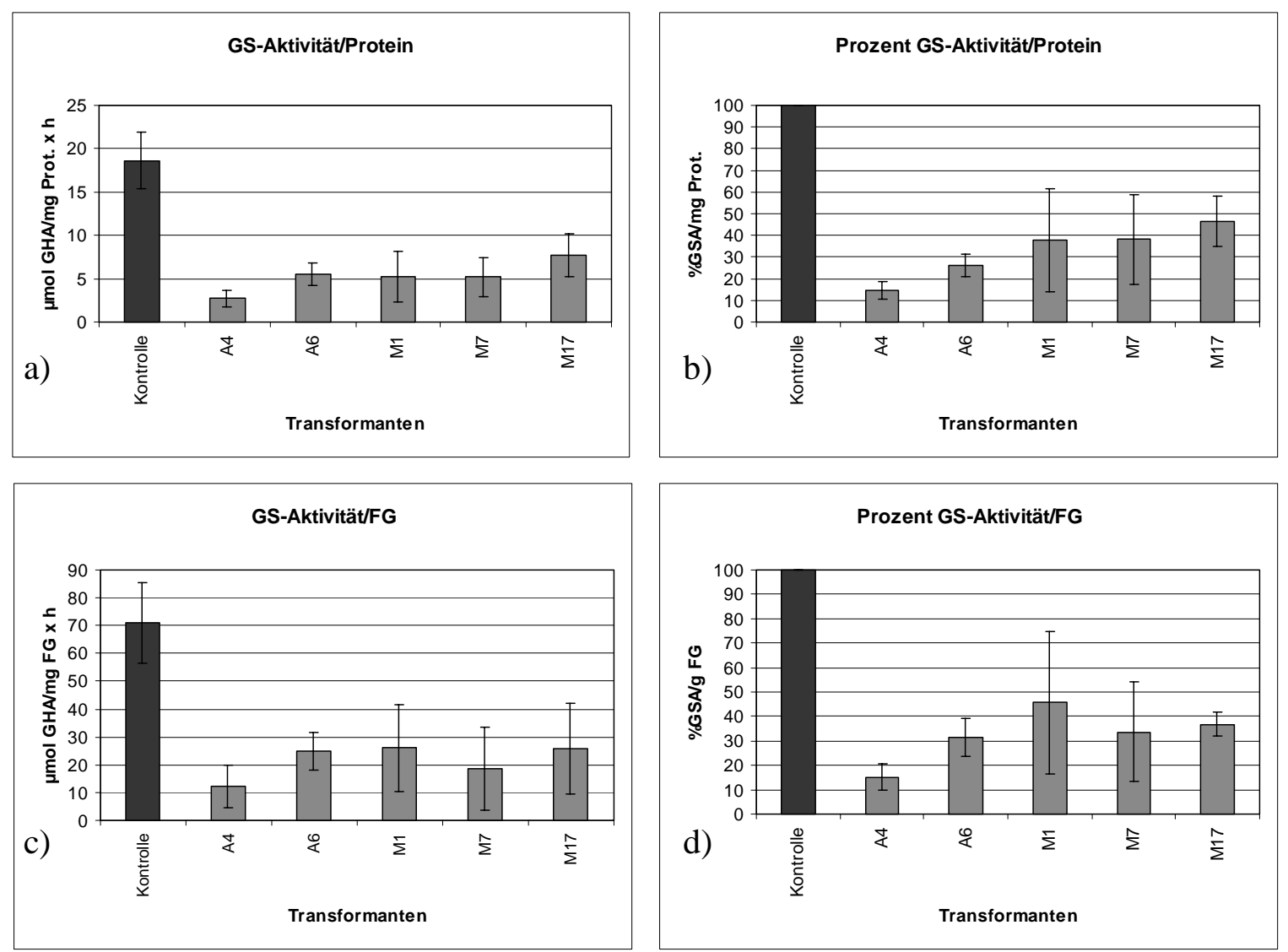

Abb. 23: a) GS-Aktivitäten bezogen auf das Gesamtprotein

b) GSA/Gesamtprotein in Prozent bezogen auf die jeweilige Kontrolle (100\%)

c) GS-Aktivitäten bezogen auf das Frischgewicht

d) GSA/Frischgewicht in Prozent bezogen auf die jeweilige Kontrolle (100 \%)

Die Auswertung der GSA-Tests der Transformanten A4, A6, M1, M7 und M17 ist in Tabelle 2 dargestellt. Alle diese Transformanten weisen signifikante Reduzierungen der GS-Aktivität auf. Die Aktivitäten liegen zwischen $14 \%$ und $47 \%$ gegenüber der Aktivität der Kontrollwurzel (100\%).

\begin{tabular}{|l|c|c|c|c|c|c|}
\hline & Kontrolle & A4 & A6 & M1 & M7 & M17 \\
\hline$\mu$ mol GHA/mg Prot. $\mathrm{x}$ & 19 & 3 & 6 & 5 & 5 & 8 \\
\hline$\mu$ mol GHA/g FG x h & 71 & 12 & 25 & 26 & 19 & 26 \\
\hline$\%$ GSA/mg Protein & 100 & 14 & 26 & 38 & 38 & 47 \\
\hline$\%$ GSA/g FG & 100 & 15 & 31 & 46 & 34 & 37 \\
\hline Anzahl der Messungen & 16 & 7 & 14 & 9 & 7 & 8 \\
\hline
\end{tabular}

Tabelle 2: Ergebnisse der GS1-Aktivitätstests 


\section{DISKUSSION}

\subsection{Phagenscreening}

Um bei einem Phagenscreening ein spezielles Gen detektieren zu können, ist es erforderlich abschätzen zu können wie viele Phagenplaques auf den Agarplatten überprüft werden müssen. Bei einem Screening einer genomischen Phagenbank muß die Genomgröße des untersuchten Objekts und die durchschnittliche Größe der in die Phagen integrierten Fremd-DNA bekannt sein, um die Mindestanzahl der zu überprüfenden Plaques zu ermitteln. Das haploide Genom der diploiden Zuckerrübenzelle beträgt ca. $1,2 \times 10^{9}$ bp und ist auf 18 Chromosomen verteilt (HEMLEBEN, 1990). Die durchschnittliche Größe eines Inserts die z. B. in einen Lambda DASH Phage (Stratagene) einkloniert werden kann beträgt $16 \mathrm{~kb}$, so daß mindestens $1,5 \times 10^{5}$ Phagen überprüft werden müssen, um einmal das gesamte Genom zu erfassen.

Die Zahl der zu untersuchenden Phagenplaques einer cDNA-Phagenbank ist dagegen schwer zu bestimmen. Eine cDNA-Phagenbank repräsentiert nur die mRNA von Genen, die zum Extraktionszeitpunkt exprimiert wurden. Die mRNA-Population eines Organismus kann stark unterschiedlich sein, je nach dem Alter des Organismus, dem Organ aus dem die mRNA gewonnen wurde oder der Tageszeit. Auch die Ernährung und andere Einflüsse können die Quantität und die Qualität der mRNA verändern.

Als Richtwert wurde in dieser Arbeit davon ausgegangen, daß in höheren Pflanzen etwa 10000 - 30000 Gene gleichzeitig exprimiert werden (HEMLEBEN, 1990). Die mRNAs liegen dabei jedoch nicht einzeln vor, sondern je nach mRNA in einer stark unterschiedlichen Anzahl von Kopien. Nach der Kopienanzahl werden mRNAs in drei Klassen gegliedert, die Klasse der häufigen mRNAs ist mit einer Kopienzahl von bis zu 12000 Kopien pro Zelle vertreten, wobei nur wenige Gene so häufig transkribiert werden. Die mittlere Klasse der mRNAs besitzen bis zu 300 Kopien pro Zelle und die Klasse der seltenen mRNAs, die den Großteil der exprimierten Gene vertreten, liegen in bis zu 15 Kopien pro Zelle vor (ALBERTS, 1986). Damit möglichst von jedem mRNA-Klon eine cDNA-Kopie bei einem Phagen-Screening vertreten ist, wurden pro Erst-Screening ca. 120000 pfu überprüft, das entspricht in etwa der 4 - 12fachen Menge an exprimierenden Genen. 
Die cDNA-Banken, die für das Screening verwendet wurden, waren aus Zuckerrübengeweben erstellt, welche mit hoher Wahrscheinlichkeit die GS1-mRNA beinhalten. Seneszentes Blattgewebe diente für eine cDNA-Bank als Ausgangsmaterial. Denn im Blattgewebe von Brassica napus wurde mit beginnender Seneszenz, die durch Abnahme des Chlorophyllgehalts gekennzeichnet ist, ein Anstieg der GS1-mRNA-Menge nachgewiesen (BUCHANAN-WOLLASTON und AINSWORTH, 1997). Auch in Oryza sativa (KAMACHI et al., 1991, 1992), Radieschen (WATANABE et al., 1994) und anderen Spezies (Higashi et al., 1998; Bernhard und Mantile, 1994; Perez-Rodriguez und VALPUESTA, 1996) wurde eine seneszenzabhängige Zunahme der GS1-Expression gezeigt. Bei der Zuckerrübe konnten MÄCK und TISCHNER (1994) einen Aktivitätsanstieg der GS1 in Blättern bei einsetzender Seneszenz nachweisen.

Eine andere cDNA-Bank wurde mit extrahierter mRNA aus Wurzelgewebe erstellt und von: N. SANDAL, Laboratory of Gene Expression, University of Aahus, Denmark bezogen. Denn die cytosolische GS1 kommt im Gegensatz zur plastidären GS2 hauptsächlich in photosynthetisch inaktiven Pflanzengeweben wie z.B. den Wurzeln vor (HIREL et al., 1984; GROAT und SHRADER, 1982; LARA et al., 1983). Bei GS1-Aktivitätstest von verschiedenen Zuckerrübengeweben zeigte sich außerdem die höchste spezifische Aktivität in den Faserwurzeln und es konnte in 2D-PAGEs gezeigt werden, daß die GS1-Untereinheiten in der Wurzel mit denen des Blattes identisch sind (BRECHLIN, 1995).

Trotz der oben genannten Voraussetzungen konnte aus der cDNA-Bank auf der Basis seneszenten Blattgewebes, auch nach mehrmaligem Plattieren, keine GS1 detektiert werden. Da die RNA, die für die Präparation der cDNA-Bank eingesetzt wurde, intakt war und nicht durch RNAsen degradiert (Abb. 3), die Synthese der cDNA im Falle des radioaktivem Parallelansatzes ein gutes Resultat bezüglich der cDNA-Größen zeigte (Abb.4) und nach Variationen der Hybridisierungsbedingungen (Herabsetzung der Stringenz, Hybridisierung bei $58^{\circ} \mathrm{C}, 16 \mathrm{~h}$ ) zwei vollständige Klone der GS2 gefunden wurden, kann davon ausgegangen werden, daß die cDNA-Bank grundsätzlich in Ordnung war. Da für das Phagen-Screening die Phagen-cDNA-Bank nicht amplifiziert worden ist, kann ein Verlust von cDNA-Klonen durch unsymmetrische Amplifikationsereignisse ausgeschlossen werden. Das dennoch keine GS1-Klone gefunden wurden, kann darauf zurückzuführen sein, daß trotz Verwendung seneszenten Blattmaterials, in der die GS1 besonders aktiv ist, keine oder nur geringe Mengen an GS1-mRNA isoliert wurden die bei den Präparationsschritten der cDNA-Bank verloren gingen. 


\subsection{In vitro Transkription/Translation}

In verschiedenen höheren Pflanzen wurden oft mehrere Gene gefunden, die für GS1Untereinheiten kodieren (Brassica napus: 2 GS1-Gene, BUCHANON-WOLLASTON und Ainsworth, 1997; Medicago truncatula: 3 GS1-Gene, StAnford et al., 1993; Pisum sativum: 3 GS1-Gene, WALKER et al., 1995). Bei 2D-PAGE-Untersuchungen von Beta vulgaris L. bezüglich der Proteinzusammensetzung des GS1-Oktamers, wurden bis zu vier Protein-Spots gefunden, die bei einer Größe von ca. 43 kDa lagen (BRECHLIN, 1995). Dieser Befund legte den Schluß nahe, daß auch in der Zuckerrübe mehrere Gene für verschiedene GS1-Untereinheiten kodieren.
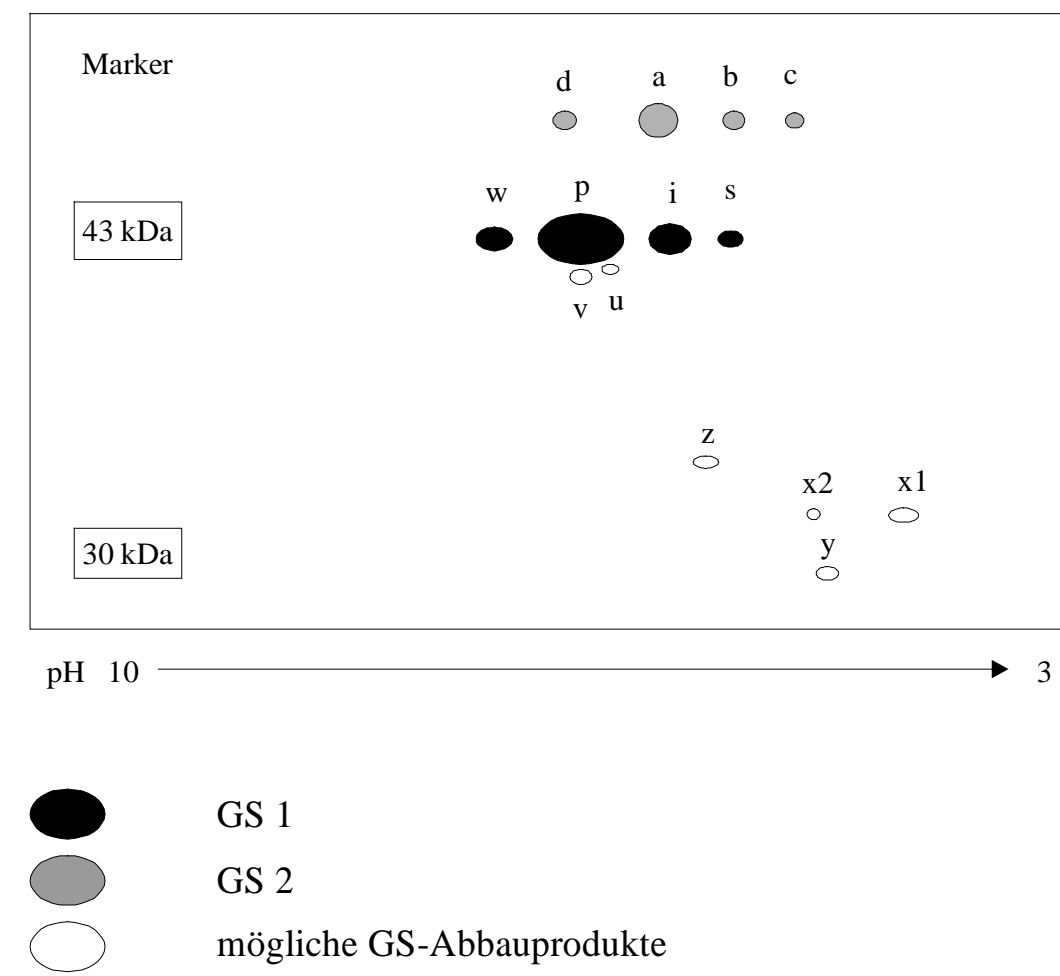

Abb. 24: Schema der GS-Protein Verteilung im 2D-PAGE (nach BRECHLIN, 1995).

Bei der hier beabsichtigten Antisense-Repression der GS1 sollte nur die ProteinUntereinheit „P“ an ihrer Expression gehindert werden, da diese als einzige GS1-UE in seneszenten Zuckerrübenblättern im 2D-PAGE nachgewiesen werden konnte (BRECHLIN et al., 1999). 
In den in vitro Transkriptions/Translations-Untersuchungen wurde von der klonierten Zuckerrüben cDNA-Sequenz der GS1 ein radioaktiv markiertes Protein synthetisiert. Dieses Protein wurde wie unter Kap. 3.3 angegeben in 2D-PAGEs aufgetrennt und nach Western Blotting wurde von den Membranen eine Autoradiographie erstellt. Da das in vitro synthetisierte Protein von einem einzigen Gen abstammt, konnte erwartet werden, daß das radioaktiv markierte Protein auch nur ein Signal auf dem Röntgenfilm erzeugen würde. Dies war bei einigen Versuchen jedoch nicht der Fall. Neben dem Hauptspot, der in allen Versuchen auftrat und eindeutig als Untereinheit „P“ identifiziert werden konnte, erschienen bei einigen Versuchen auch schwächere Signale, die den Spots „W“, „I“ und „S“ zugeordnet werden konnten.

Dieses Ereignis wirft die Frage auf, wie diese zusätzlichen Signale entstehen können. Durchgeführte Blindversuche (ohne cDNA) lieferten kein radioaktives Protein. Daher müssen alle Signale von Proteinen stammen, die von der eingesetzten GS1-cDNA transkribiert und translatiert wurden. Die detektierten Spots zeigen keine auffälligen Größenunterschiede sie liegen alle bei ca. $43 \mathrm{kDa}$. Sie unterscheiden sich nur durch verschiedene isoelektrische Punkte. Da die Proteine mit den verschiedenen isoelektrischen Punkten von einem einzigen Gen kodiert werden, scheint eine posttranslationale Modifikation des in vitro synthetisierten Proteins vorzuliegen. Das Reticulocytenlysat, das für die Translation verwendet wurde, enthält viele Enzyme und Substanzen, die für die Translation notwendig sind. Aktive Modifikationen des in vitro translatierten Proteins durch den Enzym-Apparat des Reticulocytenlysats, wie z. B. Phosphorylierungen durch Phosphokinasen sind denkbar. Auch degenerative Veränderungen, wie die Oxidation der Proteine, sind möglich (ORTEGA et al., 1999; RivetT und Levine, 1990). Da die Spots des in vitro erzeugten Proteins mit den Spots des Blattextraktes übereinstimmen, ergibt sich daraus, daß alle in der Zuckerrübe vorkommenden $43 \mathrm{kDa}$ Untereinheiten der GS1 möglicherweise von nur einem Gen kodiert werden und das Genprodukt posttranslational modifiziert wird wobei die gezeigten verschiedenen Untereinheiten entstehen. 


\subsection{Der ,Hairy Root"“-Modellorganismus}

Das „Hairy Root“"-System ist als Modell gut geeignet, um die Wirksamkeit von AntisenseGenkonstrukten relativ schnell zu testen. Gegenüber einer Transformation nur mit einem A. tumefaciens Bakterienstamm, zur Regeneration vollständiger Zuckerrübenpflanzen, ist die Cotransformation sowohl mit A. tumefaciens als auch mit $A$. rhizogenes effektiver.

Für die Kontrollen wurde jedoch noch eine zusätzliche Transformation von ZuckerrübenBlattstielen durchgeführt, die nur mit A. rhizogenes erfolgte. Diese Transformanten bilden ebenfalls nur Faserwurzeln („Hairy Roots“), die GS-Expression entspricht aber der Expression von Faserwurzeln des Zuckerrüben Wildtyps.

Die nach der Transformation selektierten Wurzeln lassen sich unter sterilen Bedingungen auf Agarplatten einfach und platzsparend kultivieren und bilden in Flüssigkultur genügend Biomasse für die verschiedensten Untersuchungen. Sie zeigen eine stabile Expression aller Wurzel-spezifischen Stoffwechselwege (FLORES et al., 1993) und können als Modell für verschiedene Untersuchungen eingesetzt werden.

Die „Hairy Roots“ sind jedoch nur ein Modellsystem. Gerade in dieser Arbeit, bei der die Reduktion der GS1-Aktivität im Vordergrund stand, wird deutlich, daß die Ergebnisse nicht uneingeschränkt auf vollständige Zuckerrübenpflanzen übertragbar sind. Bei intakten Zuckerrübenpflanzen überwiegt im reifen Blatt die Aktivität der GS2. In den „Hairy Roots“ ist dagegen die GS2 kaum vorhanden. Eine vollständige Ausschaltung der GS1Aktivität würde bei den Wurzeln sehr wahrscheinlich lethal wirken, weil eine ausreichende Stickstoffassimilierung nicht gewährleistet wäre. Einige der Transformanten zeigten wohl deshalb auch ein so geringes Wachstum, daß sie nicht in ausreichender Menge kultiviert werden konnten und noch vor den ersten Untersuchungen abstarben. Eine solch schädliche Wirkung ist für intakte Zuckerrüben-Transformanten nicht $\mathrm{zu}$ befürchten, da die Stickstoffassimilierung hier überwiegend im grünen Blatt durch die GS2 gesichert ist.

Die Frage, ob durch Reduktion der GS1-Aktivität in intakten Zuckerrüben weniger Glutamin in die Speicherwurzel eingelagert wird, kann das „Hairy Root“-System nicht beantworten. 


\subsection{GS1 antisense DNA-Fragmente}

Die Effektivität einer Reduzierung der Genexpression mit der antisense RNA-Technik hängt nicht allein von der Stärke des verwendeten Promoters ab, sondern unterliegt auch Faktoren, die nicht beeinflussbar sind oder über deren Mechanismen noch zu wenig bekannt ist. Diese Faktoren sind der Integrationsort des Antisense-Konstrukts in das Wirtsgenom, die Kopienzahl mit der es in das Genom einer Zelle integriert wird, die Länge der Antisense-DNA und deren Basensequenz (VAN DER KROL et al., 1988). Aufgrund dieser Faktoren erhält man immer eine Population von Transformanten, die das zu hemmende Gen unterschiedlich stark exprimieren.

Durch die Verwendung von drei verschiedenen DNA-Fragmenten des GS1-Gens der Zuckerrübe in antisense Orientierung sollte hier ein möglichst effizienter GS1Sequenzabschnitt zur Reduzierung der GS-Aktivität in den Zuckerrüben „Hairy Roots“ ermittelt werden.

Da zu Beginn dieser Arbeit davon auszugehen war, das die GS1 der Zuckerrübe von einer Multigenfamilie codiert wird (BRECHLIN, 1999), aber nur ein einziges spezielles Gen der GS1 reprimiert werden sollte, wurden für zwei der Antisense-Genkonstrukte die GS1Fragmente so ausgewählt, daß sie Sequenzen der untranslatierten Regionen (UTR) enthielten. Dadurch sollte die Spezifität gegen das zu reprimierenden Gens erhöht werden. Denn bei Intronbereichen und der 5'- und 3'-UTR lassen sich auch bei Genfamilien der GS1 in der Regel keine hohen Sequenzhomologien nachweisen (DuBOIS et al., 1996; WALKER et al., 1995; WATANABE et al., 1994). Da die Sequenz des codierenden Teils des GS1-Gens bereits zu GS1-Genen anderer Pflanzen (V. aconitifolia: 81 \%, Lin et al., 1992; O. sativa: $81 \%$, Sakamoto et al., 1989; L. japonicus: $80 \%$, Thykjaer et al., 1997) große Homologie aufweist, war davon auszugehen, daß die Homologie zu anderen GS1-Genen einer möglichen Multigenfamilie in der Zuckerrübe ebenfalls sehr hoch sein würde. Bei einem Einsatz von Antisense-Fragmenten des codierenden Teils der Sequenz könnte es daher zu einer unerwünschten Reduzierung der Expression anderer GS-Gene kommen. TEMPLE et al. (1998) konnten durch den Einsatz einer Sequenz aus dem 3' UTR in antisense Orientierung, gezielt den mRNA-Gehalt einer einzigen GS1-Subspezies in Alfalfa verringern, ohne die Expression eines zweiten GS1-Gens, das auf DNA-Ebene bis zu $82 \%$ mit dem ersten GS1-Gen homolog ist, zu beeinflussen.

Die Sequenzen der in dieser Arbeit eingesetzten GS1-DNA-Fragmente wurden mit der 
gefundenen Sequenz der Zuckerrüben-GS2 verglichen, um einen Anhaltspunkt zu bekommen, inwieweit die einzelnen Antisense-Fragmente die Expression der GS2 beeinflussen könnten. Das erste DNA-Fragment, Fragment A ( 320 bp) aus dem 5' -UTR und dem Anfangsbereichs des kodierenden GS1-Gens, zeigt auf DNA-Ebene eine Homologie von $60 \%$ mit der GS2. Das Fragment M ( 770 bp) aus dem Mittelteil des GS1-Gens weist eine 73 \%ige Homologie zur GS2 auf. Die Homologie des dritten Fragments, das Fragment E ( 230 bp) aus dem 3' UTR-Endbereiches des GS1-Gens, beträgt nur $41 \%$ zur plastidären GS2.

Da das Antisense-Genkonstrukt (Typ E), das die Sequenz der 3' UTR enthielt, die geringste Homologie zur GS2 aufweist, wäre es theoretisch am besten für die Transformation geeignet. Denn die hohe Spezifität des Konstrukts E minimiert eine mögliche Beeinflussung der Expression der GS2. Es zeigte sich jedoch nach den Untersuchungen der transgenen „Hairy Roots“, daß die Transformanten des Typs E keine signifikante Reduzierung der GS1-Aktivität aufwiesen (Der Transformant E 3 zeigt zwar im Mittel eine Reduzierung der GS1-Aktivität um 20\%, besitzt aber eine Standardabweichung von ca. 17 \%). Da, wie bereits oben erwähnt, Antisense-Repression von Genen mit 3' UTR-Sequenzen schon erfolgreich durchgeführt wurden (bis zu $80 \%$ weniger GS1-mRNA, TEMPLE et al., 1998), ist auszuschließen, daß eine AntisenseRepression mit einer Sequenz der 3’ UTR grundsätzlich nicht erzielt werden kann. Es ist möglich, daß das Antisense-Genkonstrukt des BIN E Vektors durchaus zu einer Reduzierung der GS1-Expression führen kann, aber die Zahl der selektierten Transformanten des Typs E (10 unabhängige Transformanten) zu gering war, um einen Transformanten mit deutlich verringerter GS-Aktivität zu finden. Es kann aber auch nicht ausgeschlossen werden, daß die mRNA-Sequenz des Antisense-Genkonstrukts E für eine Verringerung der GS1-mRNA grundsätzlich nicht geeignet ist.

Die beiden anderen eingesetzten Genkonstrukte lieferten dagegen Transformanten mit deutlich reduzierter GS1-Aktivität. Das Genkonstrukt A verursachte bei 5 von 10 Transformanten eine Reduzierung der GS1-Aktivität (30\% - $86 \%$ Reduktion) und bei dem Genkonstrukt M zeigten 7 Transformanten von insgesamt 18 eine deutliche GS1Aktivitätsreduzierung (20\%-66\% Reduktion). Die Konstrukte A und M sind für die Reduzierung der GS-Aktivität mit der antisense RNA-Technik besser geeignet als das Konstrukt E. 


\subsection{Southern Blot}

Der Southern Blot (Abb. 14) zeigt für die mit Hind III und für die mit BamH I geschnittene genomische DNA der Kontrollwurzeln jeweils eine Bande. Die Bande der Hind III verdauten genomischen DNA liegt bei ca. 3,6 kb, die Bande der BamH I geschnittenen DNA liegt bei ca. 3,2 kb. Dieses Ergebnis deckt sich mit den von Schill (1998) gezeigten Ergebnissen mit Southern Blots aus Zuckerrübenkeimlingen.

Die Signale der Transformanten M1, M7 und M17, die von den eingeschleusten AntisenseKonstrukten stammen, sind um ein vielfaches stärker als die Signale, die die genomische GS1-Sequenz erzeugte, obwohl diese Banden von größeren DNA-Fragmenten stammen. Wenn zwei DNA-Fragmente eines Verdaus äquimolar vorliegen und die Homologie der Sonde zu beiden Fragmenten gleich hoch ist (wie hier), dann kann das Signal von dem kleineren Fragment nicht stärker sein als das des größeren Fragments. Dies deutet darauf hin, daß diese Transformanten das Antisense-Gen mehrfach in ihr Genom integriert haben und somit ein stärkeres Signal liefern können, als eine einzelne Kopie.

Das Antisense-Konstrukt des Typs A der Transformanten A4 und A6 ist bei dem Hind III/EcoR I Verdau nur sehr schwach nachweisbar. Die schwachen Signale sind möglicherweise darauf zurückzuführen, daß diese Konstrukte nur einfach in das Genom dieser Transformanten eingebaut wurden.

Im Vergleich mit den GS1-Aktivitäten (Kontrolle=100 \%) der Transformanten A4 (14\%), A6 (26 \%), M1 (38 \%), M7 (38 \%) und M17 (37 \%) bedeutet das, daß die Mehrfachkopien in den Transformanten M1, M7 und M17 zu keiner stärkeren Reduktion der GS1 führen als die mutmaßlichen Einzelkopien der Transformanten A4 und A6. Das zeigt, daß das Konstrukt A eine wesentlich effektivere Hemmung der GS1-Aktivität ermöglicht als das Konstrukt M.

Es fällt auf, das jedes Konstrukt entweder als Mehrfach- oder als Einzelkopie vorliegt. Es ist möglich, daß die große Effizienz des Konstrukts A bei der Repression der GS1 bewirkt, daß der Einbau mehrerer Konstrukte dieses Typs die gesamte GS-Aktivität ausschaltet, was für die „Hairy Roots“ wahrscheinlich lethal wirken würde. Denn da die Wurzeln nur geringste Mengen an GS2 bilden, würde der N-Metabolismus völlig zum Erliegen kommen.

Das in dem gezeigten Southern Blot (Abb. 14) alle Transformanten des Typs M einen 
multiplen Einbau des Konstrukts M aufweisen kann eine Folge der Auswahl sein. Für den Southern Blot wurden Transformanten ausgewählt, die eine hohe Reduktion der GS1Aktivität zeigten. Wenn das Konstrukt M schwächer wirkt als das Konstrukt A, dann sind mehr Kopien dieses Konstrukts notwendig, um die gleiche Wirkung zu erzielen.

\subsection{Northern Blot}

Der in Kap. 3.7. dargestellte Northern Blot (Abb. 15b) zeigt nur in der Spur mit der aufgetragenen Kontrollwurzel eine distinkte Bande bei ca. 1,4 kb, der Größe die der GS1mRNA entspricht. Ein schwacher „Schmier“ ist in allen Spuren zu erkennen und wahrscheinlich auf unspezifische Bindungen der Sonde zurückzuführen die beim Waschen von der Membran nicht vollständig entfernt wurden. In den Spuren der Transformanten M1 (Spur 4) und der Transformante M17 (Spur 6) ist ein stärkerer „Schmier“ zu sehen, der in der Höhe der 1,4 kb Bande der Kontrollwurzel beginnt und sich zu niedrigeren Molekulargewichten hin erstreckt. Dieser „Schmier“ ist auf eine Degradation der GS1mRNA wegen der Anwesenheit der Antisense-mRNA zurückzuführen (BOURQUE, 1995; JiANG et al, 1994). Das Foto des RNA-Gels (Abb. 13 a) von dem der Blot erstellt wurde zeigt zwar ebenfalls einen „RNA-Schmier“ in allen Spuren, der repräsentiert aber die mRNA, die durch die große Menge an eingesetzter Gesamt-RNA (25 $\mu \mathrm{g})$ stärker in Erscheinung tritt. Die rRNAs sind als deutliche Banden zu erkennen und erscheinen nur wegen der großen Menge an aufgetragener Gesamt-RNA auf dem Gelfoto (Abb. 15a) durch Überbelichtung diffus. Die deutlichen rRNA-Banden zeigen, daß eine unspezifische Degradation durch RNAsen ausgeschlossen werden kann.

\subsection{D-PAGE}

Nach 2D-PAGE, Western Blotting und Immunodetektion mit spezifischen GS-Antikörpern zeigen bei der Kontrollwurzel die drei bei 43 kDa liegenden Spots, die mit „W“, „P“ und „I“ bezeichnet wurden (Brechlin, 1995). Zusätzlich ist noch ein Spot mit einem geringeren 
Molekulargewicht zu erkennen, der den gleichen isoelektrischen Punkt besitzt, wie der Spot mit der Bezeichnung „P“ und ein mögliches Abbauprodukt des GS1-Proteins darstellt. Western Blots nach 2D-PAGE von den ausgewählten Transformanten A4 und A6 zeigen nur einen Spot. Dieser Spot zeigt bei gleicher Menge an eingesetztem Gesamtprotein $(35 \mu \mathrm{g})$ deutlich weniger GS1-Protein als die Kontrollewurzel. Der eine GS1- Spot, der Transformante A6 ist nach dem in Kap. 3.8.2. gezeigten Ergebnissen dem Spot mit der Bezeichnung „P“ zuzuordnen.

Das bei der Transformation eingesetzte Antisense-Gen des Typs A enthält neben dem Anfangsbereich der kodierenden Sequenz auch die 5' UTR, die kaum Sequenzähnlichkeiten mit möglichen anderen GS1-mRNAs einer Multigenfamilie besitzen dürfte (Dubois et al., 1996; WALKer et al., 1995; WATANABE et al., 1994). Wenn die Hypothese zutrifft, daß die verschiedenen 43 kDa großen GS1-Spots der Zuckerrübe, die in 2D-PAGEs nachgewiesen werden können, von Proteinen stammen, die durch verschiedene GS1-Gene kodiert werden, dann hätte bei der Transformante nur der Spot mit der Bezeichnung „P“ an Intensität abnehmen dürfen. Auf die Proteinmenge der Spots mit der Bezeichnung „W“ und "I“ hätte die Transformation keinen Einfluß haben sollen. Da aber alle Proteinspots an Intensität abgenommen haben kann das Konstrukt A entweder die Expression der möglichen verschiedenen GS1-Gene ebenfalls beeinflussen, denn die Antisense-mRNA des Typs A enthält auch Sequenzen des kodierenden Bereichs der GS1 und eine Beeinflussung ist deshalb nicht auszuschließen oder die verschiedenen Untereinheiten sind posttranslational modifiziert und werden nur durch ein einziges Gen kodiert.

\subsection{GS-Aktivitätstest}

Der GS-Aktivitätstest, so wie er in dieser Arbeit durchgeführt wurde, ist eine diskontinuierliche Messung, bei der im Gegensatz zu einer kontinuierlichen Messung, nur ein Messpunkt pro Ansatz erhoben wird. Eine Veränderung der Reaktionsgeschwindigkeit über den gesamten Messzeitraum hinweg kann somit nicht verfolgt werden und führt z. B. bei einem Absinken der Reaktionsgeschwindigkeit $\mathrm{zu}$ einem scheinbar geringerem Aktivitätswert. 
Bei in vitro Untersuchungen der GS-Aktivität fand Elliot (1955) eine Proportionalität des gebildeten GHA zum eingesetzten Enzym bis zu einer Konzentration von 1,3 mM GHA und Rowe et al. (1970) zeigt eine Linearität der enzymatischen Reaktion in einem Konzentrationsbereich von 0,2 - 1,2 mM gebildetem GHA. Crauel (1998) konnte jedoch bei GSA-Messungen mit Zuckerrüben-Rohextrakt aus Blättern diese Linearität des Tests nicht bestätigen.

Um die in dieser Arbeit durchgeführten GS-Aktivitätstests miteinander vergleichen zu können, wurden immer die gleichen Inkubationszeiten und die gleichen Mengen an Wurzel-Rohextrakten gewählt. Es wurde bei jeder Messung die Aktivität von mindestens einer Kontrollwurzel mitbestimmt. So konnten eventuell auftretende Abweichungen der Messbedingungen, die z. B. durch gealterte oder frisch angesetzte Inkubationslösungen bedingt sein können, ausgeglichen werden. Parallelmessungen von Rohextrakten aus separat aufgearbeiteten Kontrollwurzeln zeigten nur geringe Schwankungen der GSAktivität. Werden die Messwerte der Proben einer Messung auf die jeweilige Kontrollprobe bezogen (in Prozent), dann sind die Messungen aus verschiedenen GSAktivitätstests direkt miteinander vergleichbar.

Die durchschnittlichen Werte der GS-Aktivitätsmessungen der Kontrollwurzeln lagen bei 18,6 $\mu \mathrm{mol} \mathrm{GHA} / \mathrm{mg}$ Protein $\mathrm{x}$ h und 71,0 $\mu \mathrm{mol}$ GHA/g FG x h. Diese Werte decken sich mit denen, die für Faserwurzeln der Zuckerrübe bestimmt worden sind (BRECHLIN, 1995). Dabei ergab sich für $\mathrm{NO}_{3}{ }^{-}$ernährte Pflanzen im Durchschnitt ca. $14 \mu \mathrm{mol} \mathrm{GHA} / \mathrm{mg}$ Protein x h und für $\mathrm{NH}_{4}$ ernährte Pflanzen ca. $25 \mu \mathrm{mol}$ GHA/mg Protein x h. Bezogen auf das Frischgewicht wurden für $\mathrm{NO}_{3}$ ernährte Pflanzen ca. $27 \mu \mathrm{mol}$ GHA/g FG ermittelt und für $\mathrm{NH}_{4}$ ernährte Pflanzen ca. $107 \mu$ mol GHA/g FGx h. Der Mittelwert der beiden gemessenen GS-Aktivitäten der jeweils unterschiedlich ernährten Pflanzen entspricht fast den Werten der „Hairy Roots“-Kontrollwurzeln, die wie auch die untersuchten Transformanten in Nährlösungen angezogen wurden, die sowohl $\mathrm{NO}_{3}$, als auch $\mathrm{NH}_{4}$ als Stickstoffquelle enthielten.

Die GS-Aktivitäten der „Hairy Roots“ unterscheiden sich entsprechend den Faserwurzeln der Zuckerrübe deutlich von den Aktivitäten der Zuckerrübenblätter, für die, je nach Blattalter, im Durchschnitt ca. 1,7 $\mu \mathrm{mol}$ GHA/mg Protein $\mathrm{x}$ h und ca. $15 \mu \mathrm{mol}$ GHA/g FG x h gemessen wurden (CRAUEL, 1998; BRECHLIN et al., 1999). 


\subsection{Das Gen der GS1 der Zuckerrübe}

In vielen höheren Pflanzen wird die cytosolische GS1, im Gegensatz zur plastidären GS2, von einer Multigenfamilie kodiert (TINGEY et al., 1988; CulLIMORE et al., 1984; FordE und Cullimore, 1989; Peterman und Goodman, 1991; Hirel et al., 1993; Lam et al., 1996; BUCHANON-WOLLASTON und AINSWORTH, 1997; STANFORD et al., 1993; WALKER et al., 1995). Auch in der Zuckerrübe wurde eine Multigenfamilie für die GS1 vermutet. Bei Untersuchungen mit der Anionenaustauschchromatographie von Zuckerrübenextrakten konnten verschiedene GS1-Holoenzyme voneinander getrennt und isoliert werden (MÄCK und TISCHNER, 1994; BRECHLIN et al., 1999) und in 2D-PAGEs wurden mehrere GS1Spots durch immunologische Methoden detektiert (BRECHLIN et al., 1999).

In dieser Arbeit konnten jedoch keine Hinweise gefunden werden, die das Vorhandensein einer Multigenfamilie für die GS1 in der Zuckerrübe bestätigen. Im Gegenteil, alle in dieser Arbeit gemachten Befunde deuten darauf hin, daß die GS1 der Zuckerrübe nur von einem Gen kodiert wird.

Die Southern Blots der genomischen DNA der Kontroll-,,Hairy Roots“ von Zuckerrüben zeigen bei verschiedenen Restriktionsverdauen jeweils nur eine Bande. Gleiche Ergebnisse zeigen Southern Blots genomischer DNA von Zuckerrübenkeimlingen.

In der Regel unterscheiden sich die Intronbereiche und die 3'- sowie 5'-UTR in ihrer DNA-Sequenz auch bei Genen einer Multigenfamilie so stark, daß Sequenzhomologien nicht mehr nachzuweisen sind (DUBOIS et al., 1996; WALKER et al., 1995; WATANABE et al., 1994). Es ist daher sehr unwahrscheinlich, daß bei unterschiedlich geschnittener genomischer DNA, die DNA-Fragmente verschiedener Gene, auch wenn sie einer Multigenfamilie angehören, immer die gleichen Größen besitzen. Eine evolutionsmäßig junge Gen-Duplikation kann jedoch zu „Zwillings-Genen“ führen, die dann auch in ihren nichttranslatierten Bereichen fast identisch sind (WALKER et al., 1995) und somit auch im Southern Blot nicht voneinander unterschieden werden können.

Die in den Southern Blots ermittelten Werte über die Größen der GS1-Fragmente verschiedener Restriktionsverdaue stimmen mit den Daten über die genomische Sequenz der GS1 aus Zuckerrübe überein (SCHILL, 1998).

Die genomische Struktur der GS1 aus Zuckerrübe (Abb. 25), soweit sie aufgeklärt werden konnte, zeigt im Vergleich mit genomischen GS1-Sequenzen anderer Pflanzen, daß die Exon/Intron-Organisation stark konserviert ist (Tabelle 3). Dies gilt nur für Größe und 
Anzahl der Exons und ist kein Hinweis auf Sequenzhomologien der Introns.

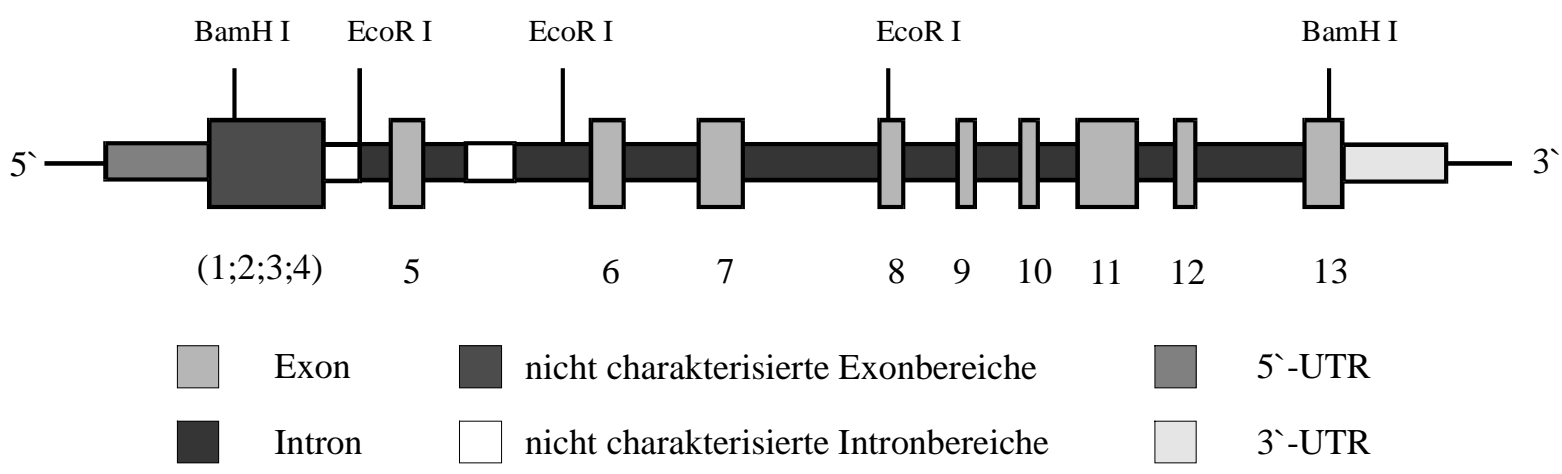

Abb. 25: Schema der genomische Organisation des GS1-Gens der Zuckerrübe (nach SCHILL, 1998).

\begin{tabular}{|c|c|c|c|c|c|}
\hline Exon & Intron & $\begin{array}{l}\text { 4.8.1.1.1.1.1 } \\
\text { eta vulgaris }\end{array}$ & Medicago sativa & Pisum sativum & Lupinus luteus \\
\hline \multirow[t]{2}{*}{1} & & $?$ & $\begin{array}{l}194 \mathrm{bp} \\
\text { mit 5-UTR }\end{array}$ & $\begin{array}{l}162 \text { bp } \\
\text { mit } 5 \text {-UTR }\end{array}$ & $\begin{array}{l}155 \text { bp } \\
\text { mit } 5 \text {-UTR }\end{array}$ \\
\hline & 1 & $?$ & & & \\
\hline \multirow[t]{2}{*}{2} & & $?$ & $40 \mathrm{bp}$ & $40 \mathrm{bp}$ & $40 \mathrm{bp}$ \\
\hline & 2 & $?$ & & & \\
\hline \multirow[t]{2}{*}{3} & & $?$ & 104 bp & $104 \mathrm{bp}$ & $104 \mathrm{bp}$ \\
\hline & 3 & $?$ & & & \\
\hline \multirow[t]{2}{*}{4} & & $?$ & $49 \mathrm{bp}$ & $49 \mathrm{bp}$ & $49 \mathrm{bp}$ \\
\hline & 4 & $?$ & & & \\
\hline \multirow[t]{2}{*}{5} & & $107 \mathrm{bp}$ & $107 \mathrm{bp}$ & $107 \mathrm{bp}$ & $107 \mathrm{bp}$ \\
\hline & 5 & $? /(91 \mathrm{bp})$ & & & \\
\hline \multirow[t]{2}{*}{6} & & $88 \mathrm{bp}$ & $88 \mathrm{bp}$ & $88 \mathrm{bp}$ & $88 \mathrm{bp}$ \\
\hline & 6 & $223 \mathrm{bp}$ & & & \\
\hline \multirow[t]{2}{*}{7} & & $129 \mathrm{bp}$ & $129 \mathrm{bp}$ & $129 \mathrm{bp}$ & $129 \mathrm{bp}$ \\
\hline & 7 & $376 \mathrm{bp}$ & & & \\
\hline \multirow[t]{2}{*}{8} & & $75 \mathrm{bp}$ & $75 \mathrm{bp}$ & $75 \mathrm{bp}$ & $75 \mathrm{bp}$ \\
\hline & 8 & $105 \mathrm{bp}$ & & & \\
\hline \multirow[t]{2}{*}{9} & & $54 \mathrm{bp}$ & $54 \mathrm{bp}$ & 54 bp & $54 \mathrm{bp}$ \\
\hline & 9 & $107 \mathrm{bp}$ & & & \\
\hline \multirow[t]{2}{*}{10} & & $38 \mathrm{bp}$ & $38 \mathrm{bp}$ & $38 \mathrm{bp}$ & $38 \mathrm{bp}$ \\
\hline & 10 & $99 \mathrm{bp}$ & & & \\
\hline \multirow[t]{2}{*}{11} & & $160 \mathrm{bp}$ & $160 \mathrm{bp}$ & $160 \mathrm{bp}$ & $160 \mathrm{bp}$ \\
\hline & 11 & $80 \mathrm{bp}$ & & & \\
\hline \multirow[t]{2}{*}{12} & & $60 \mathrm{bp}$ & $\begin{array}{l}360 \text { bp } \\
\text { mit 3`-UTR }\end{array}$ & $\begin{array}{l}417 \text { bp } \\
\text { mit 3`-UTR }\end{array}$ & $\begin{array}{l}505 \text { bp } \\
\text { mit } 3^{`}-U T R\end{array}$ \\
\hline & 12 & 472 bp & & & \\
\hline 13 & & $\begin{array}{l}89 \text { bp } \\
\text { ohne } 3 \text {-UTR }\end{array}$ & & & \\
\hline
\end{tabular}

Tabelle 3: Vergleich der GS1-Exon-Größen der Zuckerrübe mit denen aus anderen Pflanzen (nach SCHILL, 1998). 
Die genomische GS1-Sequenz wurde aus DNA-Fragmenten verschiedener Phagen-Klone einer genomischen DNA-Bank und durch PCR amplifizierte DNA-Fragmente genomischer Zuckerrüben-DNA ermittelt (SCHILL, 1998). Da alle sich überschneidenden Sequenzen einschließlich der 3'-UTR mit der in dieser Arbeit gefundenen Sequenz der GS1-cDNA zu $100 \%$ identisch sind, kann mit hoher Wahrscheinlichkeit angenommen werden, daß alle bisher gefundenen GS1-Sequenzen der Zuckerrübe von ein und demselben Gen stammen.

Obwohl bisher nur ein GS1-Gen in der Zuckerrübe gesichert nachgewiesen werden konnte, zeigen sich bei 2D-PAGEs von Zuckerrüben-Rohextrakten nach Immunodetektion mehrere Spots des GS1-Proteins.

Auch bei der in vitro Transkription/Translation der gefundenen GS1-cDNA konnten nach 2D-PAGEs in einigen Versuchen bis zu vier Spots von GS1-Untereinheiten nachgewiesen werden. Da das in vitro synthetisierte Protein von nur einem Gen exprimiert wurde, kann als Erklärung für die verschiedenen GS1-Protein-Spots eine posttranslationale Modifikation der Proteine wie z.B. die der Phosphorylierungen oder der Oxidation angenommen werden.

Eine Phosphorylierung des GS1-Enzyms konnte zwar bisher noch nicht gezeigt werden, da aber die ermittelte AS-Sequenz der GS1 in Zuckerrüben Motive für mögliche Phosphorylierungsstellen aufweist (AS 273 Serin), ist die Phosphorylierung als eine Möglichkeit der posttranslationale Modifikation für die Regulation der GS1-Aktivität in der Zuckerrübe denkbar.

Ein weiterer Hinweis darauf, daß die GS1 möglicherweise ein Phosphopeptid ist, zeigen Versuche mit 14-3-3-Proteinen, die an Proteine binden können, die in ihrer AS-Sequenz über ein Phosphoserin-Motiv verfügen (MUSLIN et al., 1996, YAFFE et al., 1997). Sowohl GS1- als auch GS2-Proteine aus Blumenkohl können 14-3-3-Proteine binden und verlieren ihre Bindungsfähigkeit nach Behandlung mit alkalischer Phosphathase (MOORHEAD et al., 1999).

Für die GS2 aus Tabak konnten Phosphorylierungen des Proteins mit einem Phosphoserinspezifischen Antikörper nachgewiesen werden (RIEDEL, 2000).

Ein posttranslationale Modifikation durch Oxidation von GS-Enzymen konnten in Bakterien und auch in Pflanzen gezeigt werden (LEVINE, 1983a; RIVETT und LEVINE, 1990; ORTEGA et al., 1999). Proteine können durch Sauerstoffradikale oxidiert werden, die 
in Pflanzen durch physiologische Prozesse wie der Photosynthese, der MitochondrienRespiration und der Stickstofffixierung entstehen (Allen, 1995; DALTON, 1995). Auch reaktive Sauerstoffverbindungen, die durch enzymatische Redoxreaktionen erzeugt werden (LEVINE et al., 1981; HARDing et al., 1997; STADTMAN und OLIVER, 1991) und verstärkt unter Streßbedingungen entstehen (ITURBE-ORMAETXE et al., 1998; LOW und MERIDA, 1996; Pell et al., 1997; LANDGRARF et al., 1997), können an Proteinoxidationen beteiligt sein. Reaktive Sauerstoffverbindungen entstehen auch verstärkt während der PflanzenSeneszenz.

In 2D-PAGE-Analysen von Sojabohnen-Wurzelextrakten konnte gezeigt werden, daß oxidierte GS-Proteine durch einen veränderten Isoelektrischen Punkt von nichtoxidierten GS-Proteinen unterschieden werden können (ORTEGA et al., 1999). In der gleichen Arbeit wurde außerdem dargestellt, daß die Oxidation der GS-Proteine ihre Aktivität reduziert und die oxidierte Form der GS einem stärkeren Abbau durch endogene Proteasen unterliegt.

Diese Befunde können erklären, warum in der Zuckerrübe verschiedene GS1-Holoenzyme mit unterschiedlich hohen Aktivitäten isoliert werden konnten (MÄCK und TISCHNER, 1994) und warum zu verschiedenen Entwicklungsstadien unterschiedlich viele Untereinheiten der GS1 gefunden werden konnten (BRECHLIN et al., 1999).

Der proteolytische Abbau von Proteinen ist abhängig von der Aktivität der Proteasen. Die Expression von endogenen Proteasen ist während der Blattseneszenz besonders hoch (BUCHANAN-Wollaston, 1997). Wenn bei der Zuckerrübe, wie für die Sojabohne gezeigt, oxidierte Formen der GS1 entstehen und diese ebenfalls sensitiver gegenüber proteolytischer Degradation sind, als ihre nichtoxidierten Formen, dann ist das Auftreten von nur einer GS1-Untereinheit (der nichtoxidierten Form) in Extrakten aus seneszenten Zuckerrübenblättern zu erwarten.

Wenn eine posttranslationale Modifikation des GS1-Proteins für die verschiedenen GS1Untereinheiten verantwortlich ist, die in 2D-PAGEs aufgetrennt werden können, dann kann auch erklärt werden, warum in den Typ A-Transformanten alle GS1-Untereinheiten reduziert werden obwohl nur ein GS1-Antisense-Konstrukt exprimiert wird. Es ist aber auch nicht auszuschließen, daß das Antisense-Konstrukt, die Expression anderer GS1Gene einer möglichen GS1-Multigenfamilie beeinflussen könnte.

Es kann nicht mit Sicherheit gesagt werden, daß die GS1 der Zuckerrübe von nur einem Gen kodiert wird und nicht von einer Multigenfamilie. Die Summe der Indizien die in 
dieser Arbeit vorgestellt werden sprechen jedoch dafür.

Für das Ziel dieser Arbeit ist die Frage, ob die GS1 der Zuckerrübe von einer Multigenfamilie kodiert wird oder nicht, nicht von ausschlaggebender Bedeutung. Es könnte sogar ein Vorteil für die Antisense-RNA-Methode sein, wenn die GS1 von nur einem Gen kodiert wird. Denn die spezifische Reprimierung eines Gens einer Multigenfamilie durch sein Antisense-Gen, könnte durch eine verstärkte Expression der anderen Gene dieser Genfamilie möglicherweise kompensiert werden. Die spezifische Hemmung der GS1 ist aber notwendig um die GS2 nicht zu beeinflussen. Ob die GS2 durch die eingesetzten Antisense-Konstrukte beeinflußt wird oder nicht konnte mit dem „Hairy Root“-System nicht geklärt werden, da die GS2 in diesem Gewebe nur in geringsten Mengen vertreten ist, ist eine Aussage darüber nicht möglich ist. Die Möglichkeit einer Reduktion der GS1-Aktivität mit der Antisense-RNA-Methode konnte dagegen für das „Hairy Root“-Modellsystem mit Erfolg gezeigt werden.

Weitere Transformations-Versuche müssen klären, ob bei vollständigen Zuckerrübenpflanzen eine Reduktion der GS1 zu einem vermindertem Glutamingehalt in der Speicherwurzel führt. Dazu erscheint die Verwendung des Antisense-Konstrukts A am geeignetsten, da die Effektivität dieses Konstrukts am höchsten ist.

Da der Glutamintransport in die Speicherrübe verstärkt mit beginnender Blattseneszenz erfolgt und um negative Auswirkungen der reduzierten GS1-Expression während des Wachstums zu vermeiden, sollte das GS1-Antisense-Konstrukt unter Kontrolle eines Seneszenz spezifischen Promotors stehen. 


\section{ZUSAMMENFASSUNG}

Von seneszentem Zuckerrübenblättern wurde eine cDNA-Bank erstellt. Mit dieser cDNABank und einer wurzelspezifischen cDNA-Bank wurde mit einer GS1-cDNA-Sonde aus Tabak ein Phagenscreening durchgeführt.

Es wurden eine vollständige cDNA der GS1 und zwei vollständige (identische) cDNAs der GS2 aus den cDNA-Banken isoliert und kloniert.

Die cDNA der Zuckerrüben-GS1 wurde in vitro transkribiert und mit ${ }^{35}$ S-Methionin translatiert und das synthetisierte Protein durch 2D-PAGE mit den Protein-Untereinheiten der Zuckerrübe verglichen. Das von der cDNA synthetisierte Protein entsprach der GS1Untereinheit „P“. Protein-Spots mit den Bezeichnungen „,““, „S“ und „W“ die ebenfalls nachgewiesen werden konnte sind möglicherweise durch posttranslationale Modifikation der GS1 entstanden.

Von der GS1-cDNA ausgehend wurden drei verschiedene Antisense-DNA-Konstrukte in BIN 19 Vektoren kloniert. Die Konstrukte enthielten je einen CaMV 35S Promoter, die Antisense-DNA (BIN A: mit der 314 bp-Sequenz aus dem 5-untranslatiertem Anfangsbereich der cDNA, BIN M: mit der 770 bp-Sequenz aus dem Mittelteil des Codierenden Bereichs und BIN E: mit dem 231 bp großer Bereich des $3{ }^{-}$-untranslatiertem Ende der Zuckerrüben GS 1-cDNA ) und eine Terminationssequenz.

Mit diesen Vektoren wurden Cotransformationen mit A. tumefaciens und A. rhizogenis von Zuckerrüben-Blattstielen durchgeführt. 10 unabhängigen Transformanten (Hairy Roots) des Typs A, 18 unabhängige Transformanten des Typs $M$ und 10 unabhängige Transformanten des Typs E konnten selektiert, regeneriert und untersucht werden.

Durchgeführte GS1-Aktivitätsmessungen zeigten für alle Messungen der Typ E-Wurzeln, bezogen auf die Kontroll-Wurzel, keine meßbare Reduzierung der GS1-Aktivität. Die transgenen Wurzeln des Typs A zeigten eine Reduzierung der GS1-Aktivitäten um bis zu $86 \%$ und die des Typs $M$ wiesen eine Reduzierung um bis zu $66 \%$ auf.

In Westernblots von SDS-Gelen und 2D-PAGEs zeigten die Transformanten des Typs A und M gegenüber den Kontroll-Wurzeln eine Reduzierung an Gesamt-GS1-Protein.

Intakte GS1-mRNA konnte in Northern Blots nur bei der Kontrollwurzel nachgewiesen werden. Das bedeutet, daß eine effiziente Expression der GS1-Antisense-Gene (Abbau der doppelsträngigen GS1-mRNA-Hybride) in den untersuchten Transformanten (Typ A und M) erfolgt. 
Southern Blots zeigen die erfolgreiche Transformation auf DNA-Ebene. Die Transformanten des Typs $\mathrm{M}$ zeigen in den Southern Blots einen multiplen Einbau der GS1-Antisense-DNA, wobei sie eine geringere Reduzierung der GS1-Aktivität aufweisen, als die Transformanten des Typs A. Dies zeigt, das die Effektivität des AntisenseKonstrukts A von allen drei Konstrukten am höchsten ist.

Hinweise darauf, daß die GS1 der Zuckerrübe durch eine Multigenfamilie kodiert wird, wie es für andere höhere Pflanzen gezeigt wurde, konnten nicht gefunden werden. Alle hier erzielten Befunde deuten darauf hin, daß die GS1 von einem einzigen Gen exprimiert wird und das die verschiedenen Untereinheiten der GS1 durch posttranslationale Modifikationen entstehen.

Für das „Hairy Root“-Modell konnte eine Repression der GS1-Aktivität erfolgreich gezeigt werden. Ob eine reduzierte GS1-Aktivität tatsächlich zu einem reduzierten Glutamingehalt in der Speicherwurzel von vollständigen Zuckerrübenpflanzen führt, kann nur in weiterführenden Versuchen geklärt werden. 


\section{LITERATURVERZEICHNIS}

Alberts B., Bray D., Lewis J., RAFF M., Roberts K. und WAtson J. D. (1986)

Molekularbiologie der Zelle.

VCH Verlagsgesellschaft

Allen C. A., HaKansson G. und Allen J. F. (1995)

Redox coditions specify the proteins synthesized by isolated chloroplasts and mitochondria.

Redox Rep 1: 119-123

Becker T. W., CABoche M., Carrayol E. und Hirel B. (1992)

Nucleotide sequence of a tobacco cDNA encoding plastidic glutamine synthetase and light inducibility, organ specifity and diurnal rhythmicity in the expression of the corresponding genes of tobacco and tomato.

Plant Mol Biol 19: 367-379

BERNHARD W. Und MANTILE P. (1994)

Differential expression of glutamine synthetase genes during the senescence of Arabidopsis thaliana rosette leaves.

Plant Sci 98: 7-14

BOURQUE J. E. (1995)

Antisense strategies for genetic manipulations in plants.

Sci 105: 125-149

BRADFORD ,M. M. (1976)

A rapid sensitive method for the quantification of microgram quantities of protein utilizing the principel of protein-dye binding.

Anal.Bio.Chem.72: 248-254

BRECHLIN P. (1995)

Die Zusammensetzung der cytosolischen Glutaminsynthetase (GS 1) der Zuckerrübe (Beta vulgaris L.) im Verlauf der Ontogenie von Blatt und Pflanze.

Diplomarbeit, Universität Göttingen

BREChLin P., Mäck G., BURbA M. und Tischner R. (1999)

Changes in the isoform pattern and subunit composition of GS-1 in sugar beet leaves depent on leaf age.

Plant Physiol 155: 497-502

BUCHANAN-Wollastan V. und Ainsworth C. (1997)

Leaf senescence in Brassica napus: cloning of senescence related genes by subtractive hybridisation.

Plant Mol Biol. 33: 821-834 
BUCHANAN-WOLLASTON V. (1997)

The molecular biology of leaf senescense.

J Exp Bot 48: 181- 199

Burba M., NitzschKe U. und RitTerbusch R. (1984)

Die N-Assimilation der Pflanze unter besonderer Berücksichtigung der Zuckerrübe. Zuckerindustrie 109: 613-627

Cock J. M., Brock I.W., Watson A. T., Swarup R., Morby A. P. und Callimore J. V. (1991)

Regulation of glutamine sythetase genes in leaves of Phaseolus vulgaris.

Plan Mol Biol. 17: 761-771

Crauel A. (1998)

Untersuchungen zur Tagesperiodizität der GS-1 in Zuckerrüben.

Diplomarbeit, Universität Göttingen

CRAWFORD N. M. (1995)

Nitrate: Nutrient and signal for plant growth.

Plant cell 7: 859-868

Cullimore J. V. und BenNetT M. J. (1988)

The molecular biology and biochemestry of plant glutamine synthetase from root nodules of Phaseolus vulgaris L. and other legumes.

J Plant Physiol 132: 387-393

Cullimore J. V., Gebhardt C., SAARElainen R., Miflin B. J., IDler K. B. und BAKeR R. F. (1984)

Glutamine synthetase of Phaseolus vulgaris L.: organ-specific expression of a multigene family.

J Mol Appl Genet 2: 589-599

DALTON D. A. (1995)

Antioxidant defenses of plants and fungi.

Oxidative stress and Antioxidant Defenses in Biology. Chapman \& Hall: 298-355

Del SAl G., MANiFioletti G. und SchneIDER C. (1989)

The CTAB-precipitation method: A common mini-scale preparation of template DNA from phagamids, phages or plasmids suitable for for sequencing.

Bio Techniques 7: 514-519

Dubois F., Brugière N., SANGwan R. S. und Hirel B. (1996)

Localization of tobacco cytosolic glutamine synthetase enzymes and the corresponding transcripts shows organ- and cell-specific patterns of protein sythesis and gene expression.

Plant Mol Biol. 31: 803-817 
DunBAR B.S., KimMURA H. und TimmONS T. M. (1990)

Protein analysis using high-resolution tow-dimensional polyacrylamide gel electrophoresis.

Methods in Enzymology 182: 441-459

EDWARDS J. W. und CORUZZI G. M. (1989)

Photorespiration and light act in concert to regulate the expression of the nuclear gene for chloroplast glutamine synthetase.

Plant Cell 1: 241-248

Edwards J. W., Walker E. L. und CoruZzi G. M. (1990)

Cell-specific expression in transgenic plants reveals nonoverlapping roles for chloroplast and cytosolic glutamine synthetase.

Proc Natl Acad Sci USA 87: 3459-3463

ELLIOT W. H. (1955)

Glutamine synthesis.

Methods in enzymology II, Article 44, Academic Press

Elmlinger M. W., Bolle C., Batschauer A., Oelmüller R. und Mohr H. (1994)

Coaction of blue light and light absorbed by phytochrome in control of glutamine synthetase gene expression in Scots pine (Pinus sylvestris L.) seedlings.

Planta 192: 189-194

Flores H. E., Dai Y., Cuello J. L., Maldonado-Mendoza I. E. und Loyola-Vargas V. M. (1993)

Green Roots: photosynthesis and photoautotrophy in an underground plant organ.

Plant Physiol 101: 363-371

Forde B. J. und CULlimore J. V. (1989)

The molecular biology of glutamine synthetase in higher plants.

Oxford Surv Plant Mol Biol 6: 247-296

Franz T. A., PETERSON D. M. und Durbin R. D. (1982)

Sources of ammonium in oat leaves treated with tabtoxin or methionine sulfoximine. Plant Physiol 69: 345-348

GIVAN C. V. (1979)

Metabolic detoxifikation of ammonium in higher plants.

Phytochemistry 18: 375-382

GLass A. D. M., SidDiQI M. Y., Ruth T. J. und RufTY T. W. (1990)

Studies of the uptake of nitrate in barley. II. Energetics.

Plant Physiol 93: 1585-1589

GOYAL S. S. und HuFFAKER R. C. (1986)

The uptake of $\mathrm{NO}_{3}^{-}, \mathrm{NO}_{2}^{-}$and $\mathrm{NH}_{4}^{+}$by intact wheat (Triticum aestivum) seedlings. Plant Physiol 82: 1051-1056) 
GROAT R. G. und SCHRADER L. E. (1982)

Isolation and immunochemical characterisation of plant glutamine synthetase in alfalfa (Medicago sativa $\mathrm{L}$.) nodules.

Plant Physiol. 70: 1759-1761

HARDing S. A., OH S-H. und RoberTs D. M. (1997)

Transgenic tobacco expressing a foreign calmodulin gene shows an enhanced production of active oxygen species.

EMBO J 16: 1137-1144

HEMLEBEN V.(1990)

Molekularbiologie der Pflanzen.

UTB Gustav Fischer

Hemon P., Robiins M. P. und Cullimore J. V. (1990)

Targeting of glutamine synthetase to mitochondria of transgenic tobacco.

Plant Mol Biol 15: 895-904

Higashi K., ShiOTA H. und Kamada H. (1998)

Patterns of expression of the genes for glutamine synthetase isoforms during somatic and zygotic embryogenesis in carrot.

Plant Cell Physiol. 39: 418-424

Hirel B., McNally S. F., Gadal P., Sumar N. und Stewart G. R. (1984)

Cytosolic glutamine synthetase in higher plants. A comparative immunological study. Eur. J. Biochem. 138: 63-66

HiRel B., Miao G. H. und Verma D. P. S. (1993)

Metabolic and developmental control of glutamine synthetase genes in legume and nonlegume plants.

Control of plant gene expression, CRC Press Boca: 443-458

Hoff T., Truong H. N. und CABoche M. (1994)

The use of mutants and transgenec plants to study nitrate assimilation.

Plant Cell Environ 17: 489-506

Horsch R. B., Fry F. E., HofFMAnN N. L., EichHoltz D., Rogers S. G. und Fraley R. T. (1985)

A simple and general method for transferring genes into plants.

Science 227: 1229-1231

Iturbe-OrmaetXe I., Escuredo P. R., ARreSe-IgOR C. und BeCANA M. (1998)

Oxidative damage in pea plants exposed to water deficit or paraquat.

Plant Physiol 116: 173-181

JiAnG C. Z., KLIEBEnStein D. E., Ke N. und Rodermel S. (1994)

Destabilization of rbcS sense transcripts by antisense RNA.

Plant Mol Biol 25: 569-576 
JOY K. W. (1988)

Ammonia, glutamate and asparagine: a carbon-nitrogen interface.

Can J Bot 66: 2103-2109

Kamachi K., Yamaya T., Hayakawa T., Mae T. und Ojima K. (1991)

A role for glutamine synthetase in the remobilization of leaf nitrogen during natural senescence in rice leaves.

Plant Physiol. 96: 411-417

KamaChi K., Yamaya T., Hayakawa T., Mae T. und Ojima K. (1992)

Changes in cytosolic glutamine synthetase polypeptide and its mRNA in a leaf blade of rice plants during natural senescence.

Plant Physiol 98: 1323-1329

KAWAKAMI N. und WATANABE A. (1988)

Senescence specific increase in cytosolic glutamine synthetase and its mRNA in radish cotelydones.

Plant Physiol 88: 1430-1434

Keys A. J., Bird I. F., Cornelius M. J., Lea P. J., Wallsgrove R. M. und Miflin B. J. (1978)

Photorespiratory nitrogen cycle.

Nature 275: 741-743

KOZAK M. (1984)

Compilation and analysis of sequences upstream from the translational start site in eucaryotic mRNA

Nucleic Acid Res 12: 857-873

Lam H. M., Coschigano K., Schultu C., Melo-Oliveira R., Tjaden G., Oliveira I., NGAi N., Hsieh M. H. und CoRUZZI G. (1995)

Use of Arabidopsis mutants and genes to study amide amino acid biosynthesis.

Plant Cell 7: 887-898

LÄMMLI U.K. (1970)

Cleavage of structural proteins during assembly of the head of bacteriophage T4.

Nature 227: 680-685

LANDGRAF P., OHMANN E. und TSCHIERSCH H. (1997)

Light induced oxidative stressin Euglena gracilis.

Photosynthetica 33: 433-442

Lara M., Cullimore J. C., Lea P. J., Miflin B. J., Johnston A. W. B. und Lamb J. W. (1983)

Appearance of a novel form of glutamine synthetase during nodule development in Phaseolus vulgaris L..

Planta 1557: 254-258 
Lara M., Porta H., Padilla J., Folch J. und SANCheZ F. (1984)

Heterogenity of glutamine synthetase polypeptides in Phaseolus vulgaris L..

Plant Physiol 76: 1019-1023

Lea P. J., Robinson S. A. und Stewart G. R. (1990)

The enzymology and metabolism of glutamine, glutamate and asparagine.

The biochemistry of plants 16: 121-159

LEVINE R. L. (1983)

Oxidative modification of glutamine synthetase. I. Inactivation is due to loss of one histidine residue.

J Biol Chem 258: 11823-11827

Li M. G., Villemur R. Hussey P. J., Silflow C. D., GantT J. S. und Snustad D. P. (1993)

Differential expression of six glutamine synthetase genes in Zea mays.

Plant Mol Biol 23: 401-407

LightFoot D. A., Green N. K. und Cullimore J. V. (1988)

The chloroplast-located glutamine synthetase of Phaseolus vulgaris L.: nucleotide sequence, expression in different organs and uptake into isolated chloroplasts.

Plant Mol Biol 11: 191-202

Lin Z., Miao G. H. und Verma D. P. (1992)

A cDNA sequence encoding glutamine synthetase is preferentially expressed in nodules of Vigna aconitifolia.

Plant Physiol 107: 279-280

LOGEMANN J., SCHELL J. und WILLMITZER L. (1987)

Improved method for isolation of RNA from plant tissues.

Anal. Biochem.163: 16-20

LOW P. S. und MERIDA J. R. (1996)

The oxidative burst in plants devense: function and signaltransduction.

Physiol Plant 96: 533-542

MÄCK G. (1988)

Untersuchungen zum Stickstoffmetabolismus in Zuckerrübenpflanzen unterschiedlicher Entwicklungsstadien.

Dissertation, Universität Göttingen

MÄCK G. und TISCHNER R. (1990)

Glutamine synthetase oligomers and isoforms in sugarbeet (Beta vulgaris L.).

Planta 181: 353-359 
MÄCK G. und TISCHNER R. (1994)

Activity of the tetramer and octamer of glutamine synthetase isoforms durng primary leaf ontogeny of sugar beet (Beta vulgaris L.).

Planta 194: 353-359

MANDEL M. und Higa A. (1970)

Calcium-dependent bacteriophage DNA infection.

J. Mol Biol. 53: 159-162

MC NALly S. F. und HiREL B. (1983)

Glutamine synthetase isoforms in higher plants.

Physiol Veg 21: 761-774

MIFLIN B. J. und LEA P. J. (1980)

The pathway of nitrogen assimilation in plants.

Phytochemistry 15: 873-885

Migge A., Carryol E., Hirel B., Lohmann M., Meya G. und Becker T. W. (1998)

Regulation of the subunit composition of plastidic glutamine synthetase of the wild-type and the phytochrome-deficient aurea mutant of tomato by blue/UV-A- or by UV-Blight.

Plant Mol Biol 37: 689-700

Moorhead G., Douglas P., Cotelle V., Harthill J., Morrice N., Meek S., Deiting U., Stitt M., Scarabel M., AitKen A. und MacKintosh C. (1999)

Phosphorilation-dependent interactions between enzymes of plant metabolism and 14-33 proteins.

Plant J 18: 1-12

Muslin A. J., TAnner J. W., Allen P. M. und Shaw A. S. (1996)

Interaction of 14-3-3 with signaling proteins is mediated by recognition of phosphoserine.

Cell 84: 889-897

ORTEGA J. L., Roche D. und SENGUPTA-GoPAlan C. (1999)

Oxidative turnover of soybean root glutamine synthetase. In vitro and in vivo studies. Plant Physiol 119: 1483-1495

Pell E. J., Schlagnhaufer C. D. und Arteca R. N. (1997)

Ozone-induced oxidative stress: mechanism of action and reaction.

Physiol Plant 100: 264-273

Pereira S., Carvalho H., Sunkel C. und Salema R. (1992)

Immunocytolocalization of glutamine synthetase in mesophyll and phloem of leaves of Solanum tuberosum L..

Protoplasma 167: 66-73 
PÉREZ-RODRÍGUEZ J. und VALPUESTA V. (1996)

Expression of glutamin synthetase genes during natural senescence of tomato leaves. Physiol. Plant. 97: 576-582

Peterman T. K. und Goodman H. M. (1991)

The glutamine synthetase family of Arabidopsis thaliana: Light regulation and differential expression in leaves, roots and seeds.

Mol Gen Genet 230: 145-154

Rhodes D., Rendon G. A. und Stewart G. R. (1975)

The control of glutamine synthetase level in Lemna minor.

Planta 125: 201-211

RIEDEL J. (2000)

Untersuchungen zur posttranslationalen Modifikation und der Regulation der chloroplastidären Glutaminsynthetase in Tabak.

Dissertation, Universität Göttingen

RiVETT A. J. und LEVINE R. L. (1990)

Metal-catalyzed oxidation of Escherichia coli glutamine synthetase: correlation of structural and functional changes.

Arch Biochem Biophys 278: 26-34

Roche D., Temple S. T. und Sengupta-Gopalan C. (1993)

Two classes of differentially regulated glutamine synthetase genes are expressed in the soybean nodule: a nodule-specific class and a constitutively expressed class.

Plant Mol Biol 22: 971-983

Rowe W. B., Ronzio R. A., Wellner P. V. und Meister A. (1970)

Glutamine Synthetase (Sheep Brain).

Methods in Enzymology XVII, Article 129, Academic Press

SaKakibara H., Kawabata S., Takahashi H., Hase H. und SugiYama T. (1992)

Molecular cloning of the family of glutamine synthetase genes from maize: expression of genes for glutamine synthetase and ferrodoxin-dependent glutamat synthase in photosynthetic and non-photosynthetic tissues.

Plant Cell Physiol. 33: 49-58

Sakamoto A., Ogawa M., Masamura T., Shibata D., Takeba G., Tanaka K. und FujiI S. (1989)

Three cDNA sequences coding for glutamine synthetase polypeptides in Oryza sativa L..

Plant Mol Biol 13: 611-614

SAKURAi N., HAYAKaWA T., NAKAMURA T. und YAmaYA T. (1996)

Changes in the cellular locallization of cytosolic glutamine synthetase protein in vascular bundles of rice leaves at various stages of development.

Planta 200: 306-311 
SAMBROOK J., FRITSCH E.F. und MANIATIS T. (1989)

Molecular Cloning a Laboratory Manual.

Cold Spring Harbor Laboratory Press

SCHILL M. (1998)

Molekularbiologische Untersuchungen der GS-1-Gene der Zuckerrübe Beta vulgaris L. Diplomarbeit, Universität Göttingen

Schiweck H., JeANTUER-De Beukelear C. und Vogel M. (1993)

Das Verhalten der stickstoffhaltigen Nichtzuckerstoffe von Rüben während des Fabrikationsprozesses.

Zuckerindustrie 118: 15-23

SHAPIRO B. M. und STADTMAn E. R. (1970)

Glutamine synthetase (Escherichia coli).

Methods in Enzymology XVII,eds.: Tabor H., Tabor C. W.: 910-922

StadtMan E. R. und Oliver C. N. (1991)

Metal-catalized oxidation of proteins. Physiological consequences.

J Biol Chem 266: 2005-2008

Stanford A. C., LARsen K., Barker D. G. und Cullimore J. V. (1993)

Differential expression within the glutamine synthetase gene family of the model legume Medicago truncatula.

Plant Physiol. 103: 73-81

STEWART G. R. und RHODES D. (1977)

Comparison of characteristics of glutamine synthetase and glutamate dehydrogenase from Lemna minor.

New Phytol 79: 257-258

SuKanya R., Li M. G. und SNustad D. P. (1994)

Root and shoot specific responses of individual glutamine synthetase genes of maize to nitrate and ammonium.

Plant Mol Biol 26: 1935-1946

Temple S. J., Bagga S. und Sengupta-Gopalan C. (1998)

Down-regulation of specific members of the glutamine synthetase gene family in alfalfa by antisense RNA technology.

Plant Mol Biol. 37: 535-547

ThykJaer T., Danielsen D., SeH Q. und StougaArd J. (1997)

Organization and expression of genes in the genomic region surrounding the glutamine synthetase Gln1 gene from Lotus japonicus.

Unpublished

DBSOURCE EMBL: locus LJGLN1, accession Y12859 
TINGEY S. V. und CORUZZI G. M. (1987)

Glutamine synthetase of Nicotiana plumbaginifolia.

Plant Physiol 84: 366-373

Tingey S. V., Tsai F. Y., Edwards J. W., Walker E. L. und Coruzzi G. M. (1988)

Chloroplast und cytosolic glutamine synthetase are encoded by homologous nuclear genes which are differentially expressed in vivo.

J Biol Chem 263: 9651-9657

TingeY S. V., WALKer E. L. und CORUZZi G. M. (1987)

Glutamine synthetase genes of pea encode distinct polypeptides which are differetially expressed in leaves, roots and nodules.

EMBO Journal 6 no 1: 1-9

TJADEN G., EDWARDS J. W. und CORUZZI G. M. (1995)

Cis elements and trans-acting factors affecting regulation of a nonphotosynthetic lightregulated gene for chloroplas glutamine synthetase.

Plant Physiol 108: 1109-1117

Towbin H., Staehelin T. und GoRdon J. (1979)

Electrophoretic transfer of proteins from polyacrylamid-gels to nitrocellulose sheets:

Procedure and some applications.

Proc Natl Acad Sci USA 76: 4350-4354

VAn der Krol A. R., Lenting P. E., Veenstra J., VAn Der Meer I. M., Koes R. E., Gerats A. G. M., Mol J. N. M. und StuitJe A. R. (1988)

An antisense chalconesynthase gene in transgenic plants inhibits flower pigmentation. Nature, 333: 866-869

Vincent R., Frasier V., Chaillou S., Limamiv M. A., Deleens E., Phillipson B., DOUAT C., Boutin J. P. und HiRel B. (1997)

Overexpression of a soybean gene encoding cytosolic glutamine synthetase in shoots of transgenic Lotus corniculatus L. plants triggers changes in ammonium assimilation and plant development.

Planta 201: 424-433

WALKER E. L. und CoRUZZI G. M. (1989)

Developmentally regulated expression of the gene family for glutamine synthetase in Pisum sativum.

Plant Physiol 91: 702-708

Walker E. L., Weeden N. F., TAYlor C. B., Green P. und Coruzzi G. M. (1995)

Molecular evolution of duplicate copies of genes encoding cytosolic glutamine synthetase in Pisum sativum.

Plant Mol Biol. 29: 1111-1125 
WARNER R. L. und KLEINHOFS A. (1992)

Genetics and molecular biology of nitrate metabolism in higher plants.

Plant Physiol 85: 245-252

Watanabe A., Hamada K., Yokoi H. und Watanabe A. (1994)

Biphasic and differential expression of cytosolic glutamine synthetase genes of radish during seed germination in senescence of cotyledons.

Plant Mol Biol. 26: 1807-1817

Yaffe M. B., Rittinger K., Volinia S., Caron P. R., Aitken A., LefFers H., Gamblin S. J., SMerdon S. J. und CANTLEY L. C. (1997)

The structural basis for 14-3-3: phosphopeptide binding specifity.

Cell 91: 961-971 


\section{LEBENSLAUF}

Name:

Geburtsdatum:

Geburtsort:

Staatsangehörigkeit:

$1971-1975$

$1975-1977$

$1977-1984$

Juni 1984

$1984-1986$

$1986-1996$

Februar 1996

April 1996 - April 2000

April 1996

\section{Guido Wolf Hoffmann}

27.05.1965

Braunschweig

deutsch

Grundschule Rüningen, Braunschweig

Orientierungsschule Stöckheim, Braunschweig

Gymnasium Hoffmann von Fallersleben, Braunschweig

Allgemeine Hochschulreife

Wehrdienst in Braunschweig

Studium der Biologie an der Technischen Universität

Braunschweig

Diplom in Biologie

wissenschaftlicher Mitarbeiter am Albrecht-von-HallerInstitut für Pflanzenwissenschaften der Universität Göttingen Beginn der Arbeiten zu vorliegender Dissertation 